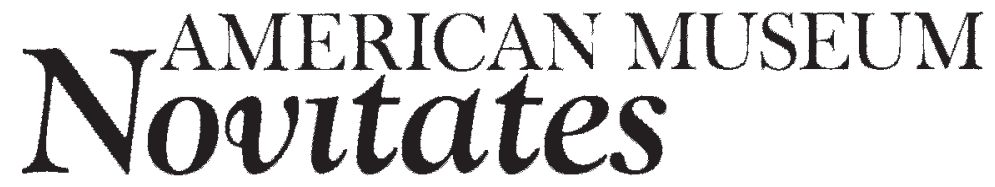

PUBLISHED BY THE AMERICAN MUSEUM OF NATURAL HISTORY CENTRAL PARK WEST AT 79TH STREET, NEW YORK, NY 10024 Number 3584, 47 pp., 19 figures

\title{
A Complete Late Cretaceous Iguanian (Squamata, Reptilia) from the Gobi and Identification of a New Iguanian Clade
}

\author{
JACK L. CONRAD ${ }^{1}$ AND MARK A. NORELL ${ }^{2}$
}

\begin{abstract}
Iguania is a diverse clade with an incompletely known fossil record. Here, we describe and name the earliest iguanian known from a complete skeleton. The specimen (IGM 3/858) comes from Ukhaa Tolgod (Upper Cretaceous of Mongolia) and offers important insights into the evolutionary history of iguanian osteology. The new taxon is diagnosed by a combination of character states, including the presence of a frontoparietal fontanelle, absence of an enlarged nuchal fossa, and unflared tooth crowns. We performed a cladistic analysis including 54 taxa scored for 202 informative morphological characters. A strict consensus of 46 shortest recovered trees reveals that the new taxon is a basal member of a previously unidentified clade of Cretaceous iguanians, probably endemic to the Gobi. This clade of Gobi iguanians is nested within a monophyletic Pleurodonta (non-acrodontan iguanians).
\end{abstract}

\section{INTRODUCTION}

Iguania is a remarkably diverse squamate clade spanning five continents and occupying a variety of ecological niches and habitat types (Frost and Etheridge, 1989; Bauer, 2003; Uetz, 2006). Despite their extant diversity of form and the large number of species represented in modern faunas (Frost and Etheridge [1989] reports 993 extant species; Uetz's [2006] count suggests 1,442), the iguanian fossil record is very incomplete, especially prior to the Neogene.

The past decade has seen a dramatic increase in the discovery of fossil iguanian material. Especially surprising is the large amount of diversity from continental Asia. Gao and Hou (1995) described Anchaurosaurus gilmorei based on an incomplete skeleton in 1995. Later, Gao and Norell (2000) described a wealth of new

\footnotetext{
${ }^{1}$ Division of Paleontology, American Museum of Natural History (jconrad@amnh.org).

2 Division of Paleontology, American Museum of Natural History (norell@amnh.org).
} 
material from the Mongolian Late Cretaceous relating to previously described taxa (ISOdontosaurus gracilis, Mimeosaurus crassus, Phrynosomimus asper, Priscagama gobiensis, and Polrussia mongoliensis) and several new taxa (Ctenomastax parva, Temujinia ellisoni, and Zapsosaurus sceliphros) discovered as part of the Mongolian Academy of Science-American Museum of Natural History expeditions. Consequently, our knowledge of the Cretaceous iguanian fauna from the Gobi and our understanding of iguanian morphology have increased dramatically.

Many fossil lizards are known from Ukhaa Tolgod, a 'Djadockhta-like' locality whose geology recently has been reviewed and summarized (Loope et al., 1998; Gao and Norell, 2000; see also references therein). Ukhaa Tolgod has been and continues to be an immensely productive 'fossil bonanza' (Gao and Norell, 2000: 7), yielding the remains of numerous tetrapods, including mammals; many saurischian and ornithischian dinosaurs; and thousands of lizard specimens. Among the most breathtaking of the lizard specimens collected on these recent expeditions is a complete iguanian (fig. 1). Although it was illustrated in Gao and Norell (2000: fig. 37), we describe this new taxon here for the first time.

In addition to naming the new Ukhaa Tolgod iguanian, we present a phylogenetic data matrix to identify its placement on the iguanian family tree. The new taxon shares important characteristics with some other Cretaceous iguanians from the Gobi. Together, these early iguanians offer new insights into the evolutionary history of Iguania.

\section{SYSTEMATIC PALEONTOLOGY}

SQUAMATA OPPEL, 1811 IGUANIA COPE, 1864 PLEURODONTA COPE 1864

Saichangurvel davidsoni, new genus and species

figures $1,3-4,6-7,8 \mathrm{~A}, 9-12,13 \mathrm{~A}, 14-18$

Etymology: Saichan- (Mongolian: 'beautiful') + gurvel (Mongolian: 'lizard') and davidsoni after Amy Davidson, who collected and prepared the specimen. Davidson's beautiful lizard.
Holotype: IGM 3/858.

Type Locality and Horizon: Ukhaa Tolgod, Nemegt Basin, Mongolian Gobi Desert; Upper Cretaceous Djadokhta Formation (Loope et al., 1998) (fig. 2).

Known Distribution: Known only from the type locality and horizon.

Diagnosis: IGM 3/858 differs from Ctenomastax parva and Temujinia ellisoni (each monospecific; hereafter, Ctenomastax and Temujinia, respectively) in possessing an apparently uncalcified region of the skull roof around the pineal foramen; a parietal fontanelle (similar to that seen in some extant Crotaphytidae). It differs from Temujinia and Zapsosaurus sceliphros (hereafter, Zapsosaurus) in lacking the enlarged paired fossae for the spinalis capitis. It differs from Ctenomastax in lacking caniniform teeth; from Zapsosaurus by the absence of strongly flared marginal tooth crowns and the more robust shape of the retroarticular tubercle; and from Anchaurosaurus gilmorei, Isodontosaurus gracilis, and Polrussia mongoliensis (each monospecific; hereafter, Anchaurosaurus, Isodontosaurus, and Polrussia, respectively) in possessing light dermal sculpturing on the parietal and frontal and the anterolateral orientation of the ectopterygoid. It differs from Isodontosaurus in lacking a posteriorly spatulate nasal process of the premaxilla, which does not make contact with the frontal on the dorsal skull roof; in possessing a weakly inclined anterior margin of the maxillary nasal process; in possessing a jugal that lies mostly dorsal to the maxilla; in possessing a supratemporal; and in possessing a mediolaterally developed postfrontal. It differs from Polrussia in possessing a midline contact of the maxillae posteriorly to the premaxillary nasal process, an elongate supratemporal, a distinct postfrontal, and an anteriorly oriented ectopterygoid. It differs from both Isodontosaurus and Polrussia in possessing a forked medial margin of the postfrontal and in lacking a dorsal process on the squamosal.

\section{DESCRIPTION}

Gao and Norell (2000: 106-107; fig. 37) illustrated and briefly mentioned and IGM 3/ 858 , noting its exceptional preservation. The entire skeleton is preserved in articulation and lacks only the right postorbitofrontal, squamo- 


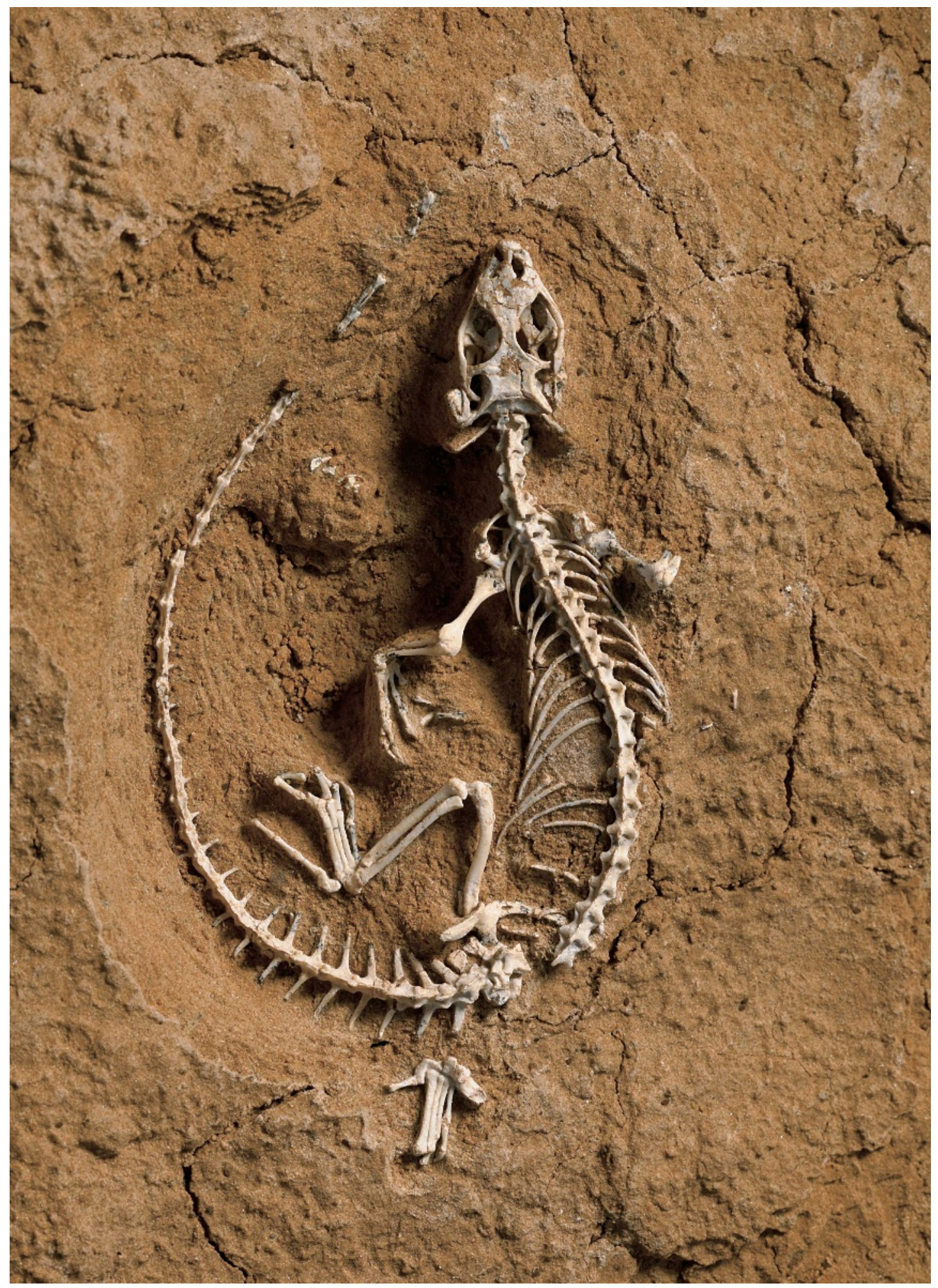

Fig. 1. Saichangurvel davidsoni (IGM 3/858) in dorsal view as preserved. 


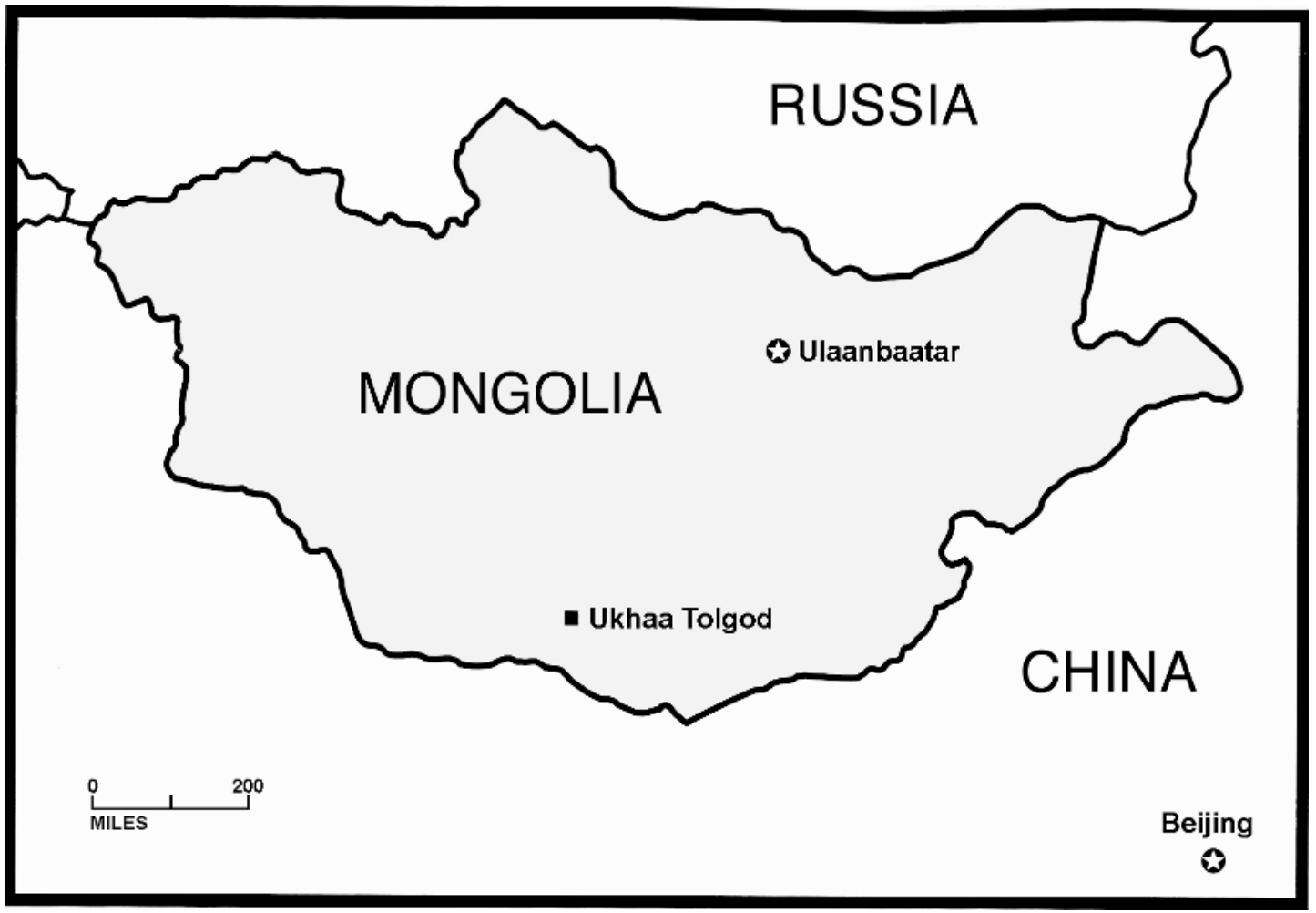

Fig. 2. Map of Mongolia showing the location of Ukhaa Tolgod.

sal, and quadrate, the right forelimb and manus, the right femur and both hind-limb zeugopodia, and part of the distal tail (fig. 1). These portions of the skeleton were exposed prior to and during the thunderstorm in which IGM 3/858 was discovered. Because the specimen remains ventrally embedded in sandstone matrix, some ventral and medial elements (such as parts of the palate and pectoral girdle) are not visible. As noted by Gao and Norell (2000), the fantastic preservation of the specimen indicates a rapid burial. Rapid burial is typical of many of the Ukhaa Tolgod and Bayn Dzak fossils (see Loope et al., 2005) and is thought to have occurred when semi-stable sand dunes catastrophically mobilized when they became supersaturated with water.

\section{SKULL Form}

The skull is lightly built, with large orbits and a complete supratemporal arch (figs. 1, 3-4). The antorbital snout makes up roughly one quarter of the length of the skull from the tip of the premaxilla to the anterodorsal margin of the foramen magnum. As preserved, the orbital region is slightly more elongate than the snout, making up approximately three quarters of the skull length. The nares are slightly retracted, a condition exaggerated by the fact that the snout tip has rotated slightly dorsally with respect to the rest of the skull (cf. figs. 3-4). The acuminate suborbital fenestra is visible in dorsal view through the orbit and is somewhat smaller than the supratemporal fenestra and approximately one half the length of the orbit. The supratemporal fenestra is posteriorly bordered by the ectopterygoid and pterygoid and anteriorly bordered by the palatine and jugal. The teardrop-shaped supratemporal fenestra is round anteriorly and tapers posteriorly. It is bounded anteriorly by the postorbital and postfrontal, medially by the parietal, laterally by the postorbital and squamosal, and posteriorly by the squamosal, supratemporal, and parietal. 

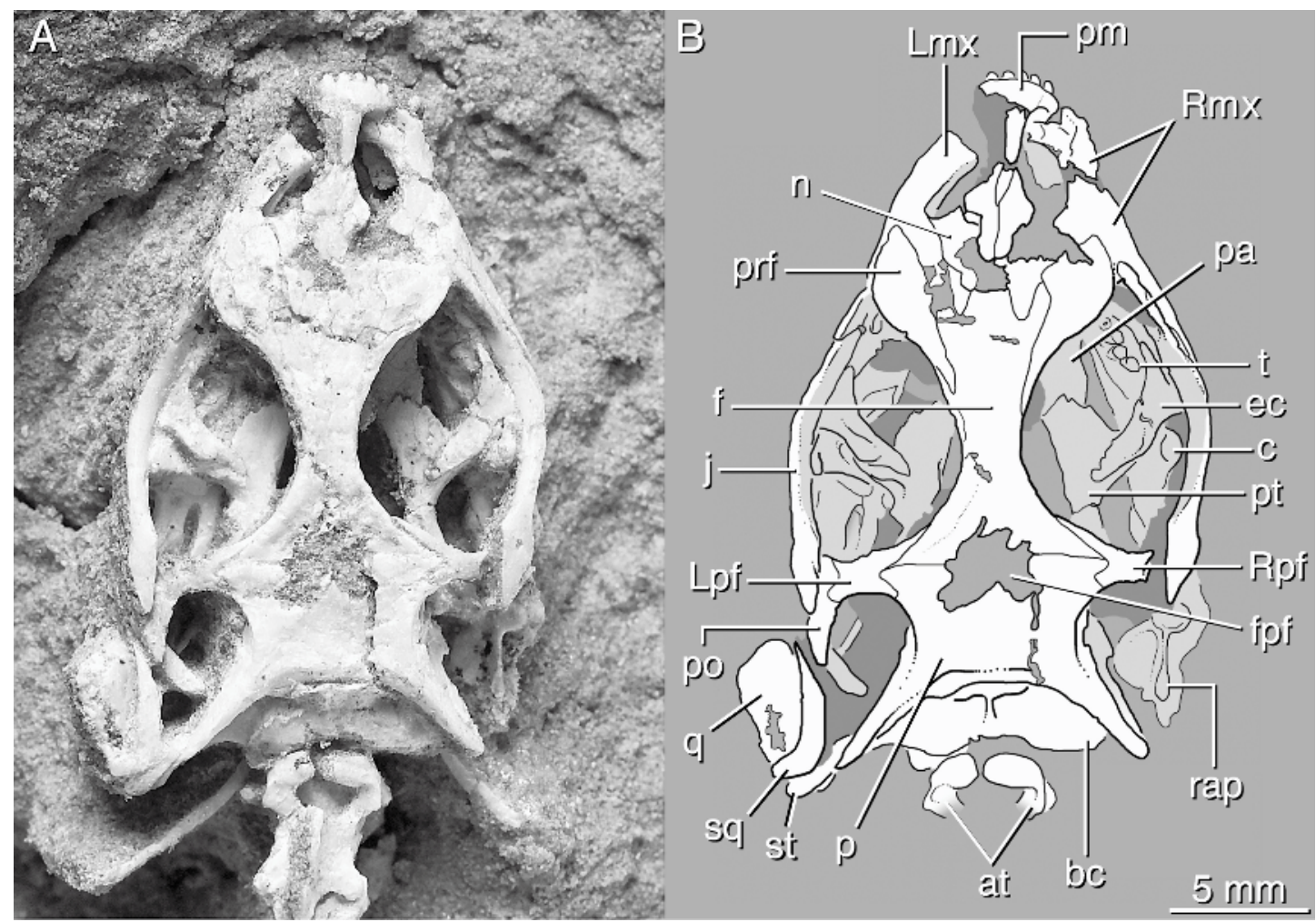

Fig. 3. Skull of Saichangurvel davidsoni (IGM 3/858). A, photograph; and B, drawing of the skull as preserved, in dorsal view.

Two ceratobranchials, identified as left and right ceratobranchials I, are preserved extending posteriorly from beneath the skull (figs. 1, $3 \mathrm{~A})$. These are elongate rods extending posteriorly to about the level of the posterior margin of the axis.

\section{SKULl Roof}

Premaxilla (figs. 1, 3-4): The premaxilla is fused. It is displaced slightly out of its natural articulation with the maxilla, although parts of the articular surfaces remain in contact, and the premaxillary contact with the nasals remains articulated. The premaxilla retains seven visible teeth and probably contains 10 tooth positions. The premaxillary nasal process is broadest at its base and tapers dorsally. It is only about two tooth positions wide at its widest point but is still wider than deep. The premaxillary nasal process is broken near its base and near its contact with the nasal, but extends to near the posterior margin of the external naris. The margin between the nasal process and the main body of the premaxilla is not strongly angulated; instead, it curves down to the dental margin. A maxillary facet is present on the dorsal margin of this curved surface, but apparently was not exposed on the external skull surface. There are no ethmoidal foramina through the premaxilla.

Maxilla (figs. 1, 3-4, 9): Both maxillae are well preserved, but the left side lacks the premaxillary process, and there is minor dorsal damage to the nasal process. The maxillae are sub-triangular, with an anteriorly placed nasal process that extends vertically along the side of the snout and medially near the naris. This condition also is present in Temujinia, Ctenomastax, and Crotaphytidae. The maxilla is sutured to the premaxilla without a premaxilla-maxilla aperture (sensu Gao and Norell, 1998; Conrad, 2006b, in 


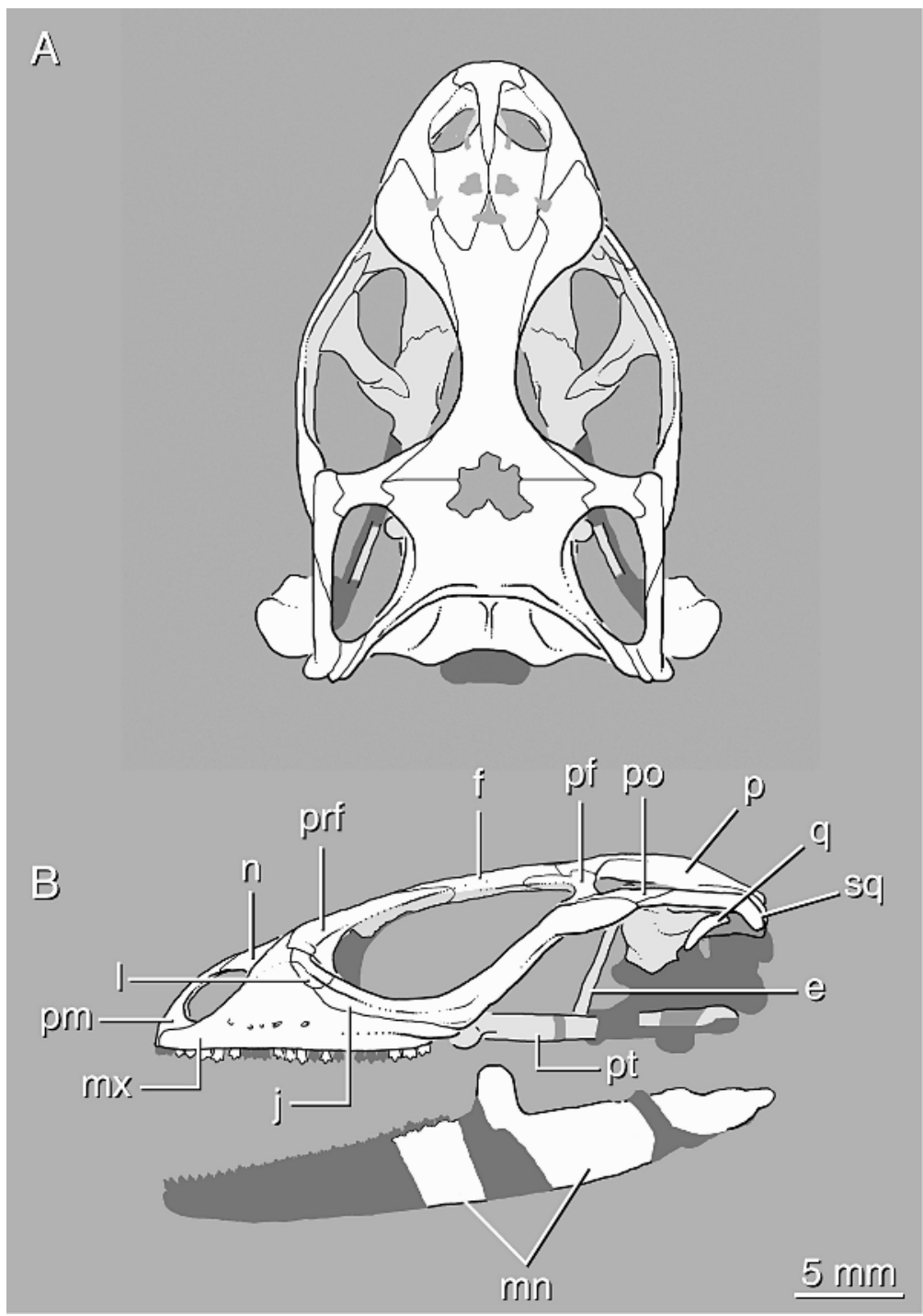

Fig. 4. Reconstructed skull of Saichangurvel davidsoni (IGM 3/858). A, dorsal view; B, left lateral view. Note that reconstructed elements appear as semiopaque shadows. No detail is given for the mandible in $\mathbf{B}$, because only the medial view is visible as the specimen is preserved (see fig. 8).

press). Although only the right premaxillary process is preserved, it is complete and shows that the anterior terminus was forked into septomaxillary and anterior rami (fig. 3). The septomaxillary ramus of the premaxillary process projects medially. Based on the size of the septomaxillary ramus and the articular surfaces present on the premaxilla, as described earlier, it is clear that the septomaxillary rami would have met at the midline posteroventral to the premaxillary nasal process in the complete articulated skull. The shorter, anterior ramus approaches the base of the premaxillary nasal process without actually overlapping it. Posterodorsal to the premaxillary process, the maxilla extends in a gentle slope posteriorly such that the anterior margin of the nasal process is not strongly offset from the dorsal surface of the premaxillary process (fig. 4). The apex of the 

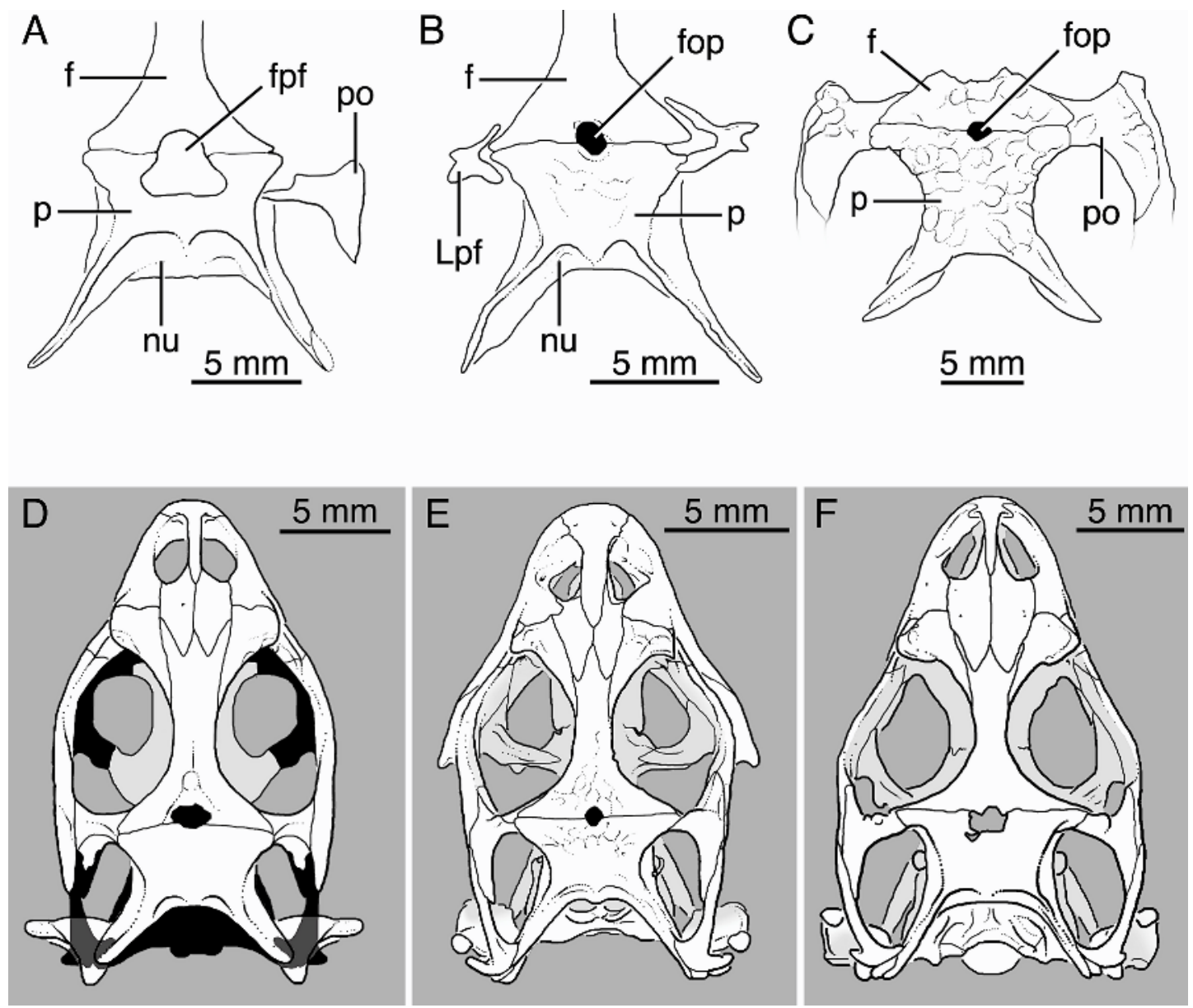

Fig. 5. Drawings of dorsal skull surfaces in the area of the parietal foramen: A, Temujinia ellisoni; $\mathbf{B}$, Zapsosaurus sceliphros; C, Priscagama gobiensis. Dorsal view of skulls: D, Ctenomastax parva; E, Gambelia wislizenii; F, Diplolaemus bibroni (REE 2506). A-C, modified after photos in Gao and Norell (2000); D, composite illustration modified after Gao and Norell (2000: figs. 3-4). Reconstructed areas are shown as semitransparent shadow layers. E, modified after Maisano (2003a).

nasal process overlaps the anterodorsal margin of the prefrontal and extends medially onto the skull roof, where it contacts the nasal. The posterior margin of the nasal process is slightly emarginated, accommodating the anterior projection of the lacrimal. Its margin is posteroventrally oriented toward the dental margin and the posterior terminus of the maxilla. The dental margin extends to about the level of the midpoint of the orbit. Slight damage to the posteriormost tip of the alveolar margin prevents identifying whether the ectopterygoid was exposed on the external surface of the skull behind the maxilla, as it is in Leiocephalus, Oplurus, some iguanids (including Dipsosaurus dorsalis), and various scleroglossans. Five maxillary labial foramina are preserved, all situated anterior to the orbit and well separated from the dental margin.

NAsAl (figs. 3-4): The paired nasals make contact for approximately one half their length, but are damaged near their middle (fig. 3). Each nasal, as exposed, is subrhomboid, tapering anteriorly and posteriorly. The anterolateral surface is gently curved laterally, forming part of the dorsal margin of the external naris. The premaxilla overlaps 


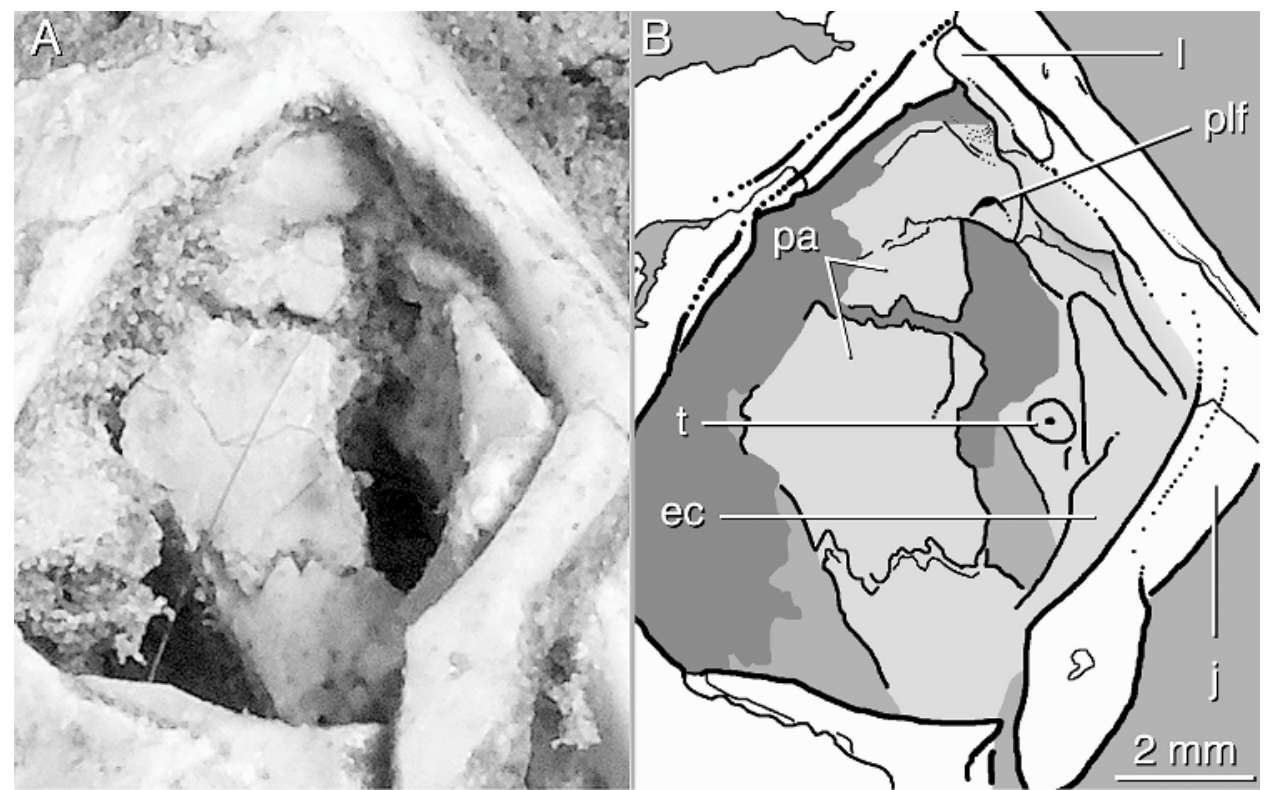

Fig. 6. A, photograph; and $\mathbf{B}$, drawing of the posterodorsal view of the orbital wall and palate of Saichangurvel davidsoni (IGM 3/858).

the nasals anteriorly, and the frontals invade the internasal suture for more than one third of the length of the nasals. The nasal tapers posteriorly where it dorsally overlies the frontal in a manner suggestive of a nasal lamina of the frontal.

Prefrontal (figs. 3-4): Each robust prefrontal is teardrop-shaped in dorsal view, with a broad anterior process and an elongate frontal process. No dermal sculpturing is present on the prefrontal. The prefrontal boss is expressed as a laterally projecting tubercle on the anterolateral corner of the orbit, near the anterior limit of the lacrimal (most visible in fig. 4B). This configuration is more similar to the condition seen in Ctenomastax (fig. 5D), Temujinia (Gao and Norell, 2000), and crotaphytids (Maisano, 2003a) than modern Iguana or Zapsosaurus sceliphros, in which the prefrontal boss is less robust and more contiguous with the rest of the skull surface. The frontal process extends posteriorly to near the midpoint of the orbit, but does not approach the postorbitofrontal. Most of the prefrontal medial border is bounded by the anterior part of the frontal. The prefrontal is blocked from contacting the jugal inside the orbital rim by a lacrimal-palatine contact (fig. 6). A single, small lacrimal foramen is present about midway up the orbital lamina of the prefrontal. It is enclosed dorsally, medially, and ventrally by the prefrontal and laterally by the lacrimal. The prefrontal and palatine are in broad contact in a straight, slightly ventromedially oriented suture.

LACRIMAL (figs. 3-4, 6): Both lacrimals are preserved in articulation with the maxillae and jugals. The lacrimals remain in articulation with the prefrontals, but dorsoventral compression of the skull has shifted the prefrontals slightly ventrally with respect to the lacrimals, jugals, and maxillae.

The lacrimal lies at the anterior end of the jugal. The outline of the lacrimal (its dorsal and ventral margins) is continuous with the anterior part of the jugal with only a small point of maxillary invasion between the two (fig. 4B). The lateral part of the jugal-lacrimal suture is nearly horizontal, and its orbital part is dorsomedially oriented. Dorsally, the lacrimal abuts the ventral surface of the prefrontal boss. The suborbital ridge arises from the point where the prefrontal makes contact with the lacrimal and extends posteriorly along the suborbital process and up the postorbital process of the jugal. 


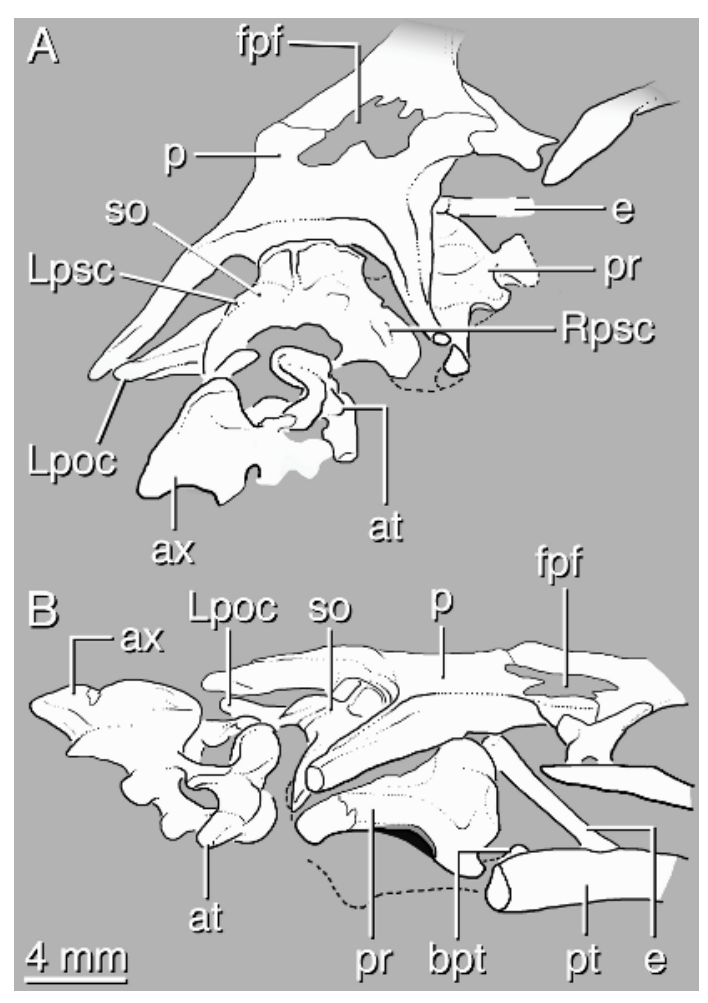

Fig. 7. Drawing of the braincase, posterior skull roof, and anterior cervical vertebrae of Saichangurvel davidsoni (IGM 3/858): A, posterolateral view; B, lateral view.

JugAL (figs. 1, 3-4, 6): Although both jugals are well preserved and in articulation with the maxillae and lacrimals, they have been pushed somewhat out of position from their contacts with the supratemporal arch (figs. 1, 3). The left side is closer to its original position, but still has slid over the anterodorsal surface of the postorbital. The right jugal has turned somewhat dorsolaterally. The jugal is broadly exposed dorsal to the maxilla in lateral view and would have overlapped the ventrolateral surface of the postorbital and the squamosal.

The jugal is composed of a suborbital process and a postorbital process forming an obtuse angle to each other. No posteroventral process is present, but there is a moderately sharp point where the posteroventral process occurs in many lizards (including Anchaurosaurus, Ctenomastax, Temujinia, Zapsosaurus, and many other iguanians). A squamosal ramus of the postorbital process is present. The squamosal ramus is flattened mediolaterally and overlies the lateral surface of the postorbital when in natural articulation. The suborbital ridge extends from its origin on the lacrimal and curves around the ventrolateral and posterior portions of the orbit. The postorbital process of the jugal lacks the anterior and posterior flanges seen in many acrodonts, corytophanids, and some polychrotids; thus, it is not dilated. There is no dermal sculpturing on the jugal.

Postfrontal (figs. 3-4): Saichangurvel davidsoni retains a separate postfrontal and postorbital. The right postorbital has been lost or is incomplete and hidden by the jugal and matrix (fig. 3). Regardless, it is out of articulation with the postfrontal, allowing a clear view of the postorbital facet on the postfrontal.

The postfrontal is a mediolateral bar joining the frontal and parietal with the supratemporal arch. As in Temujinia, the postfrontal is medially forked, with a long frontal process and a shorter parietal process, the latter fitting into a notch on the dorsolateral surface of the parietal. The frontal process is approximately twice as long as the parietal process, but does not approach the prefrontal. As in Temujinia and Ctenomastax, the postfrontal is a mediolaterally oriented bar. It borders the orbit and the supratemporal fenestra. Gao and Norell (2000) noted that this postfrontal morphology is unusual for iguanians and is more like that in scleroglossans. However, even among scleroglossans, the mediolateral-bar morphology of the postfrontal is relatively rare (Conrad, in press).

Postorbital (figs. 3-4): Only the left postorbital is preserved, and it has moved somewhat out of natural articulation. The jugal hides the lateral surface of the postorbital, so the latter's contribution to the posterior margin of the orbit cannot be determined. The postorbital is triangular in dorsal view. It has a short orbital surface, a long lateral surface, and a slightly curved contribution to the supratemporal fenestra. A forked facet on the postfrontal clasps the medial angle of the postorbital; the postorbital was laterally covered by the jugal in a short overlapping joint. The supratemporal process of the postorbital extends posteriorly in a tapering process that 


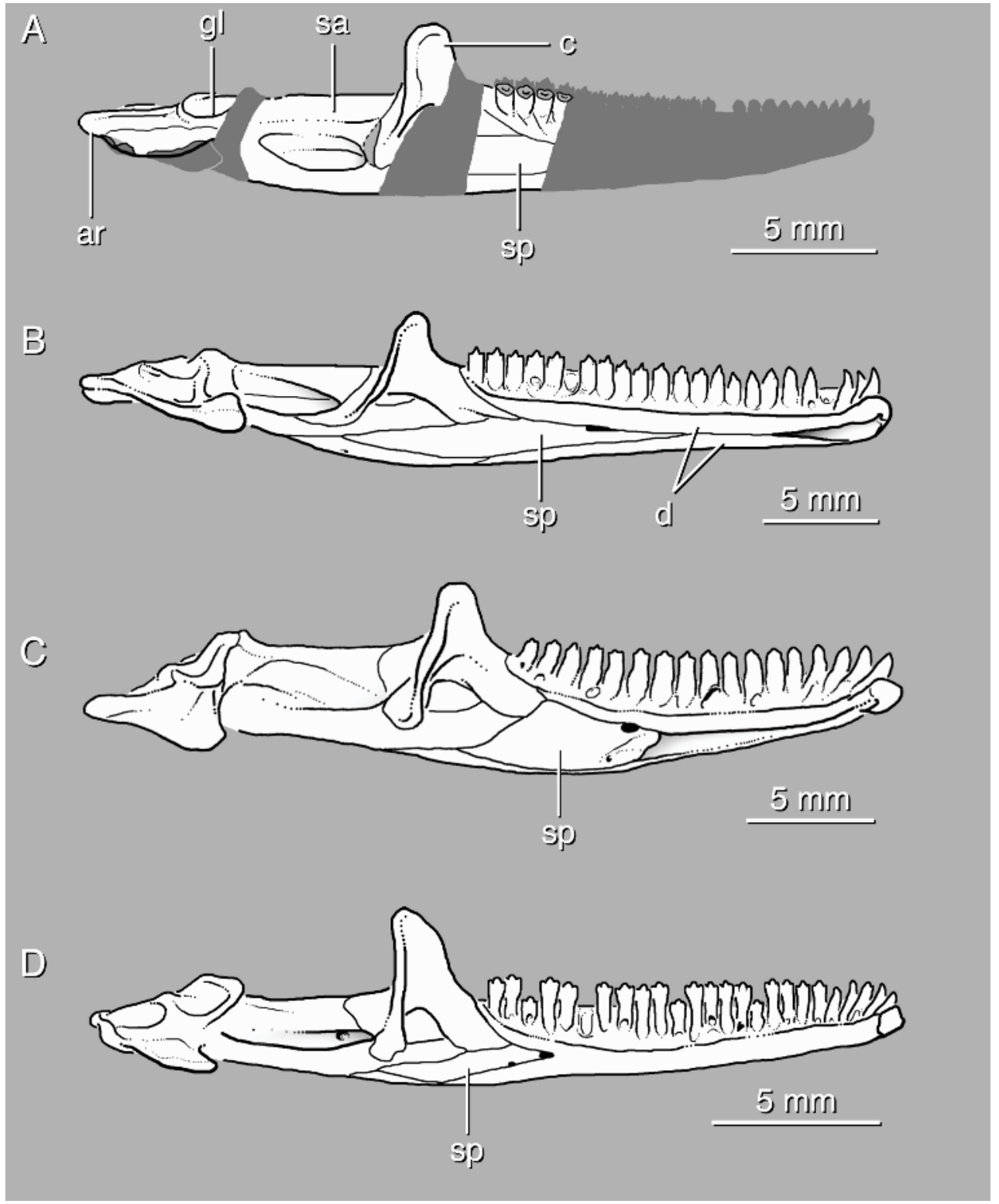

Fig. 8. Drawings of selected pleurodontan mandibles in medial view, anterior to the right. A, reconstruction of Saichangurvel davidsoni with semitransparent areas representing restored areas; B, Gambelia copei; C, Hoplocercus spinosus (AMNH 93807); D, Leiocephalus carinatus. B, modified after McGuire (1996); D, modified after Frost and Etheridge (1989). Note the variability in the splenial morphology as it relates to the closure of Meckel's canal.

does not reach the midpoint of the supratemporal fenestra. A groove on the medial surface of the squamosal suggests that it accepted the lateral surface of the postorbital in a shallow tongue-and-groove contact.
SQuamosal (figs. 1, 3-4): Only the left squamosal is preserved. It has been displaced somewhat from natural articulation with the supratemporal and postorbital by dorsal movement of the quadrate and by dorsoven- 


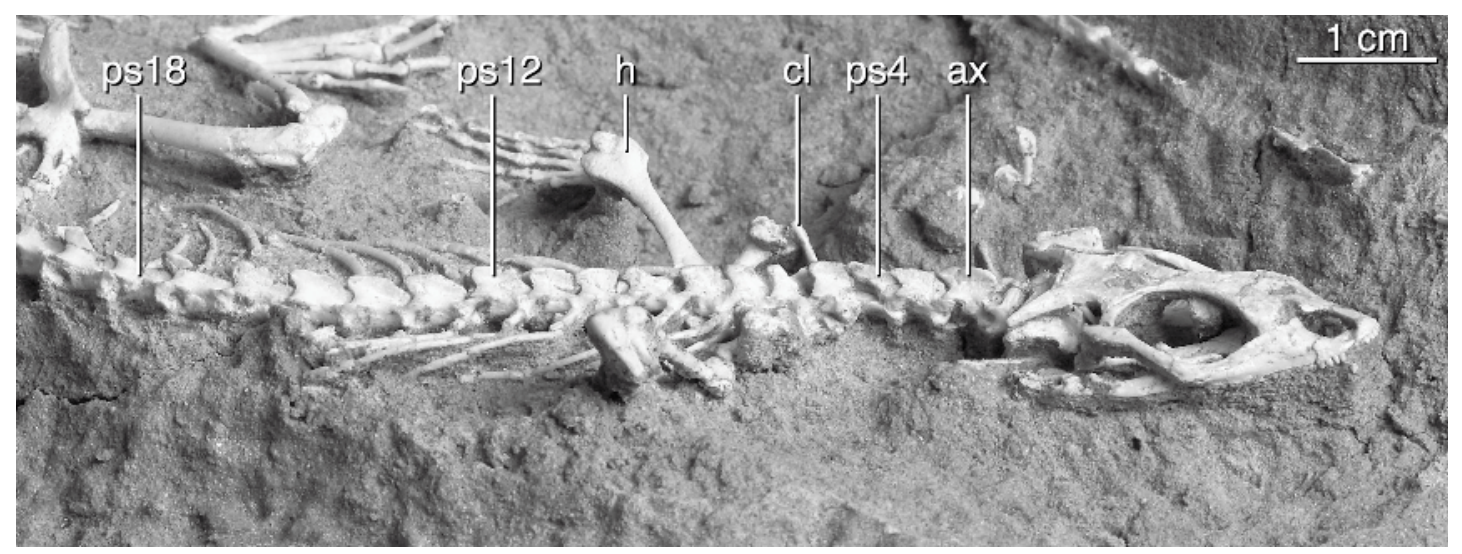

Fig. 9. Anterior part of the skeleton of Saichangurvel davidsoni (IGM 3/858) in dorsolateral view to show the variability of the presacral vertebrae as it relates to vertebral length and neural spine morphology. See the text for details.

tral compression. Even so, it is well preserved, without fractures or apparent deformation. It is a hockey-stick-shaped bone with a tapering anterior postorbitofrontal process and a downturned posterior suspensorial process. The dorsal process is absent, an unusual condition for iguanians, but one shared with Temujinia. The squamosal, paroccipital process, and supratemporal articulate with the quadrate in the streptostylic suspension of the quadrate.

SupratemPoral (fig. 3): Only the left supratemporal is preserved. It is robust compared with the 'small splint' present in Temujinia (Gao and Norell, 2000: 21). As exposed, the deepest part of the supratemporal is nearly as broad as the squamosal. The squamosal is displaced slightly posteriorly as a result of the dorsoventral compression of the skull. It remains in contact with the parietal, but the anterior part of the articular surface for it is visible on the ventrolateral face of the supratemporal process of the parietal. Based on the placement of this articular surface, the supratemporal would have extended for approximately one half the length of the supratemporal process when in life position.

Frontal (figs. 1, 3-4, 7): The azygous frontal is completely preserved, with only one major fracture near its anterior end. The ventral surface of the frontal is not visible as preserved, but it is clear that the frontals did not make contact with the prootics or basisphenoid. As is typical for pleurodontan iguanians, the frontal is hourglass-shaped in dorsal view, with the narrowest point occurring near the midpoint of the medial border of the orbit, posterior to the frontal process of the prefrontal. The anterior margin of the frontal has been damaged, but the frontonasal suture is W-shaped, with the anterolateral processes of the frontal approaching the nasal process of the maxilla. Presumably, the anterolateral processes were joined with the median process beneath the nasals, thus forming a nasal shelf. The frontoparietal suture is approximately as broad as the distance between the prefrontal bosses. The suture is transverse, though it is invaded medially by the frontoparietal fontanelle, similar to the condition seen in Zapsosaurus (fig. 5A), Anchaurosaurus, Chalarodon, some crotaphytids, Igua, and Polrussia. Unlike in Igua, Polrussia, and Zapsosaurus, the margin of this fontanelle is not smooth, but, instead, is more like that seen in Anchaurosaurus, Chalarodon, and some Gambelia, wherein the fontanelle is heart-shaped and has a somewhat ragged border. Some specimens of Temujinia show abrasion to this part of the skull, broadly resembling a frontoparietal fontanelle (see Gao and Norell, 2000: fig. 6B). This skullroof damage is not asymmetric and can easily be distinguished from the morphology present in taxa such as Chalarodon madagsacariensis, Gambelia (e.g., G. copei; fig. 5F), and Saichangurvel davidsoni. 


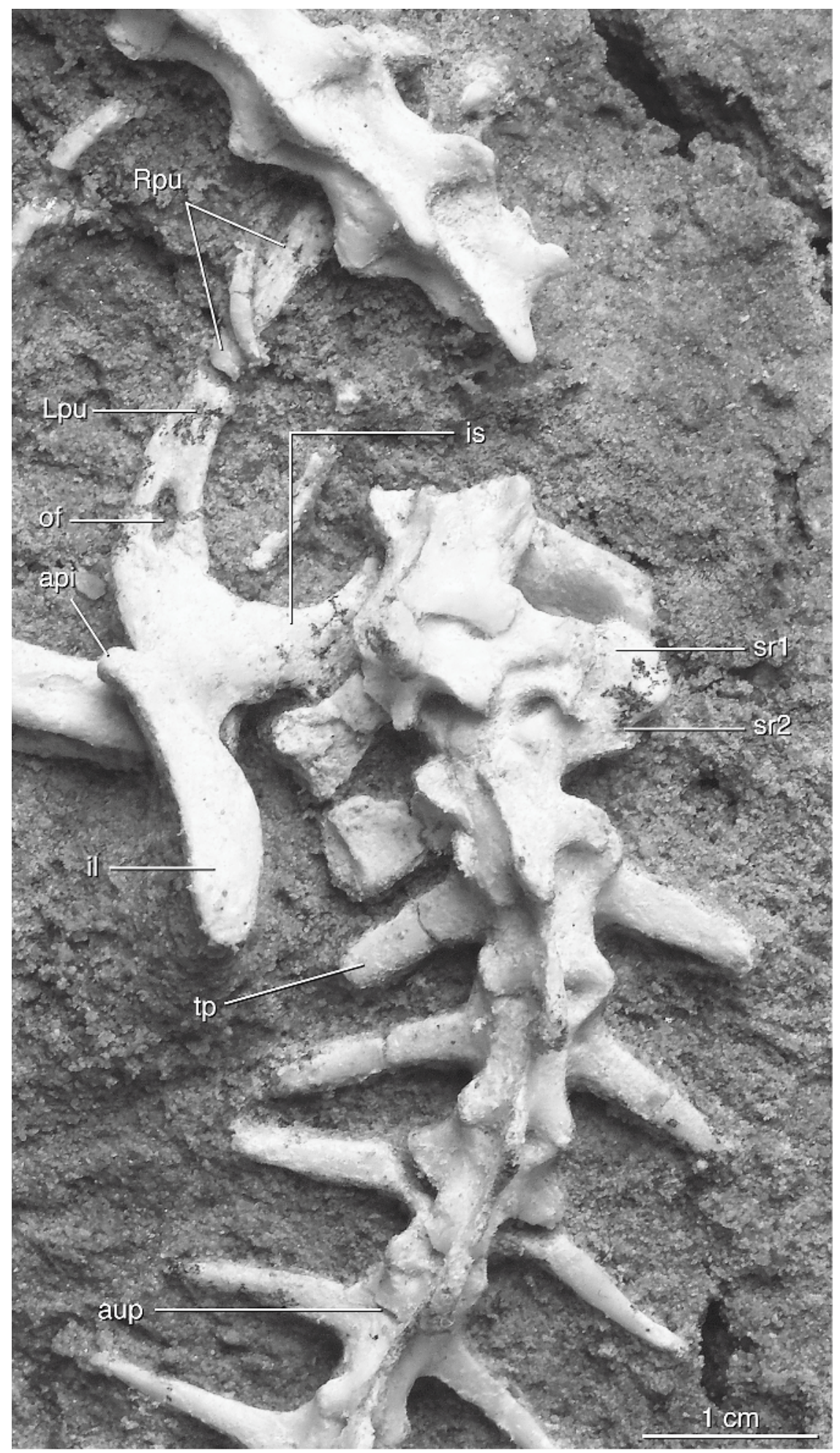

Fig. 10. Dorsal view of the sacrum and surrounding vertebrae in Saichangurvel davidsoni (IGM 3/858); anterior is toward the top. Note the presence of an autotomy plane in the fourth caudal vertebrae. 

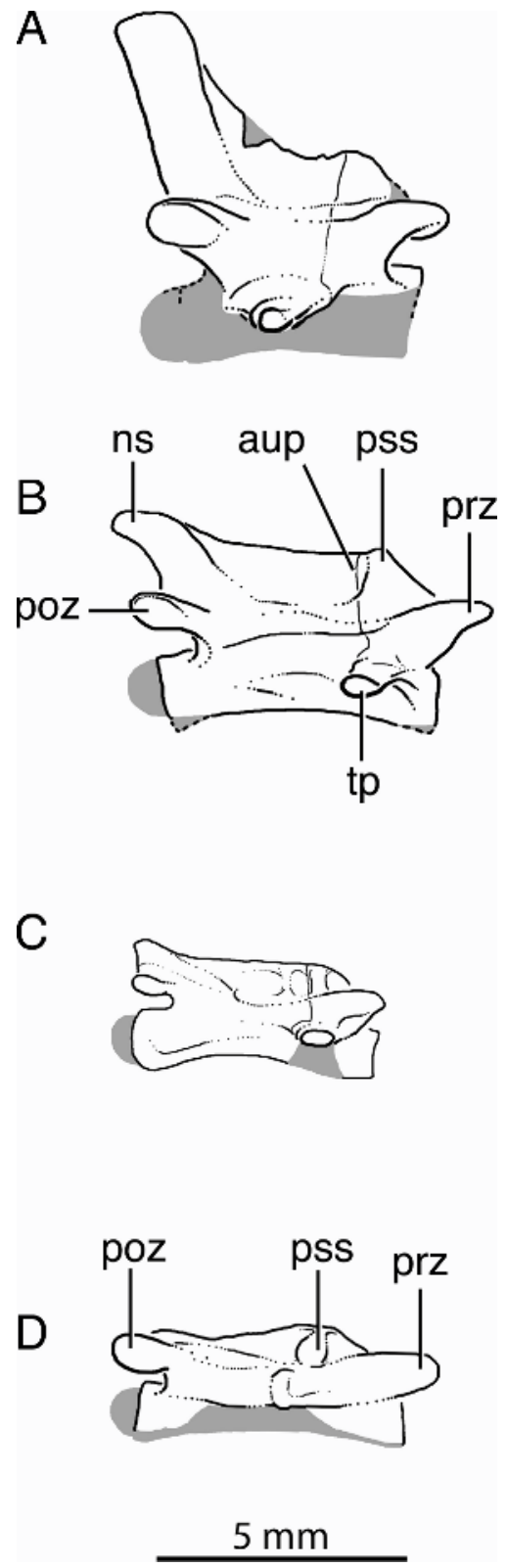

Fig. 11. Drawings of selected caudal vertebrae of Saichangurvel davidsoni (IGM 3/858) in right lateral view: A, caudal vertebra 4; B, caudal vertebra 9; C, caudal vertebra 14; D, caudal vertebra 20. Reconstructed portions (missing or hidden in the specimen) are represented as semitransparent shadows.
Parietal (figs. 1, 3-4, 7): The parietal is complete except for the distal tip of the right supratemporal process. A large crack is present along the long axis of the bone, extending anteriorly from the base of the right supratemporal process to the right side of the frontoparietal fontanelle.

The parietal table is rectangular, its mediolateral breadth being greater than its anteroposterior length (figs. 3, 4A). It is invaded anteriorly by the frontoparietal fontanelle, and its lateral margins are medially concave. The jaw adductors originated from the dorsolateral surfaces of the parietal along the parietal table and the supratemporal processes. Unlike Temujinia and Zapsosaurus, which possess two pronounced parasagittal nuchal fossae (figs. 5A, 5B), Saichangurvel davidsoni possesses weak nuchal fossae (figs. 3, 4A). A similar condition is seen in most pleurodontans. By contrast, the nuchal fossae do not extend onto the dorsal surface of the parietal in many iguanians (e.g., Priscagama; fig. 5C). Decensus parietalis are absent. The elongate, narrow, supratemporal processes extend posterolaterally from the main body of the parietal. They are subequal in length to the parietal table, and their short axis is oriented posterodorsally. The long axis shows a gentle posteroventral curve.

\section{Palate And Quadrate}

Although skull-roofing bones and matrix obscure most of the palate, some informative parts of the palatine, pterygoid, and ectopterygoid are visible (figs. 3, 6). Although the right vomer is visible through the right naris, it cannot be meaningfully characterized as preserved. Despite some dorsoventral compression of the skull, the palatal bones are mostly in natural articulation. The interpterygoid vacuity is broad posteriorly and tapering anteriorly, especially between the palatines. The right ectopterygoid has been pushed dorsally and moved very slightly out of natural articulation with the exterior skull roofing bones and the pterygoid, but the left side remains undisturbed. The left palatine is missing or hidden by matrix, and the quadrate process on the left pterygoid has been broken and moved dorsally. However, the original 


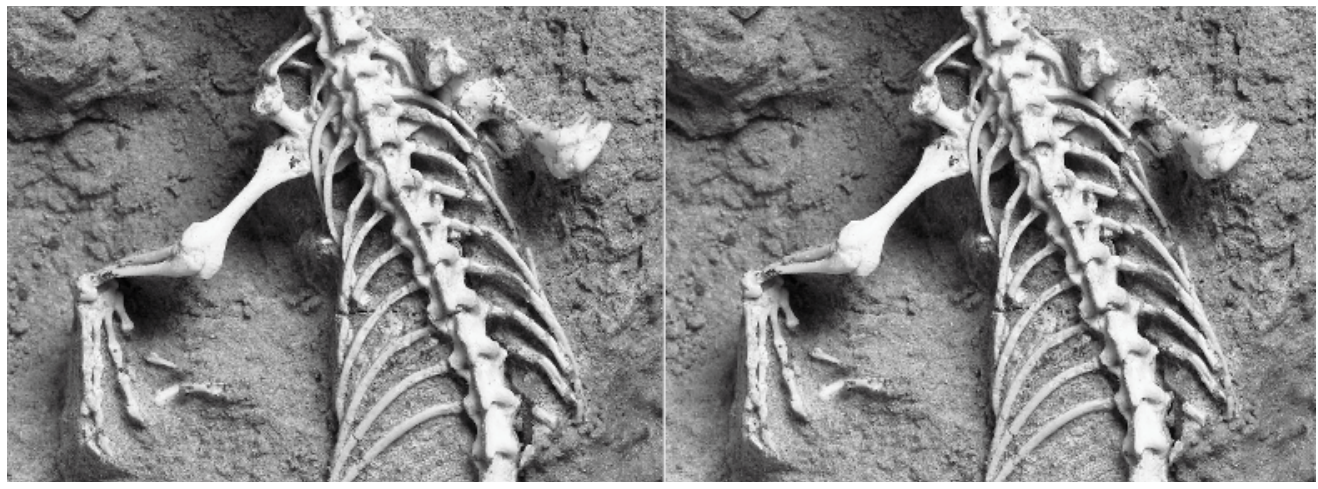

Fig. 12. Stereophotograph of the Saichangurvel davidsoni (IGM 3/858) pectoral girdle and left forelimb in dorsal view.

articulations remain for the other visible bones of the palate.

Palatine (figs. 3-4, 6): The visible portion of the palatine shows that it shared broad contacts with both the prefrontal and the pterygoid. The palatine-pterygoid contact is a scarf joint, with the palatine dorsally overlying the pterygoid. In dorsal view, the palatine-pterygoid suture is generally posterolaterally oriented, but with large interdigitations. The infraorbital canal is enclosed dorsally, medially, and ventrally by the palatine, but has a large lateral contribution from the maxilla.

PTERYGoID (figs. 3-4, 6): Most of the dorsal surfaces of the pterygoids are visible, showing that the pterygoids do not make contact with each other or with the vomers. The anterior end of the left pterygoid is visible because the palatine is not preserved. Both transverse processes are anterodorsally covered by the ectopterygoids. The posterior part of the quadrate process is missing on the right side and obscured by matrix on the left side. Presence or absence of palatal teeth cannot be determined.

The palatine process is broad near its base, but tapers anteriorly to form an acute angle at its tip. The palatine facet is very weakly developed - so much so that that it is difficult to make out in dorsal view. The short transverse process is anterolaterally directed and tapers distally. The palatine process of the pterygoid is much broader than the main body of the pterygoid posterior to the transverse process, so the anterior margin of the trans- verse process is less strongly offset than the posterior margin. A columellar fossa and epipterygoid are preserved in articulation on the dorsal surface of the right pterygoid just posterior to the transverse process. Although a ventral view is not possible, the dorsomedial view through the orbit and the interpterygoid vacuity reveals that a basicranial buttress is lacking from the ventromedial surface of the pterygoid. The quadrate processes of both pterygoids are broken, but the posterior part of the left one is present near the postorbitalsquamosal contact. The dorsoventral depth of the quadrate process is slightly less than the maximum breadth of the squamosal.

ECTOPTERYGOID (figs. 3-4, 6): Both ectopterygoids are well preserved; the left is in natural articulation, and the right one is only slightly displaced (fig. 3). Only the dorsal surface of each is visible. The ectopterygoid broadly overlaps the pterygoid in a scarf joint (i.e., it tapers in its narrowest plane distally). Both the ectopterygoid and the transverse process of the pterygoid are anterolaterally directed. By contrast, the transverse process of the pterygoid and the ectopterygoid are somewhat more laterally oriented in many acrodontans and in the pleurodontans Anchaurosaurus, Crotaphytidae, Polrussia, many polychrotids, and Temujinia.

The medial part of the ectopterygoid is bifurcated into dorsal and ventral pterygoid processes. The dorsal pterygoid process tapers medially to a point terminating near the main body of the pterygoid. The anterolateral portion curves gently and forms the postero- 


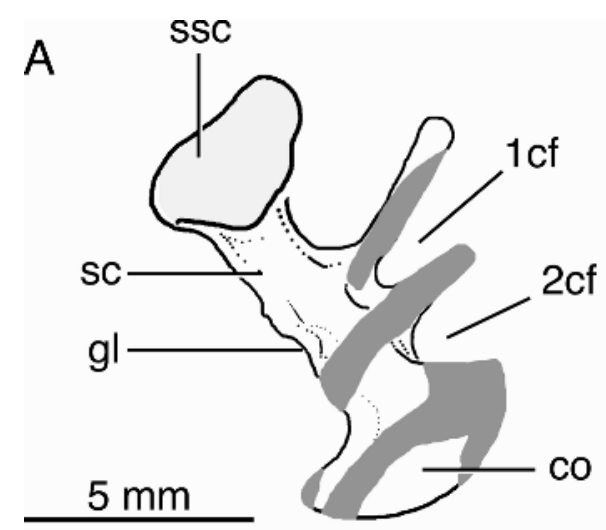

B

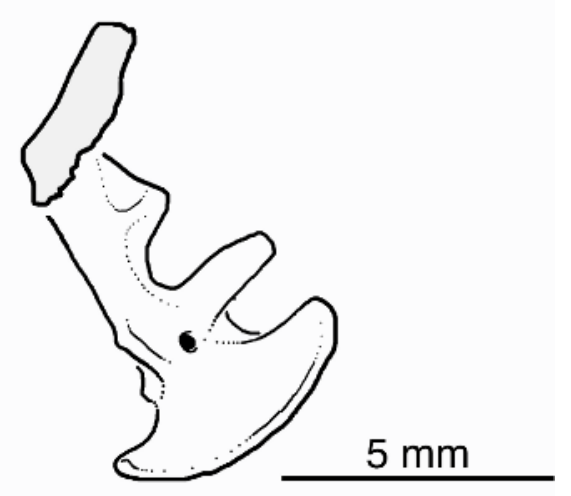

C

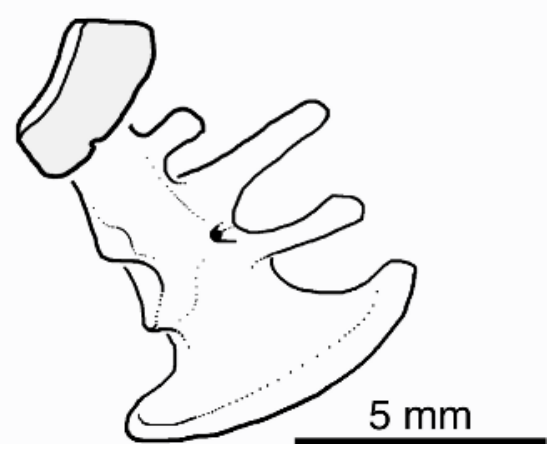

Fig. 13. A, left scapulocoracoid and suprascapula of Saichangurvel davidsoni (IGM 3/858) in dorsal view. Ribs overlie parts of the scapulocoracoid, but these hidden parts are reconstructed in gray; enough of the girdle is visible to confirm the presence of two bars forming the primary (1cf) and secondary (2cf) coracoid emarginations. The suprascapula is show as lateral margin of the suborbital fenestra at the maxillary process. The posterior margin of the ectopterygoid expands at an acute angle from the anterior margin, but is notched to accommodate the anterior portion of the coronoid when the mouth is closed. The breadth of the maxillary contact is equal to about one half the length of the anterior margin of the ectopterygoid.

QuADRATE (figs. 3-4): Only the left quadrate is preserved, and it has been moved slightly out of its natural articulation; it has rotated clockwise around its long axis so that its anterior face is directed primarily medially. Despite this movement, the quadrate remains in contact with the cranium and the mandibular glenoid. Apparently concomitant with the quadrate movement, a portion of the pterygoid has broken off and is wedged between the supratemporal arch and the braincase so that it partly obscures the quadrate-articular contact in dorsal view. The medial face of the quadrate is still mostly visible so that it can be determined that a strong pterygoid flange of the quadrate is absent.

\section{BRAINCASE}

Although hidden anterodorsally by the parietal, much of the braincase is visible. Absence of the right supratemporal arch offers a clear view of the right prootic and the anterior surface of the paroccipital process of the otooccipital (fig. 7). Most of the supraoccipital and the posterior part of the paroccipital processes are visible in dorsal view behind the parietal (figs. 3-4). Matrix and the surrounding bones hide the basisphenoid, basioccipital, and occipital condyle.

Prootic (figs. 4B, 7): The right prootic is visible in right lateral view. Its relationships with the major foramina of the braincase (e.g., the facial and vagus foramina) are not exposed, but it is largely complete at the level of the prootic crest and above. A short alar crest (crista alaris prootica of some authors) is present and extends dorsally toward the

preserved (not restored). B-C, left scapulocoracoids of the extant taxa: B, Hoplocercus spinosus (AMNH 93807); C, Crotaphytus sp. 

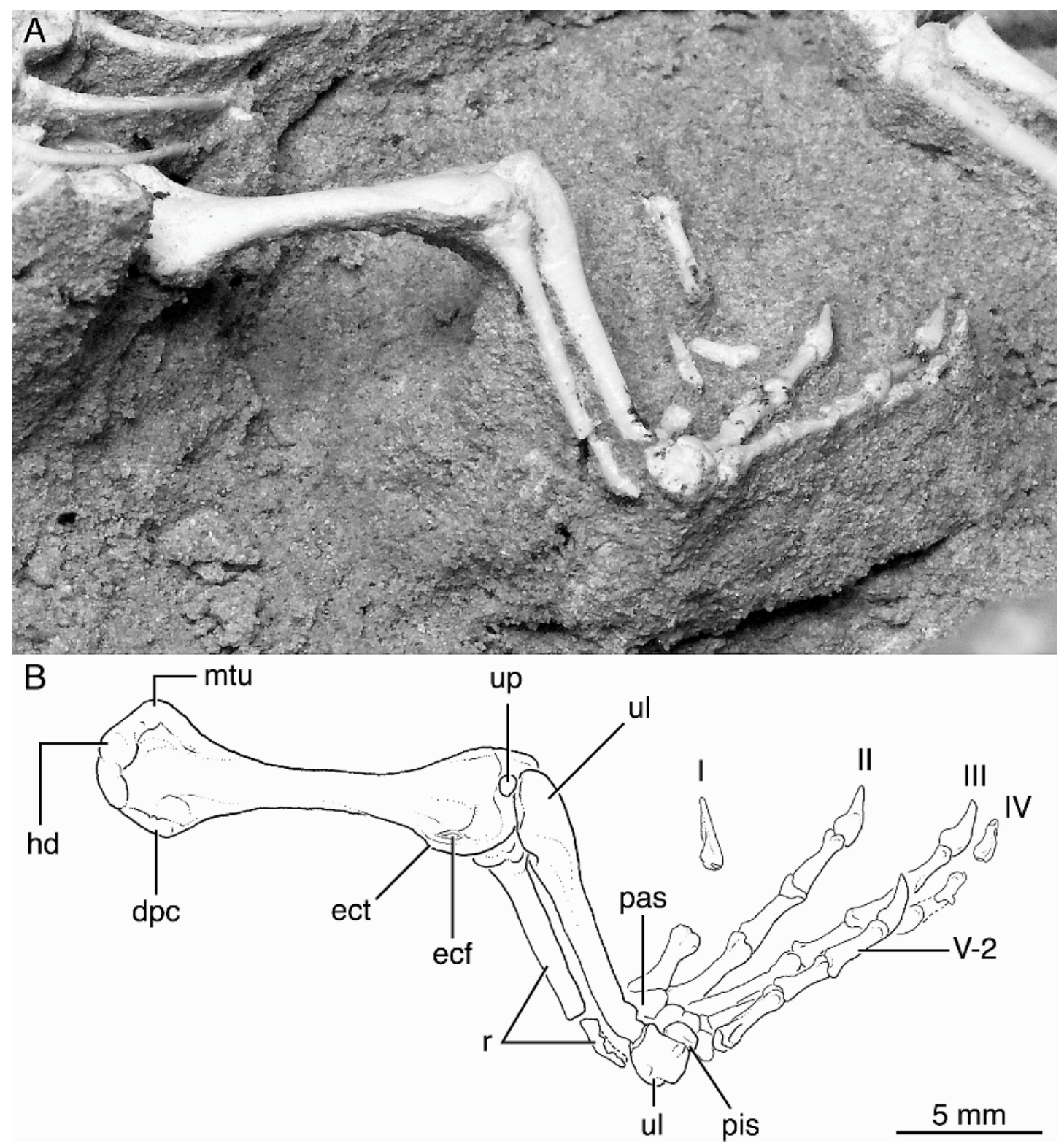

Fig. 14. Left forelimb of Saichangurvel davidsoni (IGM 3/858). A, Photo in anterior view; B, drawing in dorsolateral view.

parietal 94(1), as in many iguanians (see Etheridge and de Queiroz, 1988; Frost and Etheridge, 1989; Maisano, 2003a, b; TorresCarvajal, 2003), but this is different from the anteriorly oriented plate seen in scleroglossans. A swelling of the anterior semicircular canal is visible at the base of the alar process. The well-preserved prootic crest (crista pro- otica of some authors) extends laterally and ventrally. It is slightly damaged posteriorly, but the anterior part is well preserved and shows that it was extensive. The otooccipital process extends posteriorly onto the paroccipital process.

SuPraOCCIPITAL AND OTOOCCIPITAL (fig. 34, 7): The supraoccipital and otooccipital are 
fused, although a faint indication of a suture remains on the left side. However, this may also be a crack created during diagenesis. The right paroccipital process is broken distally, and vertebrae and matrix obscure the exits of the vagus and spinal accessory nerves.

The supraoccipital has been somewhat compressed, and its anterior margin is obscured by the overlying parietal, yet it is well preserved generally. The bony base from which the processus ascendens originates is visible just posterior to the parietal at midline. The dorsal margin of the foramen magnum is slightly damaged. The supratemporal and opisthotic areas around the foramen magnum are contiguous and set off from the paroccipital processes. A swelling for the posterior dorsal semicircular canal is present posterolaterally near the base of the paroccipital process (fig. 7), similar to the condition in Gambelia copei (see fig. 5F).

\section{MANDible}

Both mandibles are preserved in position but are mostly hidden anteriorly by matrix and the overlying skull bones. The posteromedial parts of both dentaries are narrowly visible through the orbits and suborbital fenestrae. Both coronoids are preserved in their natural articulation (or very close to it), as well as both surangulars and articulars/ prearticulars. The presence of an angular cannot be confirmed. Loss of the supratemporal arch has left the right posterior mandible exposed and only slightly damaged. The left mandibular fossa is well preserved and visible through the orbit posterior to the ectopterygoid. The right adductor fossa is preserved. It is small and dorsoventrally narrow, but only slightly smaller than that of similarly sized extant crotaphytids (fig. 8A, 8B). The right quadrate remains in contact with the right mandibular glenoid, but has rotated clockwise along its long axis in dorsal view as described above.

Coronoid (fig. 3, 4B, 8A): Both coronoids are well preserved and visible through the orbits, but with some parts obscured by the ectopterygoid, pterygoid, and jugal. The coronoid process is tall, narrow and bladelike, and projects well above the main body of the mandible. Distally, it is slightly twisted posteromedially. Its dorsal margin is rounded, rather than square, in lateral view. The ventromedial margin of the bone is arched, with anterior and posterior medial flanges. The anteromedial flange extends anteriorly to underlie the posterior part of the dentary. Anteriorly, the medially exposed margin of the flange tapers to a point between the splenial and the subdental shelf. However, disarticulated coronoids in some extant forms demonstrate that the coronoid may expand deep to these contacts, thus adding support to the dentary-splenial contact posteriorly. The posteromedial flange projects posteriorly almost to the level of the adductor fossa but does not contribute to the margin of adductor fossa as preserved. The posterior margin of the coronoid posteromedial process is vertically oriented. The posteromedial process possesses small interdigitations with the surangular, where the two contact dorsal to the adductor fossa and with the prearticular ventrally.

Surangular (fig. 8A): Both surangulars are preserved. The left surangular is visible primarily in medial view, and the right one is visible in medial and lateral view. However, the right surangular has slight damage near the mandibular glenoid and has pulled away from the prearticular/articular element where the two meet at the anterior rim of the mandibular glenoid. This separation demonstrates absence of fusion between the surangular and prearticular/articular. The suture at the contact between the surangular and the prearticular/articular is faint, but remains undisturbed, just anteroventral to the adductor fossa. The lateral contact between these elements is hidden by matrix.

The lateral surface of the surangular is laterally convex along most of its length, just as in crotaphytids, Temujinia, and Ctenomastax. This condition is variable among iguanian groups. The iguanid Ctenosaura possesses a similar condition, with a longer dorsolateral slope, but Iguana possesses no lateral convexity at all. The surangular forms all the margin of the adductor fossa except for the ventral portion, which is formed by the prearticular/articular.

Prearticular/Articular (figs. 3, 8A): The articular and prearticular commonly fuse 


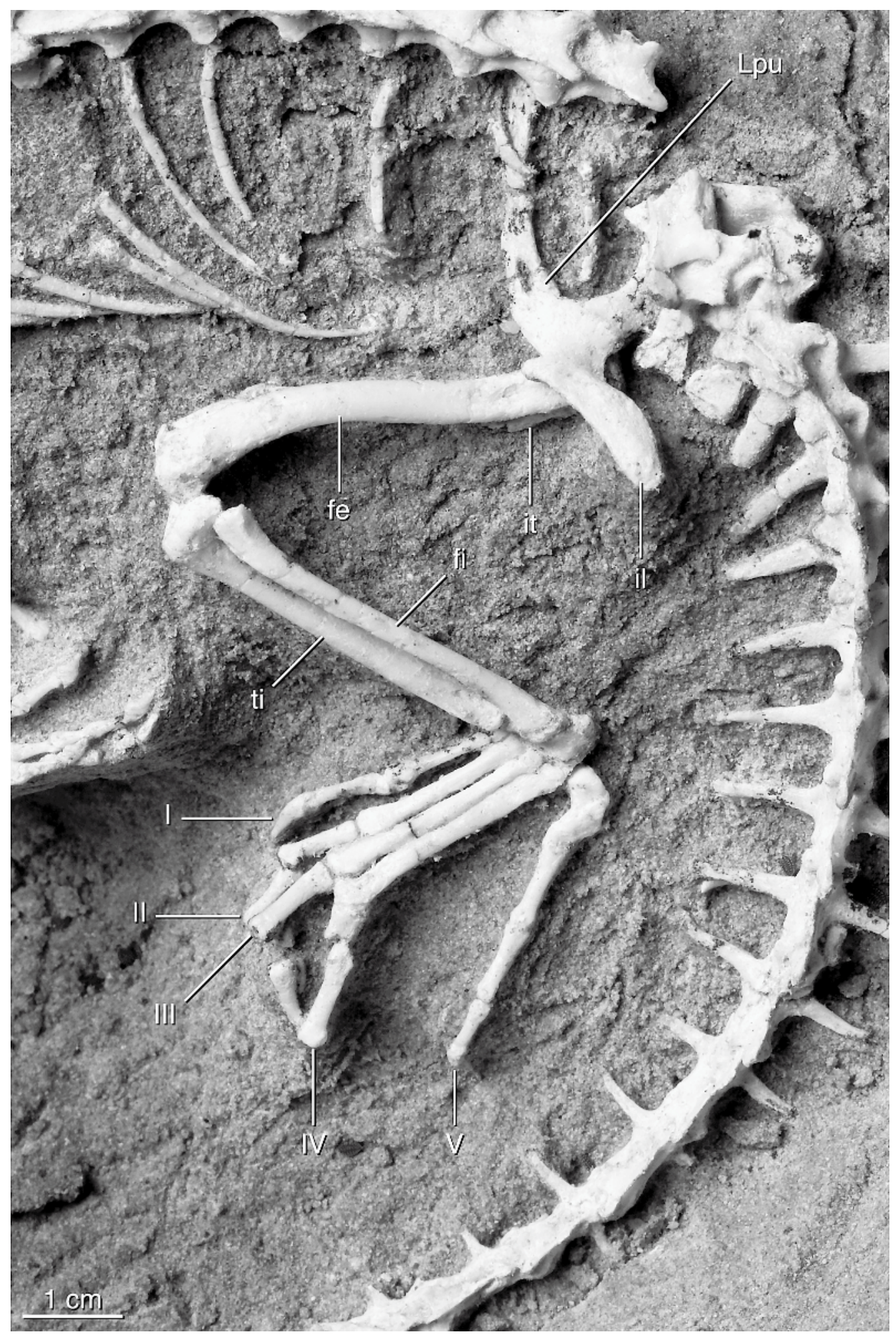

Fig. 15. Photo of the pelvis and left hind limb of Saichangurvel davidsoni (IGM 3/858) in dorsolateral view. 


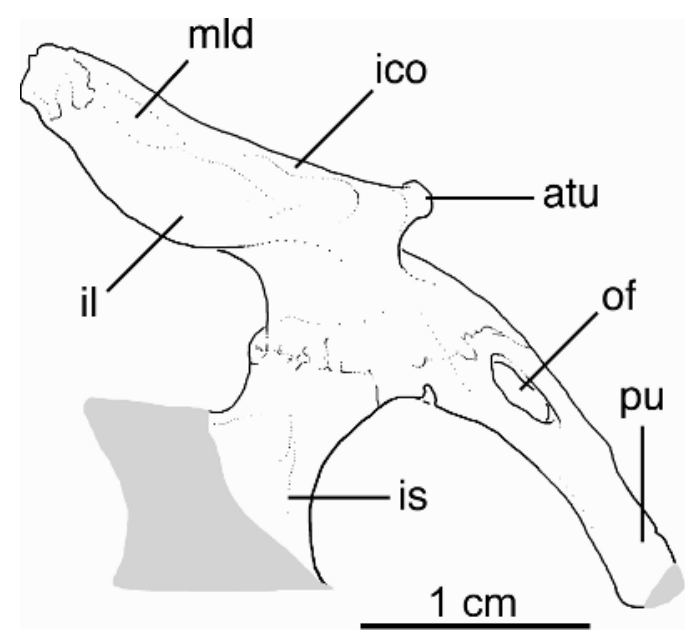

Fig. 16. Drawing of the left side of the pelvis (medial view) in Saichangurvel davidsoni (IGM 3/ 858). Reconstructed portions of the ischium and pubis are shown as semitransparent shadow layers.

in squamates and other reptiles (de Beer, 1937; Romer, 1949, 1956; Rieppel, 1993) into a single structure hereafter referred to as the prearticular. The prearticular is elongate in Saichangurvel davidsoni, forming the ventral and posteroventral margins of the adductor fossa, the mandibular glenoid, and the retroarticular process.

The articular glenoid is relatively small compared with the overall width of the mandible, more similar to the condition seen in polychrotids than crotaphytids (e.g., fig. 8B) or iguanids. The glenoid is weakly divided between medial and lateral portions and anteromedially oriented. It is bounded anteriorly and laterally by the surangular. The retroarticular process is elongate and possesses a dorsal pit or fossa. This fossa is laterally bounded by a weak tympanic crest and medially by a mandibular depressor crest. The robust articular tubercle lies along the medial margin of the retroarticular process, extending from the level of the articular glenoid posteriorly for about two thirds the length of the retroarticular process. The preserved part of the articular tubercle is expressed as a broad crest (visible in figs. 3, 8A). Damage along both the medial and lateral surfaces indicates that the preserved portion does not represent the entire tubercle,

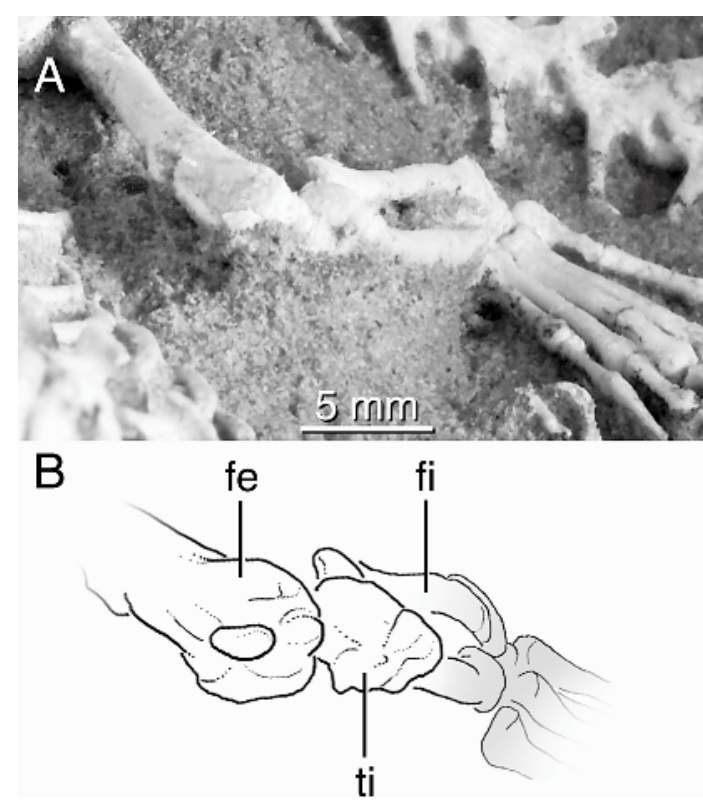

Fig. 17. Left pes of Saichangurvel davidsoni (IGM 3/858) in posterolateral view.

and it is likely that a finger-like process was originally present along the anteromedial margin of the tubercle, perhaps similar to the condition in Dipsosaurus dorsalis (see Maisano, 2003b).

Dentition: Saichangurvel davidsoni is heterodont in that the anterior teeth (those of the premaxilla and maxilla) are conical or peglike, whereas more posterior teeth are distinctly tricuspid (see fig. 4B). The premaxilla apparently contains 10 tooth positions. All of the preserved premaxillary teeth lack cusps. Only the right maxillary tooth row is exposed, and it has 19 tooth positions. The anterior two maxillary teeth are similar in size and form to those of the premaxilla. All of the more posterior teeth are tricuspid with a strong medial cone flanked by two slightly smaller accessory cusps. Only a few damaged dentary teeth are preserved at the posterior end of the tooth row (figs. $4 \mathrm{~B}, 8$ ), so the dentary-tooth count and dentary-tooth morphology are unavailable.

\section{Postcranial Axial Skeleton}

Fifty-three vertebrae are preserved, representing all regions of the axial column (figs. 1, 


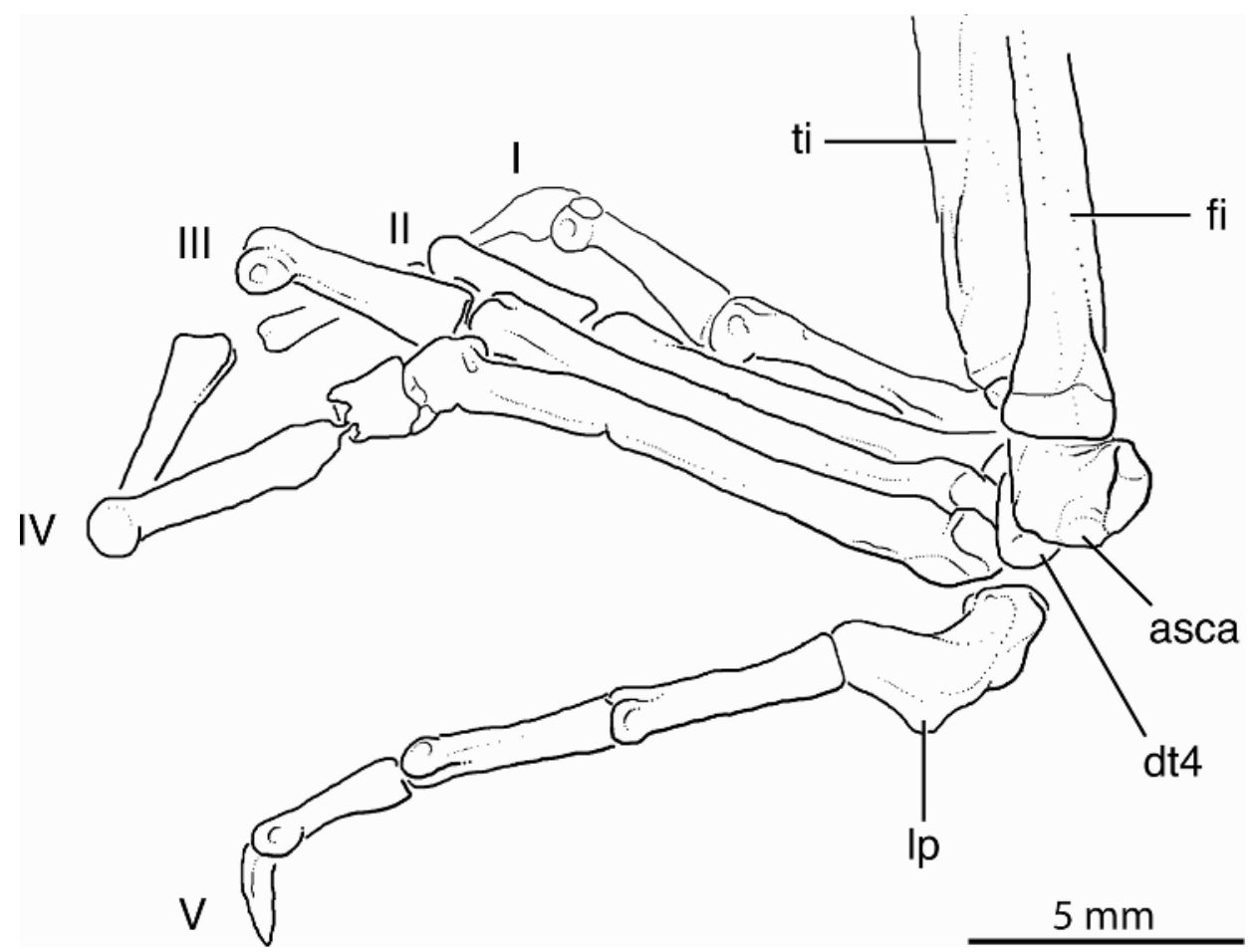

Fig. 18. Left knee of Saichangurvel davidsoni (IGM 3/858) in anterodorsal view.

9-12). Representatives from 17 presacral rib pairs and both pairs of sacral ribs are present. The first 23 presacral vertebrae are preserved in articulation. The final dorsal vertebra is the first in an unbroken string also containing both sacral vertebrae and 23 caudals. Following this is a gap, then another two caudals, another gap, and one more caudal. The preserved posterior caudals are not significantly shorter than those at the end of the continuous series of 23 , so a significant portion of the distal part of the tail may be missing.

Most of the vertebrae are in articulation, but the few dislocations demonstrate that the vertebrae are procoelous and lack a notochordal canal. None of the articulations between the anterior presacrals are visible, but the contact between the penultimate and the last dorsal shows that there was no obliqueness to the condyle-cotyle contact of the dorsal vertebrae. Zygosphenes and zygantra are absent. Nearly all of the vertebrae are preserved with intact neural spines, demonstrating that they are similar to those seen in many pleurodontans such as crotaphytids, iguanids, polychrotids, and hoplocercids.

Presacral Vertebrae (figs. 1, 9, 12): Saichangurvel davidsoni possesses 24 presacral vertebrae. Differentiation of these vertebrae into cervicals and dorsals is problematic, given that the standard landmark for diagnosing these anatomical regions (i.e., first rib with a sternal contact; McDowell and Bogert, 1954; Romer, 1956) is not well preserved. Moreover, the presence of elongate dorsal ribs does not necessarily indicate the presence of a sternal contact. Many squamates possess one or more pairs of elongate posterior cervical ribs, making the identification of the cervical-dorsal vertebral boundary especially difficult in fossil taxa (Conrad, 2006a, b). Neural spines and centrum lengths vary independently within the presacral series and vary without clear correlation to any vertebral regionalization.

The atlas is preserved in articulation with the skull and the axis (figs. 1, 7, 9). Each 


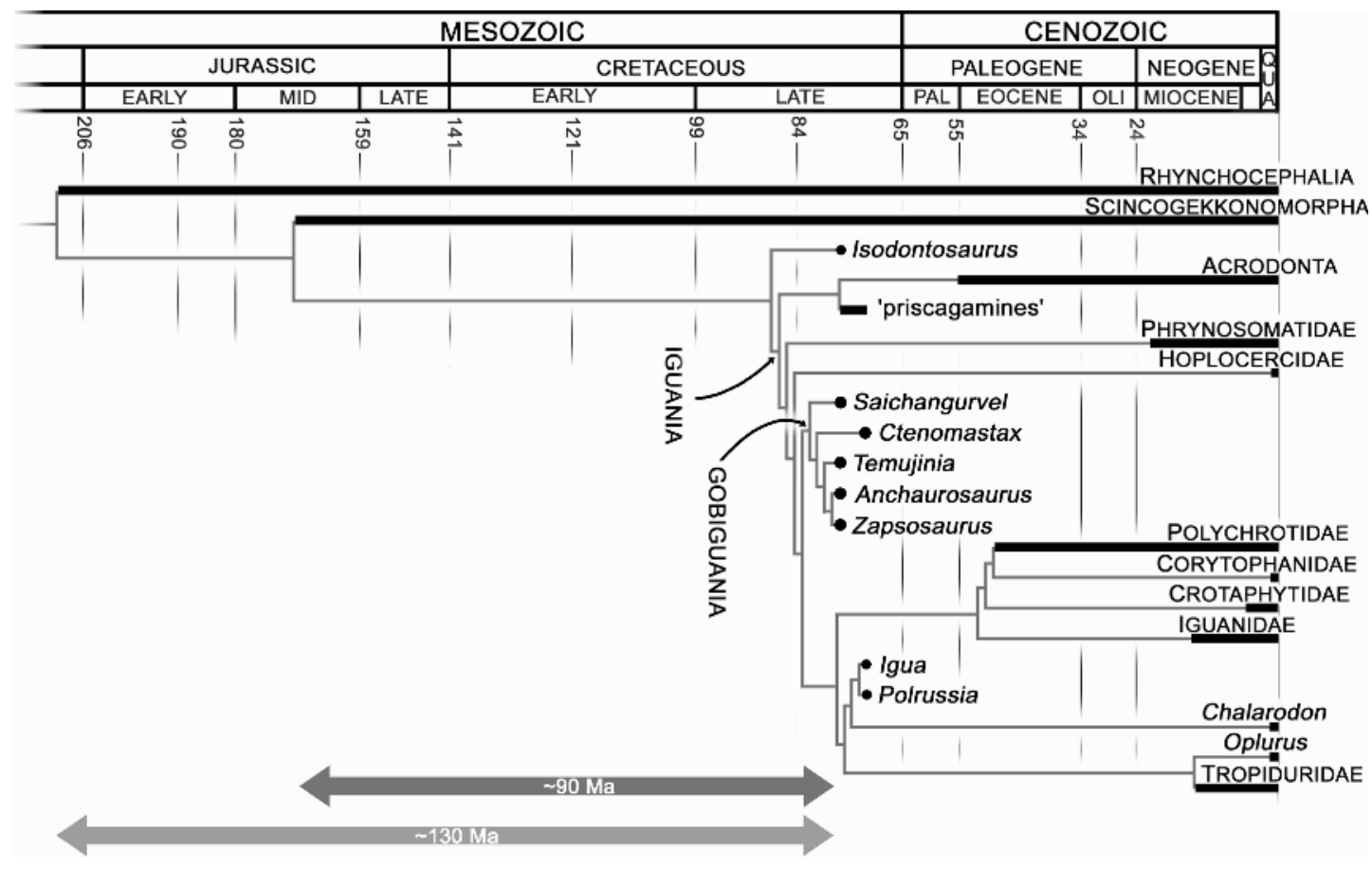

Fig. 19. Temporally calibrated cladogram showing the phylogenetic hypothesis generated by the current study. Note that many terminal taxa in this cladogram (Scincogekkonomorpha, Acrodonta, 'priscagamines', Hoplocercidae, Polychrotidae, and Tropiduridae) were subdivided for the actual cladistic analysis performed in this study (see appendix 1). Taxonomic intervals are approximate and derived primarily from Estes (1983), but supplemented by Norell and de Queiroz (1991), Evans (1994), and Conrad et al. (in press). Timescale adapted from Gradstein et al. (1999). Bremer supports for all displayed iguanian nodes is 1, except the polychrotid-corytophanid clade.

atlantal arch is oriented vertically, with an anterodorsal process that arches medially (fig. 7). The atlantal arch possesses a posteriorly directed transverse process that is developed well enough to overlap the anterior portion of the axis in lateral view. Dorsal to this, the arch is posteriorly excavated by a round intervertebral fenestra. A short postzygapophysis forms the dorsal margin of the intervertebral fenestra and is posteromedially overlapped by the axis prezygapophysis.

The dorsally exposed portion of the axis is similar in general form to the succeeding vertebrae, except that the neural spine is more elongate (fig. 9). In lateral view, the transverse process is well developed (fig. 7B) and may have originally supported a lateral ossification, although a free, fully formed rib was probably absent; the morphology of the transverse process/synapophysis is similar to that present in the anguimorph Shinisaurus crocodilurus (Conrad, 2006a). The anterior extension of the axis into the ring of the atlas is visible in lateral view, but little else of its morphology is visible.

The axis and the two succeeding vertebrae are noticeably more elongate than the immediately succeeding vertebrae (fig. 9). Presacral vertebra 5 is intermediate in length between presacrals 2-4 and presacrals 6 and 7 . Posterior to presacral 7, the vertebrae generally increase in length to about the level of vertebra 18 , whereupon they become more or less uniform in length to the penultimate presacral. Presacrals 9-13 are subequal in length to the elongate anterior vertebrae, but those posterior to presacral 13 are 
slightly longer. Elongate vertebrae 2-4 are certainly cervicals, but so are vertebrae 5 and 6 and probably 7 and 8 under the current definition. Presacral vertebra 6 is the most anterior vertebra preserved with ribs. The ribs remain in articulation and are complete. They are very short-only about 1.5 times the length of the vertebra - and would not have been connected to the sternum. Thus, there is much variation in cervical vertebral length. Crotaphytus and Iguana are much more consistent in the lengths of their cervical vertebrae, although the penultimate cervical (cervical 7) in Iguana is slightly shorter than the adjacent vertebrae.

The neural spines are variable in their anteroposterior length and do not directly correspond with the length of the vertebrae or the presence or absence of elongate ribs (see fig. 9). The axis and cervical vertebrae 3 5 possess anteroposteriorly broad neural spines. Vertebra 6 has an anteroposteriorly abbreviated neural spine; vertebra 7 possesses a more elongate neural spine; and the neural spines for vertebrae 8-16 are consistently elongate. These elongate neural spines are more robust posteriorly than anteriorly. In lateral view, the anterior margin of each describes a posterodorsally slanting surface that reaches its apex and flattens just posterior to the level of the synapophysis. Posterior to vertebra 16, the thin anterior lamina recedes, and only the robust posterior portion of the neural spine remains, giving the structure a narrower lateral profile with a more sloping anterior border. Although some of the neural spines are damaged, this neural spine pattern seems natural and differs from the more uniform morphology of the neural spines present in other observed pleurodontans.

As is common among squamates, the anterior synapophyses are more robust than the posterior ones. Although no ribs are preserved anterior to vertebra 6 , synapophyses complete with fully formed articular surfaces are present, beginning with the third vertebra.

The holocephalus ribs are best preserved on the left side of the specimen. The rib articulating with vertebra 6 is very short, but the ribs increase in size posteriorly to about the level of vertebra 15 (fig. 1). Vertebrae 15-17 appear to have the longest dorsal ribs, posterior to which the ribs become shorter approaching the sacrum. A rib remains associated with presacral vertebra 23, lying in the thyroid fenestra of the pelvis and just lateral to the vertebra. The final presacral vertebra does not have an associated rib preserved, but it retains a damaged remnant of a synapophysis of the left side. This suggests that the final presacral vertebra carried an unfused rib and that there was no lumbar region.

SACral Vertebrae (figs. 1, 10): The sacral vertebrae are well preserved, although they have been shifted somewhat from their natural articulation with each other and from the dorsal vertebrae. As preserved, the last dorsal vertebra now dorsally overlies the first sacral. The anterior end of the first sacral has been pushed ventrally with respect to the rest of the vertebral column, pulling it slightly out of natural articulation with the second sacral and exposing the articular surfaces of the two bones. Despite this movement and associated damage, the left sacral ribs remain in contact with one another; those on the right side are damaged and partly obscured by the remnants of the right ilium.

The neural spines are not markedly different between the posterior dorsal and the sacral vertebrae. Both sacral ribs are preserved, the first showing some damage on the dorsal surface, probably caused when the overlying weight of the sediment forced the separation of the ilium from the sacrum. The sacral ribs are proximally narrow, but expand distally into broad blades making contact with one another at the ilium. The first sacral rib is somewhat posteriorly deflected. The contact between the sacral ribs occurs only very distally, is very narrow, and is unfused.

Caudal Vertebrae (figs. 1, 10-11): The tail is well preserved and curled around so that the end of the preserved caudal series lies close to the skull (fig. 1). Because the vertebrae are ventrally embedded in matrix, the chevrons are not visible, and the presence or absence of pygal vertebrae is impossible to identify. No fewer than 29 caudal vertebrae made up the tail, and it is likely that there were many more. The sacral vertebrae and first 23 caudals are preserved in articulation, after which four more are preserved separated by two gaps. 
The first gap is bounded by most of the preceding vertebra and a nearly complete succeeding vertebra. The gap is the appropriate size to have included the missing portions of the surrounding vertebrae and one more complete vertebra. The second gap is bounded by two complete vertebrae and is long enough to accommodate a single vertebra. The final preserved vertebra (reconstructed as caudal vertebra 29 based on the description earlier) is still robust and retains a relatively welldeveloped neural spine compared with those of nearby vertebrae, suggesting that it was far from the tail tip; certainly, it was not the last vertebra in the caudal series.

The caudal transverse processes are single, contrasting the double caudal transverse processes present in species of Anolis and many scleroglossans (Etheridge, 1967; Estes et al., 1988). Autotomy septa are present in the caudal vertebrae, but they are somewhat faint. An apparent autotomy septum is present on caudal vertebra 4 (figs. 10,11A). That vertebra has a symmetrical transverse crack in the same position as a very faint septum line on caudal 5. Caudal vertebra 8 is also cracked, but not along septum line that occurs in the same position as that on caudal 5. Several vertebrae posterior to caudal 8 show remnants of autotomy septa. Hecht and Costelli (1969) note that autotomy septa sometimes fuse in older individuals of various lizards. The faintness of the septa in this specimen suggests their partial fusion.

The caudal vertebrae vary in their morphology along the length of the tail (fig. 11). The preserved caudals have subequal central lengths, becoming much more slender posteriorly but not shorter. This slimming of the caudals comes from a reduction in size of the neural spines and transverse processes, as well as a reduction in centrum diameter.

Anteriorly, the neural spines are extensive and similar to the general morphology present in the anterior presacrals with a posteriorly robust portion and a thinner anterior lamina (e.g., fig. 11A). However, the anterior caudal neural spines are somewhat taller than those of the anterior presacral vertebrae. Development of the thin anterior lamina is most extensive in the first four caudals and gradually reduces over the next three caudals to be absent or so poorly calcified/ossified as to preserve no remnant in caudal vertebrae posterior to caudal 8 (e.g., fig. 11B). Thus, from caudal vertebra 4-8, the neural spine transitions from a broad, square-shaped profile in lateral view to a posteriorly placed vertical tab with a slight posterior deflection. Caudal vertebra 8 retains a vertical neural spine, but caudal 9 (fig. 11B) and the following vertebrae have much shorter neural spines that are oriented more posteriorly. In addition, these vertebrae possess a sagittal lamina that is more robust than that seen in the more anterior caudal vertebrae, although it is still delicate relative to the main portion of the neural spine. The lamina extends anteriorly to the level of the transverse process, where it joins a pseudospine associated with the autotomy septum (fig. 11). The neural spine is further reduced in more posterior vertebrae. It does not extend posterior to the level of the postzygaphophyses in vertebrae posterior to caudal 15 (e.g., caudal vertebra 20; fig. 11D). At the level of caudal vertebra 21 , the neural spine is gone, leaving only the sagittal lamina.

Transverse processes are present at least to caudal vertebra 23 and may have been present in more posterior caudals, as well, but the three vertebrae posterior to caudal 23 are not well enough preserved to confirm their presence or absence (fig. 1). The first two pairs of transverse processes are somewhat posteriorly deflected and placed posteriorly so that their distal tips extend beyond the level of the postzygaphophyses (fig. 10). The third pair of transverse processes distally extends to about the same posterior level as the postzygapophysis. All subsequent transverse processes extend laterally.

The anterior transverse processes are notably longer than those posteriorly. The transverse processes on the second caudal are more elongate than the length of the vertebra itself. The lengths of the caudal transverse processes decrease posteriorly, and the transverse process on caudal 9 is shorter than the vertebral length. Caudal vertebra 12 and all succeeding caudals bear transverse processes that are equal only to about half the length of their centra or less; there are no transverse processes preserved posterior to caudal 18 . 


\section{Pectoral Girdle and Forelimb}

Both sides of the pectoral girdle are preserved and much of the pectoral girdle is visible, despite being mostly embedded in matrix ventrally (figs. 1, 12). Parts of the clavicles, scapulae, precoracoids (sensu Barrows and Smith, 1947; Costelli and Hecht, 1971; Rieppel, 1980b) and coracoids are preserved and visible on both sides of the animal. Note that the broader homology of the precoracoid within gnathostomes remains questionable (R.M. Shearman, personal commun.). Also, a thin bar of bone is visible extending from beneath the precoracoid toward the angle of the clavicle. This structure probably represents the left arm of the interclavicle; alternatively, it may represent a calcified portion of the epicoracoid. Surprisingly, remnants of both suprascapulae are preserved. The suprascapulae are preserved only as amorphous masses of calcified tissue that have folded down onto the suprascapulae. Both forelimbs are represented. Whereas the right one is preserved only from the shoulder to the proximal part of the zeugopodium, the left is almost completely preserved.

Clavicle (figs. 1, 12): The right clavicle is damaged and partly hidden by matrix, but the left clavicle is nearly complete and remains in contact with the scapula, suprascapulae, and interclavicle. The angled clavicle possesses a broad medial process, but there is no notch or foramen such as that seen in some iguanians (e.g., some polychrotids, corytophanids, and some phrynosomatids, among others). The ascending process is narrower than the medial process.

CORACOID/PRECORACOID AND EPICORACOID (figs. 12-13): Ribs and vertebrae hide parts of the endochondral component of the pectoral girdle, but the absence of visible sutures suggests that the scapula, precoracoid, and coracoid were fused. Most of the morphology of the coracoid/precoracoid unit may be reconstructed when the two sides of the specimen are compared (fig. 13).

The coracoid/precoracoid contributes the posterior margins to each a primary (anterior) and a secondary (posterior) coracoid fenestra. These coracoid fenestrae are given their shape partly by two precoracoid bars lying anteromedially. The posterior coracoid bar and the very base of the anterior coracoid bar are visible on the left side of the skeleton.

Scapula and Suprascapula (figs. 1213): Both robust scapulae are well preserved, but the left scapula is more visible than the right. Whereas the anterior margin of the scapula is gently concave, the posterior margin is straight. There is no scapular bar, and there is no subdivision of the scapular fenestra, as is seen in some iguanians. Both suprascapulae are preserved, but little of their original morphology remains. These appear to have been composed of calcified cartilage and to have collapsed onto the dorsomedial parts of the scapulae.

Humerus (figs. 1, 9, 12, 14): Both robust humeri are preserved in dorsal view, in contact with their glenoids and in articulation with their zeugopodia. The left humerus has been prepared slightly more than the right, but both retain matrix only on their ventral surfaces near the midlines of their shafts. The humeri are uncrushed and undistorted. Only very faint suture lines remain between the epicondyles and the main body of the bone humerus both proximally and distally, again indicating the maturity of this specimen (fig. 14B).

The humerus in Saichangurvel davidsoni is comparable to that of a similarly sized Crotaphytus but somewhat more robust (the minimum diameter of the humerus is approximately $12 \%$ of the humerus length in the former and $9 \%$ in the latter). Both humeral heads are slightly obscured by their contacts with the glenoids, but their general morphology is clearly preserved and is similar to that of other limbed squamates. The triangular deltopectoral crest is well developed and extends for about $0.4 \mathrm{~cm}$, with its apex situated in its distal one third. Muscle scars are visible on it lateral surface. Based on comparisons of published Iguana dissections (Romer, 1922), the clearest of these was the origin of the M. triceps c. humeralis medialis. The robust medial tubercle is similarly shaped but with a proximal apex directed posterodorsally (fig. 14). A muscle scar near the base of this tubercle is similar to the insertion point of the scapulo-humeralis anterior in Iguana as described by Romer (1922). Distally, the epicondylar region is nearly 2.5 times the width of the humerus at midshaft. The ectepicondyle arcs outward 
a little more dramatically than the entepicondyle; the former produces a tiny point at its dorsolateral margin, whereas the latter is expressed as a gentle curve that reaches its apex more distally. An ectepicondylar foramen is present near the proximolateral margin of the ectepicondyle 174(0). It is preserved on both right and left humeri. Unfortunately, the radial and ulnar condyles are mostly hidden behind the zeugopodia.

Forelimb Zeugopodium (figs. 1, 9, 12, 14): The morphology of the radius and ulna is known mostly from the left side. The distal ends of both the radius and ulna have been cracked and the end of the ulna has tuned dorsolaterally nearly 90 degrees. The exposed portion of the proximal head is rounded, but somewhat oblong, around its short axis. The ulna is longer than the radius and proximally terminates in an olecranon process. The olecranon apex occurs somewhat posterior to the main axis of the bone. Both the radius and the ulna possess narrow shafts that expand distally. As with the humerus, faint suture lines are visible at the epiphyseal-shaft contacts of both the radius and ulna, but the epiphyses were at least partly fused at the time of death. An ulnar patella is preserved on the dorsal surface of the humerus, lying just proximal to the olecranon process (fig. 14). This element is relatively small compared with the patella preserved in the left knee (below) and sits in the very faint olecranon trochlea as preserved.

Manus (figs. 1, 12, 14): The left manus is preserved with the wrist in a flexed position. Consequently, only the ventral surface of the manus is visible as preserved, and some of that surface is partly obscured by the radius, ulna, and manual sesamoids (fig. 14).

The robust radiale possesses a well-developed medial tubercle. A thin layer of matrix remains mesially between the radius and ulna, but this has been reduced through preparation to the point of being translucent, so the absence of an intermedium can be confirmed. A large pisiform is preserved in contact with the posterodistal margin of the ulna. The pisiform is rounded but more elongate proximodistally than mediolaterally. Distal carpal 5 is very narrowly visible distal to the pisiform. Two palmar sesamoids (heterotopic calcifications of the palmar aponeurosis) are present medial to the pisiform and distal to the radiale (fig. 14). They hide much of the carpus as preserved, and the larger of the two (the medial element) narrowly overlies the proximal margins of metacarpals I and II. Similar palmar sesamoids are present in many extant lizards and were recently described for a fossil shinisaurid (Conrad, 2006b).

All five metacarpals and digits are preserved. The metacarpals are indistinguishable from those of iguanians such as Crotaphytus, Iguana, and Plica. Metacarpals III and IV are of subequal length. Digits II, V, and I are of progressively lesser length. The first phalanx is missing from digit I (although it may be preserved lying distal to digit I; fig. 14A), but the ungual appears to be lying in its natural position, allowing the length of the first phalanx to be reliably estimated and the manual digital formula to be identified as 2-3-4-5-3. The penultimate phalanges are subequal in length with the next-to-penultimate ones (fig. 14). The unguals are not strongly curved and are slightly shorter than the penultimate phalanges. Ungual I is the longest in the series and appears is subequal in length to the space left by the proximal phalanx in digit I.

\section{Pelvic Girdle and Hind Limb}

All of the pelvic bones are preserved except for the right ilium (figs. 10, 15). The bones of the left side remain in natural articulation, and the partial right pubis remains articulated with the left pubis. The right ischium is preserved only ventral to the ilio-pubic peduncle and projects ventromedially beneath the first sacral and last dorsal vertebrae, probably retaining its contact with the left ischium. The pelvic bones were fused together. Very weak sutures remain visible only between the ilium and ischium (figs. 15-16).

The thyroid fenestra has been deformed somewhat by the shifting pelvic bones. However, its original shape may be inferred to have been wider than long. As is common among squamates, it was posteriorly invaded by the ischia and, perhaps, hypoischia.

ILIUM (figs. 10, 15-16): Only the left ilium is preserved. It has come apart from the sacral 
vertebrae but is undistorted and is exposed in dorsal and medial views. The lateral surface, including the acetabulum, is hidden.

The robust ilium is elongate and dorsoventrally shallow, but robust mediolaterally. A robust anterior process is present and is slightly anterolaterally deflected, just out of the main axis of the iliac blade. In natural articulation, its straight dorsal margin would have been oriented somewhat posterodorsally. The extreme distal tip of the posterior process has been damaged, so the presence or absence of a distinct fossa for the origin of the caudoiliac ligament cannot be confirmed. The ventral margin of the iliac blade is slightly arched ventrally, with a small constriction of the blade just posterior to the descending portion of the ilium. The medial surface of the iliac blade possesses a bulbous medial expansion, tapering anteriorly, that served as a buttress for the sacral contact in natural articulation (fig. 16). This bulbous buttress is developed to varying degrees in limbed lizards; it is prominent in Iguana, but weakly developed in groups such as Crotaphytidae and Polychrotidae.

Faint scars marking the attachment points for two of the major pelvic muscles are present anterodorsal and posteroventral to the tapered anterior end of the sacral buttress. Based on comparisons with a published description of Iguana by Romer (1922), the identity of these muscles and others (below) may be determined. The dorsal edge of the blade is narrowed into an ilio-costal crest. Posterodorsal to the sacral attachment points and ventral to the iliocostalis scar is an origin site for the $\mathrm{M}$. longissimus dorsi.

The suture between the ilium and ischium remains visible posteriorly, but becomes faint anteroventrally (figs. 10, 15-16). It is raised posteriorly into a ridge, but this flattens near the presumed point of common contact between the ilium, ischium, and pubis, and the suture is partly obliterated by intergrowth of the bones. The origin site of the cloacal muscle is preserved as a small tubercle at the posterior margin of the ilio-ischial contact. The ilio-pubic contact is mostly obliterated and is visible primarily as a change in contour where the two with intermittent remnants of the suture. It is dorsally arched as it extends anterolaterally. An anteroventral process of the ilium is present anterolateral to the obturator foramen (the latter fully within the pubis; see below) and is broad and rounded ventrally rather than tapered.

PubIs (figs. 10, 15-16): The left pubis is well preserved and exposed dorsally. Diagenesis has deformed the symphysial process so that it now points slightly more anteriorly than it would have originally.

The pubes meet directly at the midline so that an eipipubis did not extensively invade the contact. An epipubis may have been present originally, but it was likely small as in other iguanians [contrast with the condition in, for example, eublepharid geckos (Grismer, 1988: fig. 17) and anguimorphs (Rieppel, 1980b: fig. 8; Conrad, 2006a: fig. 7)]. The obturator foramen is very large and elongate within the main axis of the pubis. This is apparently a real condition (rather than an artifact of preparation) because the margins of the foramen are smooth and unabraded. The shape of the pectineal tubercle is hidden, but the tubercle itself may be identified lying just medial (distal) to the obturator foramen, at about the midpoint of the pubis. Thus, the tubercular and symphysial portions of the pubis are of subequal length.

IschIUM (fig. 16): Both ischia are partly covered by the final dorsal vertebra and the first sacral, and the right ischium is very incomplete. The ischium is narrow proximally where it contacts the ilium and pubis, but expands and is rectangular distally. The anterior margin of the ischium (the posterior margin of the thyroid fenestra) is bowed posteriorly. The posterior margin expands posteriorly to form a short, pointed tubercle near the midpoint of the bone posteriorly, visible only on the right ischium. Little of the posteroventral margin is visible, but it seems to run anteroventrally from the posterior tubercle toward the midline.

FEMUR (figs. 1, 15, 18): Only the left femur is preserved, and it is preserved with its posterodorsal surface facing dorsally. Its head is hidden by the overlying ilium and remains partly embedded in matrix proximally, with some damage to the internal trochanter (sensu Romer, 1956), but is otherwise well preserved and exposed. It remains 
articulated with the pelvis and the hind-limb zeugopodium.

The femur is more strongly curved than in extant Iguana and Crotaphytus or the fossil taxon Anchaurosaurus (Gao and Hou, 1995, 1996). It curves distoventrally from the femoral head to the level just beyond the internal trochanter and then forms a gentle arc to the distal tip. Besides being robust, little about the internal trochanter is apparent. A patella is preserved on the dorsal surface of the femur, just proximal to the femoral trochanters (figs. 15, 18).

Hind-Limb Zeugopodium (figs. 1, 15, 1718): Both the tibia and fibula are well preserved without deformation or serious damage, although the most proximal part of the proximal fibular head is missing. The fibula has been completely freed of matrix except for small areas near the tibial contact, but the tibia is still embedded, and its anterior surface is thus obscured. The fibula is slightly longer than the tibia, and the fibula is the only long bone preserved that retains a clear (open?) suture with its distal epiphysis on both sides. Loss of the proximal tip of the left fibula may indicate that the proximal epiphysis also was unfused. Besides a slight deflection of the fibula proximally, the tibia and fibula are both straight. The tibia has a narrow shaft that expands somewhat proximally at the trochanteric surface. The surface for articulation with the femur is triangular in dorsal view, with a weak and slightly rounded cnemial crest forming the anterior angle. A well-developed crest for the origin of pedal/ digital flexors is present along the anterolateral surface of the tibia. Both the tibia and the fibula end in distally convex articular surfaces without notching to receive the tarsus.

Pes (figs. 1, 15, 17): Extreme dorsiflexion of both pedes hides much of the tarsal region. Consequently, presence or absence of astragalus-calcaneum fusion cannot be confirmed, and the number and morphological characterization of the distal tarsals remains unknown. Because of uncertainty regarding the fusion of the astragalus and calcaneum, they will be referred to individually. A full complement of phalanges is present in neither pes. However, the preserved bones of the pedes are complete, uncrushed, and unweathered.
Surrounding bones mostly hide the anterior surfaces of both astragali, but part of the lateral articular buttress is visible on the left astragalus, and most of the posterior surface is visible on the right astragalus. The anteromedial surface of the astragalus possesses a robust rim underlying the tibial fossa. A ridge separates the tibial and fibular articular fossae of the astragalus and calcaneum, respectively, and the two articular surfaces are set at nearly right angles to each other.

Both the left (fig. 17) and right distal tarsals 4 are preserved in articulation with the rest of their respective pedes, but the surrounding bones mostly hide each. The metatarsals are preserved on both sides, but only digit I is complete on the right pes and digits I and $\mathrm{V}$ on the left.

Metatarsal IV is the longest, being only slightly longer than III. Metatarsals II, I, and $\mathrm{V}$ follow in decreasing length. Metatarsal $\mathrm{I}$ is notably thin and delicate looking, but the digit is complete and retains a robust ungual. The hooked metatarsal $\mathrm{V}$ is extremely short and is only about half the length of metatarsal I. Its lateral process and lateral plantar tubercle are well developed. The lateral plantar tubercle occurs somewhat distally, near the midpoint of the bone. A complete phalangeal formula cannot be reconstructed. Digit I possesses two phalanges and digit V possesses four. Digits II and III are each known only from two phalanges, and digit IV is known only from one. The preserved unguals are similar in form to those of the manus.

\section{PHYLOGENETIC ANALYSIS}

Historical Analyses: Iguanian monophyly is universally accepted, but the interrelationships of the iguanian groups remain contentious. Etheridge and de Queiroz (1988) published the first cladistic analysis of iguanian relationships, but did not include acrodontans in their analysis. Frost and Etheridge (1989) performed the first, and still the broadest, morphological analysis of all extant iguanian groups and included the fossil taxon Priscagama. Although they identified numerous iguanian 'families', they were unable to resolve the interrelationships of most of these clades or isolate the basal iguanian dichotomy. 
Morphological and molecular analyses alike have produced evidence for a monophyletic Acrodonta (Estes et al., 1988; Frost and Etheridge, 1989; Macey et al., 1997, 2000; Lee, 1998, 2000, 2005; Lee and Caldwell, 2000; Harris et al., 2001), and recent molecular work has suggested that Acrodonta is the sister group to all other iguanians (Pleurodonta; the metataxon Iguanidae* of Estes et al., 1988, and many subsequent authors; Schulte et al., 2003). Recent molecular analyses have questioned the monophyly of at least two of the 'family'-level groups proposed by Frost and Etheridge (1989): Polychrotidae and Tropiduridae (Frost et al., 2001; Shulte et al., 2003).

The Present Analysis: We constructed a morphological phylogenetic data set to test the phylogenetic position of Saichangurvel davidsoni within Iguania. Our data matrix includes 38 iguanian taxa, 15 representative non-iguanian lizard taxa, and the outgroup Rhynchocephalia. Where supraspecific taxa were scored (i.e., Rhynchocephalia), previous analyses of the group were relied on to identify basal taxa (Gephyrosaurus, Diphydontosaurus, Planocephalosaurus for Rhynchocephalia; Sues et al., 1994; Reynoso, 1996; Wilkinson and Benton, 1996; Evans and SigogneauRussell, 1997; Reynoso, 2000; Evans et al., 2001) to be used for most of the character scoring. These 54 taxa (appendix 1) are scored for 202 informative morphological characters (appendix 2).

We analyzed the cladistic data set using the heuristic search option (10,000 replicates) in the computer program PAUP v. $4.0 \mathrm{~b} 10$ (Swofford, 2001). All of the 37 shortest recovered trees had a length of 1,180 steps and a consistency index (CI) of 0.4025 . We also performed a bootstrap analysis $(1,000$ replicates) and collected Bremer support values. However, as with other recent analyses of iguanian relationships (Macey et al., 1997; Schulte et al., 2003; Conrad et al., in press; discussed at length in Schulte, 2003), the statistical support for the most nodes is poor. Indeed, in our phylogenetic hypothesis, only the node uniting polychrotids with corytophanids has a decay index above 1 , and none of the nodes possesses bootstrap support above $50 \%$.
Systematics: Our analysis recovers an endemic clade containing five Cretaceous iguanians from the Gobi to the exclusion of other iguanians (fig. 19). This clade is supported by the following unambiguous synapomorphies: 18(1), maxillae with strong medial processes contacting at midline behind the premaxillary nasal process; 19(1), maxillary nasal process weakly inclined and not distinctly set off from the ventral narial border; 59(1), medial forking of the postfrontal at the frontal-parietal contact; 62(2), postfrontal expressed as a mediolaterally elongate bar joining the frontal and parietal to the supratemporal arch; and 69(1), dorsal process absent from the squamosal. We term this clade Gobiguania and define it as all taxa closer to Anchaurosaurus gilmorei than to Iguana iguana, Crotaphytus collaris, or Agama agama. Gobiguania is the sister taxon to a clade containing all other pleurodontans except Phyrnosomatidae and Hoplocercidae, as shown by three unambiguous synapomorphies. These are 13(0), extensive internasal contact; 53(1), presence of a nuchal fossa extending onto the dorsal surface of the parietal (at least visible in dorsal view); and 115(1), a partly closed Meckel's canal.

Saichangurvel davidsoni is the sister taxon to all other gobiguanians, the latter being united by the shared presence of 1(1), a proportionately longer snout (making up 30\% or more of the skull length). Temujinia, Anchaurosaurus, and Zapsosaurus form a clade diagnosed by 53(2), extensive invasion of the parietal table by the nuchal fossae. Anchaurosaurus and Zapsosaurus form a clade exclusive of Temujinia based on two unambiguous synapomorphies: 7(0), dermal sculpturing absent from the frontal and parietal; and 43(1), the presence of a frontoparietal fontanelle.

This is the first broad-scale morphologybased iguanian analysis to recover a monophyletic Pleurodonta as the sister taxon to Acrodonta. This topology is supported by the presence of only two unambiguous pleurodontan synapomorphies, each of which is reversed at some point within Pleurodonta. These synapomorphies are 7(1), presence of dermal sculpturing on the frontal and parietal; and 13(1), nasals with reduced contact dorsal- 
ly, invaded anteriorly by the premaxilla and posteriorly by the frontal.

\section{DISCUSSION}

Recent and historical expeditions to the Gobi have produced Late Cretaceous fossil lizards from each of the four major lizard groups (Iguania, Gekkota, Scincomorpha, and Anguimorpha; Gilmore, 1942, 1943; Sulimski, 1975, 1978; Borsuk-Bialynicka, 1984, 1985, 1988, 1990, 1996; BorsukBialynicka and Moody, 1984; Alifanov, 1989a, b, c, 1993, 1996, 2000; Norell et al., 1992; Gao and Hou, 1995, 1996; Norell and Gao, 1997; Gao and Norell, 1998, 2000; Conrad and Norell, 2006). Such taxonomic diversity is remarkable, especially given the overall 'spottiness' of the squamate fossil record. Historically, the majority of described Gobi taxa have been autarchoglossans and acrodontan iguanians, but recent discoveries have identified two probable stem geckos (Gao and Norell, 2000; Conrad and Norell, 2006) and increased the number of known non-acrodont iguanians (faunas reviewed in Gao and Norell, 2000).

Iguania, like Squamata as a whole, has a rich, but patchy fossil record. Although many Cretaceous species have been identified, Saichangurvel davidsoni is the first known from a complete skeleton. Indeed, the recent revelation that none of the Euposaurus remains may be diagnosed as iguanians (Evans, 1993) renders Saichangurvel davidsoni the earliest iguanian known from complete remains. Thus, this taxon offers an extraordinary opportunity to examine iguanian morphology in the Late Cretaceous.

Saichangurvel davidsoni resembles other recently described Gobi pleurodontans in cranial morphology, and our analysis hypothesizes that it is closely related to Ctenomastax (fig. 5D), Temujinia (fig. 5A), Anchaurosaurus, and Zapsosaurus (fig. 5B). The Gobi pleurodontans Polrussia and Igua, also generally similar in appearance to Gobiguania, constitute the sister clade to Chalarodon madagascariensis. Opluridae (sensu Frost and Etheridge, 1989) is found to be paraphyletic with respect to Tropiduridae and the Polrussia-Igua clade, a result that will be further explored elsewhere. By contrast, the Gobi taxon Isodontosaurus is found to be the sister taxon to Iguania (sensu Estes et al., 1988). The postcranial skeleton of Saichangurvel davidsoni is relatively conservative for an iguanian, but still helps in polarizing characters throughout the pleurodontan radiation.

Gao and Hou (1995) and Gao and Norell (2000) made comparisons between the morphology of gobiguanian taxa and extant crotaphytids, noting numerous similarities. This is unsurprising, given that crotaphytids have been presumed to represent a relatively basal iguanian bauplan among extant taxa (Estes, 1983; Frost and Etheridge, 1989), with perhaps a more plesiomorphic ecology. Saichangurvel davidsoni is likewise superficially similar to extant crotaphytids, but is somewhat more robust than observed Crotaphytus and Gambelia in the postcranial skeleton.

On its surface, our phylogenetic hypothesis suggests that Gobiguania is endemic to the Cretaceous Gobi. However, the Paleocene record of squamates is extremely poor, and the current absence of gobiguanian fossils certainly does not preclude their future discovery in Cenozoic faunas or even predict their absence there. Similarly, the North American iguanian record is very poor, with the first complete skeleton not appearing until the Eocene (Conrad et al., in press), so it is also impossible confidently to limit the gobiguanian range to East Asia. Nevertheless, Late Cretaceous Djadokhta and Djadokhta-like (sensu Gao and Norell, 2000) rocks in Mongolia and China have produced mammals (Rougier et al., 2001) and some dinosaurs (Makovicky and Norell, in press). Among these are some taxa that appear to form monophyletic endemic Mongolian groups.

Gobiguanians and the other Late Cretaceous iguanians are important for understanding the Mesozoic history of Iguania as a whole. The presence of Rhynchocephalia, the sister taxon to Squamata, in the Triassic (Fraser, 1982; Wu, 1994) demonstrates that stem squamates must have been present by that time. Scincomorphs and anguimorphs are known from the Jurassic (Hoffstetter, 1966, 1967; Evans, 1998; Evans and Chure, 1998; Evans et al., 2004), indicating that the major 
lizard radiations must have occurred prior to that time and that iguanians (at least, stem iguanians) also must have been present - at least, according to the morphology-based phylogenetic hypothesis presented here. However, no iguanian fossils older than the Late Cretaceous have been identified. Given the phylogenetic hypothesis presented here, there were no fewer than seven discrete pleurodontan lineages present by the Campanian. The stem lineages of Phrynosomatidae, Hoplocercidae, Chalarodon, an Oplurus-Tropiduridae clade, and an Iguanidae-Crotaphytidae-Corytophanidae-Polychrotidae clade are not represented directly by fossils, but are implied by the presence and phylogenetic placements of Gobiguania, Polrussia, and Igua. Acrodonta is represented by the priscagamid radiation, so the stem leading to modern acrodontans must also have been present. These data, paired with the absence of earlier fossil iguanians, suggest the relatively rapid diversification of the iguanian crown group in the Late Cretaceous. Even so, the incomplete quality of the fossil record demands that this hypothesis be offered only tentatively.

As mentioned earlier and more extensively reviewed by Schulte et al. (2003), the interrelationships of the major iguanian groups has been, and continues to be, an extremely difficult problem given current data. Morphological and molecular data have both been used to attack the problem of iguanian phylogeny, with conflicting results and limited statistical robustness. Morphological data is subject to the issue of character and characterstate subjectivity, whereas molecular data cannot benefit from the use of fossil taxa to help polarize character states. Although our morphology-based phylogenetic hypothesis differs from that suggested by Schulte et al.'s (2003) molecular data, our study and theirs are similar in finding little robustness for the phylogenetic resolution of the major iguanian clades. Based on the data presented earlier, we believe that this could be due to the incompleteness of the fossil record, but it may also speak to the possibility of a rapid divergence of the major iguanian lineages in the Late Cretaceous. The continued discovery and description of fossil taxa may eventually help to unknot this mystery.
Further analysis of the gobiguanian material may have implications for the squamate family tree as a whole. In his seminal work 'The classification of Lizards' (Camp, 1923), Charles Camp laid out the major outlines of lizard evolution. An important element of Camp's phylogeny was that iguanians (composed of agamids, Iguanidae, and chameleons) formed a monophyletic sister taxon to all other lizards and that a crown clade was composed of snakes and Varanus. Although not implicitly cladistic, Camp's hypothesis of relationships largely survived later tests based on the cladistic analysis of morphological data (Estes et al., 1988). Several other recent morphological analyses (Evans and Barbadillo, 1997, 1998; Lee, 1998, 2000, 2005; Caldwell, 1999; Lee and Caldwell, 2000; Reynoso and Callison, 2000; Evans and Wang, 2005; Evans et al., 2005; Conrad, in press) and our analysis also support major elements of Camp's original tree, with few changes, as does the analysis that is presented here (fig. 16).

Recently, a series of papers based on the analysis of nucleotide sequences of proteincoding nuclear genes have proposed a novel hypothesis that is very different from the traditional one (Townsend, 2002; Townsend et al., 2004; Vidal and Hedges, 2005). This new hypothesis places dibamids and geckos + pygopods in a sequentially basal position relative to other lizards and, among other things, places iguanians as the sister taxon to Anguimorpha embedded high in the tree. Although this is a radical departure from the more traditional topology presented here, many elements of the unrooted networks of the two trees are consistent, suggesting that rooting and sampling issues may be influential factors in producing these differing hypotheses. Obviously, the only way to reconcile these hypotheses is to conduct a total evidence analysis combining all of the data into a single parsimony analysis. Such an analysis is in progress but outside the scope of this project.

Regardless of its broader relationships, Saichangurvel davidsoni is an important taxon for understanding the Late Cretaceous Gobi lizard faunas. It helps to identify an extinct radiation of Late Cretaceous iguanians and offers a comprehensive look at the skeleton of a Cretaceous iguanian. In doing so, it offers 
a previously unglimpsed moment in the skeletal evolution of one of the world's most successful reptile clades.

\section{ACKNOWLEDGMENTS}

We thank all of the members of the Mongolian Academy of Sciences-American Museum of Natural History joint expeditions of the 1990s and 2000s. Without their toil in the heat and dust, this specimen would have been lost to a rain storm. Aaron M. Bauer and an anonymous reviewer provided insightful reviews that significantly improved the quality of this paper, for which we are grateful. Darrel Frost and David Kizirian (AMNH, Herpetology), Harold Voris and Alan Resetar (Field Museum, Herpetology), Bill Simpson (Field Museum, Vertebrate Paleontology), the Florida State Museum (University of Florida), and Richard Etheridge provided additional comparative material used in this study. Amy Davidson (AMNH) collected and provided masterly preparation of IGM 3/858. Mick Ellison expertly photographed the specimen and labeled the illustrations. The authors (and this project) benefited from conversations with and drew inspiration from Saul Hudson, David Kizirian, Sterling Nesbitt, Rebecca Shearman, and Alan Turner. Many of the data for the phylogenetic analysis in this project were completed while Jack L. Conrad was a Ph.D. candidate and supported by a Doctoral Dissertation Improvement Grant (DDIG 0408064). This project was completed with the support of a Kalbfleisch Postdoctoral Fellowship (AMNH).

\section{REFERENCES}

Abdala, V., and S.A. Moro. 2003. A cladistic analysis of ten lizard families (Reptilia: Squamata) based on cranial musculature. Russian Journal of Herpetology 10: 53-78.

Alifanov, V.R. 1989a. More ancient gekkos (Lacertilia, Gekkonidae) from the Lower Cretaceous of Mongolia. Paleontologicheskii Zhurnal 1: 124-126.

Alifanov, V.R. 1989b. New priscagamids (Lacertilia) from the Upper Cretaceous of Mongolia and their systematic postion among Iguania. Paleontological Journal 1989: 68-80.

Alifanov, V.R. 1989c. The most ancient gekkos (Lacertilia: Gekkonidae) from the Lower
Cretaceous of Mongolia. Paleontologicheskii Zhurnal 1: 57-74.

Alifanov, V.R. 1993. New lizards of the family Macrocephalosauridae (Sauria) from the Upper Cretaceous of Mongolia, critical remarks on the systematics of the Teiidae (sensu Estes, 1983). Paleontological Journal 27: 70-90.

Alifanov, V.R. 1996. Lizard families Priscagamidae and Hoplocercidae (Sauria, Iguania): phylogenetic position and new representatives from the Late Cretaceous of Mongolia. Paleontological Journal 1996: 100-118.

Alifanov, V.R. 2000. The fossil record of Cretaceous lizards from Mongolia. In M.J. Benton, M.A. Shishkin, D.M. Unwin and E.N. Kurochkin (editors), The age of dinosaurs in Russia and Mongolia: 368-389. Cambridge: Cambridge University Press.

Barrows, S., and H.M. Smith. 1947. The skeleton of the lizard Xenosaurus grandis (Gray). The University of Kansas Science Bulletin 31: 227-281.

Bauer, A.M. 2003. Lizards. In H.G. Cogger and R.G. Zweifel (editors), Encyclopedia of reptiles \& amphibians: 126-173. San Francisco: Fog City Press.

Bell, G.L., Jr. 1997. A phylogenetic revision of North American and Adriatic Mosasauroidea. In J.M. Callaway and E.L. Nicholls (editors), Ancient marine reptiles. San Diego: Academic Press.

Borsuk-Bialynicka, M. 1983. The early phylogeny of Anguimorpha as implicated by craniological data. Acta Palaeontologica Polonica 28: 5-105.

Borsuk-Bialynicka, M. 1984. Anguimorphans and related lizards from the Late Cretaceous of the Gobi Desert, Mongolia. Palaeontologia Polonica 46: 5-105.

Borsuk-Bialynicka, M. 1985. Carolinidae, a new family of xenosaurid-like lizards from the Upper Cretaceous of Mongolia. Acta Palaeontologica Polonica 30: 151-176.

Borsuk-Bialynicka, M. 1988. Globaura venusta gen. et sp. n. and Eoxanta lacertifrons gen. et sp. n.-non-teiid lacertoids from the Late Cretaceous of Mongolia. Acta Palaeontologica Polonica 33: 211-248.

Borsuk-Bialynicka, M. 1990. Gobekko cretacicus gen. et sp. n., a new gekkonid lizard from the Cretaceous of the Gobi Desert. Acta Palaeontologica Polonica 35: 67-76.

Borsuk-Bialynicka, M. 1996. The Late Cretaceous lizard Pleurodontagama and the origin of tooth permanency in Lepidosauria. Acta Herpetologica Polonica 41: 231-252.

Borsuk-Bialynicka, M., and S.M. Moody. 1984. Priscagaminae, a new subfamily of the Agamidae (Sauria) from the Late Cretaceous 
of the Gobi Desert. Acta Palaeontologica Polonica 29: 51-81.

Branch, W.R. 1982. Hemipeneal morphology of platynotan lizards. Journal of Herpetology 16: 16-38.

Caldwell, M.W. 1999. Squamate phylogeny and the relationships of snakes and mosasauroids. Zoological Journal of the Linnean Society 125: 115-147.

Camp, C.L. 1923. Classification of the lizards. Bulletin of the American Museum of Natural History 48: 289-481.

Conrad, J.L. 2006a. Postcranial skeleton of Shinisaurus crocodilurus (Squamata: Anguimorpha). Journal of Morphology 267: 759-775.

Conrad, J.L. 2006b. An Eocene shinisaurid (Reptilia, Squamata) from Wyoming, U.S.A. Journal of Vertebrate Paleontology 26: 113-126.

Conrad, J.L. In press. Phylogeny and systematics of Squamata (Reptilia) based on morphology. Bulletin of the American Museum of Natural History

Conrad, J.L., and M.A. Norell. 2006. Highresolution $\mathrm{x}$-ray computed tomography of an Early Cretaceous gekkonomorph (Squamata) from Öösh (Övörkhangai; Mongolia). Historical Biology 18: 405-431.

Conrad, J.L., O. Rieppel, and L. Grande. In press. An Eocene iguanian (Squamata: Reptilia) from Wyoming, U.S.A. Journal of Paleontology

Conrad, J.L., O. Rieppel, and L. Grande. Submitted. An Eocene iguanian (Squamata: Reptilia) from Wyoming, U.S.A. Journal of Paleontology

Cope, E.D. 1864. On the characters of the higher groups of Reptilia Squamata-and especially of the Diploglossa. Proceedings of the Academy of Natural Sciences of Philadelphia 16: 224-231.

Costelli, J., Jr., and M.K. Hecht. 1971. The postcranial osteology of the lizard Shinisaurus: the appendicular skeleton. Herpetologica 27: 87-98.

de Beer, G. 1937. The development of the vertebrate skull. Oxford: Oxford University Press, 554 pp.

DeBraga, M., and R.L. Carroll. 1993. The origin of mosasaurs as a model of macroevolutionary patterns and processes. Evolutionary Biology 27: 245-322.

Estes, R. 1964. Fossil vertebrates from the Late Cretaceous Lance Formation eastern Wyoming. University of California Publications in Geological Sciences 49: 1-180.

Estes, R. 1983. Sauria terrestria, Amphisbaenia. New York: Gustav Fischer Verlag, 249 pp.
Estes, R., K. de Queiroz, and J. Gauthier. 1988. Phylogenetic relationships within Squamata. In R. Estes and G. Pregill (editors), Phylogenetic relationships of the lizard families, 119-281. Stanford: Stanford University Press.

Etheridge, R. 1967. Lizard caudal vertebrae. Copeia 1967: 699-721.

Etheridge, R., and K. de Queiroz. 1988. A phylogeny of Iguanidae. In R. Estes and G. Pregill (editors), Phylogenetic relationships of the lizard families: 283-367. Stanford: Stanford University Press.

Evans, S.E. 1993. A re-evaluation of the Late Jurassic (Kimmeridgian) reptile Euposaurus (Reptilia: Lepidosauria) from Cerin, France. Geobios 27: 621-631.

Evans, S.E. 1994. A new anguimorph lizard from the Jurassic and Lower Cretaceous of England. Palaeontology 37: 33-49.

Evans, S.E. 1998. Crown group lizards (Reptilia, Squamata) from the Middle Jurassic of the British Isles. Palaeontographica; Beiträge zur Naturgeschichte der Vorzeit. Abt. A 250: $123-154$.

Evans, S.E., and L.J. Barbadillo. 1997. Early Cretaceous lizards from Las Hoyas, Spain. Zoological Journal of the Linnean Society 119: 23-49.

Evans, S.E., and D. Sigogneau-Russell. 1997. New sphenodontians (Diapsida: Lepidosauria: Rhynchocephalia) from the Early Cretaceous of North Africa. Journal of Vertebrate Paleontology 17: 45-51.

Evans, S.E., and L.J. Barbadillo. 1998. An unusual lizard (Reptilia: Squamata) from the Early Cretaceous of Las Hoyas, Spain. Zoological Journal of the Linnean Society 124: 235-265.

Evans, S.E., and D.C. Chure. 1998. Paramacellodid lizard skulls form the Jurassic Morrison Formation at Dinosaur National Monument, Utah. Journal of Vertebrate Paleontology 18: 99-114.

Evans, S.E., and Y. Wang. 2005. Early Cretaceous lizard Dalinghosaurus from China. Acta Palaeontologica Polonica 50: 725-742.

Evans, S.E., G.V.R. Prasad, and B.K. Manhas. 2001. Rhynchocephalians (Diapsida: Lepidosauria) from the Jurassic Kota Formation of India. Zoological Journal of the Linnean Society 133: 309-334.

Evans, S.E., P. Raia, and C. Barbera. 2004. New lizards and rhynchocephalians from the Lower Cretaceous of southern Italy. Acta Palaeontologica Polonica 49: 393-408.

Evans, S.E., Y. Wang, and C. Li. 2005. The early Cretaceous lizard genus Yabeinosaurus from China: resolving an enigma. Journal of Systematic Palaeontology 4: 319-335. 
Fraser, N.C. 1982. A new rhynchocephalian from the British Upper Trias. Palaeontology 25: 709-725.

Frost, D.R., and R. Etheridge. 1989. A phylogenetic analysis and taxonomy of iguanian lizards (Reptilia: Squamata). University of Kansas Museum of Natural History, Miscellaneous Publications 81: 1-65.

Frost, D.R., R. Etheridge, D. Janies, and T.A. Titus. 2001. Total evidence, sequence alignment, evolution of polychrotid lizards, and a reclassification of the Iguania (Squamata: Iguania). American Museum Novitates 3343: $1-38$.

Gao, K.-Q., and L. Hou. 1995. Iguanians from the Upper Cretaceous Djadochta Formation, Gobi Desert, China. Journal of Vertebrate Paleontology 15: 57-78.

Gao, K.-Q., and L. Hou. 1996. Systematics and taxonomic diversity of squamates from the Upper Cretaceous Djadochta Formation, Bayan Manahu, Gobi Desert, People's Republic of China. Canadian Journal of Earth Sciences 33: 578-598.

Gao, K.-Q., and M.A. Norell. 1998. Taxonomic revision of Carusia (Reptilia: Squamata) from the Late Cretaceous of the Gobi Desert and phylogenetic relationships of anguimorphan lizards. American Museum Novitates 3230: $1-51$.

Gao, K.-Q., and M.A. Norell. 2000. Taxonomic composition and systematics of Late Cretaceous lizard assemblages from Ukhaa Tolgod and adjacent localities, Mongolian Gobi Desert. Bulletin of the American Museum of Natural History 249: 1-118.

Gauthier, J.A. 1982. Fossil xenosaurid and anguid lizards from the early Eocene Wasatch Formation, southeast Wyoming, and a revision of the Anguioidea. Contributions to Geology, University of Wyoming 21: 7-54.

Gauthier, J.A., R. Estes, and K. de Queiroz. 1988. A phylogenetic analysis of Lepidosauromorpha. In R. Estes and G. Pregill (editors), Phylogenetic relationships of the lizard families: 15-98. Stanford: Stanford University Press.

Gilmore, C.W. 1942. Osteology of Polyglyphanodon, an Upper Cretaceous lizard from Utah. Proceedings of the United States National Museum 92: 229-265.

Gilmore, C.W. 1943. Fossil lizards of Mongolia. Bulletin of the American Museum of Natural History 81: 361-384.

Gradstein, F.M., F.P. Agterberg, J.G. Ogg, J. Hardenbol, and S. Backstrom. 1999. On the Cretaceous time scale. Neues Jahrbuch für
Geologie und Paläontologie, Abhandlungen 212: 3-14.

Grismer, L.L. 1988. Phylogeny, taxonomy, classification, and biogeography of eublepharid geckos. In R. Estes and G. Pregill (editors), Phylogenetic relationships of the lizard families: 369-469. Stanford: Stanford University Press.

Harris, D.J., J.C. Marshall, and K.A. Crandall. 2001. Squamate relationships based on C-mos nuclear DNA sequences: increased taxon sampling improves bootstrap support. AmphibiaReptilia 22: 235-242.

Harvey, M.B. 1993. Microstructure, ontogeny, and evolution of scale surfaces in xenosaurid lizards. Journal of Morphology 216: 161-177.

Hecht, M.K., and J. Costelli, Jr. 1969. The postcranial osteology of the lizard Shinisaurus: 1. the vertebral column. American Museum Novitates 2378: 1-21.

Hoffstetter, R. 1966. Les Sauria (=Lacertilia) du Jurassique supérieur du Montsech (Espagne). Bulletin de la Societe geologique de France 7: 549-557.

Hoffstetter, R. 1967. Coup d'oeil sur les Sauriens (lacertiliens) des couches de Purbeck (Jurassique supérieur d'Angleterre Résumé d'un Mémoire). Colloques Internationaux du Centre National de la Recherche Scientifique 163: 349-371.

Kearney, M. 2003. Systematics of the Amphisbaenia (Lepidosauria: Squamata) based on morphological evidence from Recent and fossil forms. Herpetological Monographs 17: 1-74.

Kluge, A.G. 1967. Higher taxonomic categories of gekkonid lizards and their evolution. Bulletin of the American Museum of Natural History 135: 1-60.

Kluge, A.G. 1987. Cladistic relationships in the Gekkonoidea (Squamata, Sauria). Miscellaneous Publications: Museum of Zoology, University of Michigan 173: 1-54.

Lee, M.S.Y. 1998. Convergent evolution and character correlation in burrowing reptiles: towards a resolution of squamate relationships. Biological Journal of the Linnean Society 65: 369-453.

Lee, M.S.Y. 2000. Soft anatomy, diffuse homoplasy, and the relationships of lizards and snakes. Zoologica Scripta 29: 101-130.

Lee, M.S.Y. 2005. Squamate phylogeny, taxon sampling, and data congruence. Organisms, Diversity \& Evolution 5: 25-45.

Lee, M.S.Y., and M.W. Caldwell. 2000. Adriosaurus and the affinities of mosasaurs, dolichosaurs, and snakes. Journal of Paleontology 74: 915-937.

Loope, D.B., L. Dingus, and C.C. Swisher III. 1998. Life and death in a Late Cretaceous dune 
field, Nemegt Basin, Mongolia. Geology 26: 27-30.

Macey, J.R., A. Larson, N.B. Ananjeva, and T.J. Papenfuss. 1997. Evolutionary shifts in three major structural features of the mitochondrial genome among iguanian lizards. Journal of Molecular Evolution 44: 660-674.

Macey, J.R., J.A. SchulteII., A. Larson, N.B. Ananjeva, W. Yuezhao, R. Pethiyagoda, N. Rastegar-Pouyani, and T.J. Papenfuss. 2000. Evaluating trans-Tethys migration: an example using acrodont lizard phylogenetics. Systematic Biology 49: 233-256.

Maisano, J.A. 2003a. Gambelia wislizenii. http:// digimorph.org/specimens/Xantusia_henshawi/. Digital Morphology, Austin. Accessed 2005.

Maisano, J.A. 2003b. Dipsosaurus dorsalis. http:// digimorph.org/specimens/Dipsosaurus_dorsalis/. Digital Morphology, Austin. Accessed 2005.

Makovicky, P.J., and M. Norell. 2006. Yamaceratops dorngobiensis, a new primitive ceratopsian (Dinosauria: Ornithischia) from the Cretaceous of Mongolia. American Museum Novitates 3530: 1-42.

McDowell, S.B., Jr., and C.M. Bogert. 1954. The systematic position of Lanthanotus and the affinities of the anguinomorphan lizards. Bulletin of the American Museum of Natural History 105: 1-142.

McGuire, J.A. 1996. Phylogenetic systematics of crotaphytid lizards (Reptilia: Iguania: Crotaphytidae). Bulletin of Carnegie Museum of Natural History 32: 1-143.

Meszoely, C.A.M. 1970. North American fossil anguid lizards. Bulletin of the Museum of Comparative Zoology 139: 87-150.

Norell, M.A., and K. de Queiroz. 1991. The earliest iguanine lizard (Reptilia: Squamata) and its bearing on iguanine phylogeny. American Museum Novitates 2997: 1-16.

Norell, M.A., and K.-Q. Gao. 1997. Braincase and phylogenetic relationships of Estesia mongoliensis from the Late Cretaceous of the Gobi Desert and the recognition of a new clade of lizards. American Museum Novitates 3211: $1-25$.

Norell, M.A., M.C. McKenna, and M.J. Novacek. 1992. Estesia mongoliensis, a new fossil varanoid from the Late Cretaceous Barun Goyot Formation of Mongolia. American Museum Novitates 3045: 1-24.

Oppel, M. 1811. Die Ordnungen, Familien, und Gattungen der Reptilien als Prodrom einer Naturgeschichte derselben. München: Joseph Lindauer, 86 pp.

Pregill, G.K., J.A. Gauthier, and H.W. Greene. 1986. The evolution of helodermatid squamates, with description of a new taxon and an overview of Varanoidea. Transactions of the San Diego Society of Natural History 21: 167-202.

Reynoso, V.-H. 1996. A Middle Jurassic Sphenodon-like sphenodontian (Diapsida: Lepidosauria) from Huizachal Canyon, Tamaulipas, Mexico. Journal of Vertebrate Paleontology 16: 210-221.

Reynoso, V.-H. 2000. An unusual aquatic sphenodontian (Reptilia: Diapsida) from the Tlayu Formation (Albian), central Mexico. Journal of Paleontology 74: 133-148.

Reynoso, V.-H., and G. Callison. 2000. A new scincomorph lizard from the Early Cretaceous of Puebla, México. Zoological Journal of the Linnean Society 130: 183-212.

Rieppel, O. 1980a. The phylogeny of anguinimorph lizards. Basel: Naturforschenden Gesellshaft, $86 \mathrm{pp}$.

Rieppel, O. 1980b. The postcranial skeleton of Lanthanotus borneensis (Reptilia, Lacertilia). Amphibia-Reptilia 1: 95-112.

Rieppel, O. 1993. Patterns of diversity in the reptilian skull. In J. Hanken and B.K. Hall (editors), The skull: v. 2. Patterns of structural and systematic diversity: 344-390. Chicago: The University of Chicago Press.

Rieppel, O., and H. Zaher. 2000. The braincases of mosasaurs and Varanus, and the relationships of snakes. Zoological Journal of the Linnean Society 129: 489-514.

Romer, A.S. 1922. The locomotor apparatus of certain primitive and mammal-like reptiles. Bulletin of the American Museum of Natural History 46: 517-606.

Romer, A.S. 1949. The vertebrate body. Philadelphia: W. B. Saunders Company, $643 \mathrm{pp}$.

Romer, A.S. 1956. Osteology of the reptiles. Chicago: The University of Chicago Press, $772 \mathrm{pp}$.

Rougier, M.J., M.J. Novacek, M.C. McKenna, and J.R. Wible. 2001. Gobiconodonts from the Early Cretaceous of Oshih (Ashile), Mongolia. American Museum Novitates 3348: 1-30.

Schulte, J.A., II., J.P. Valladares, and A. Larson. 2003. Phylogenetic relationships within Iguanidae inferred using molecular and morphological data and a phylogenetic taxonomy of iguanian lizards. Herpetologica 59: 399419.

Schwenk, K. 1988. Comparative morphology of the lepidosaur tongue and its relevance to squamate phylogeny. In R. Estes and G. Pregill (editors), Phylogenetic relationships of the lizard families: 569-597. Stanford: Stanford University Press. 
Sues, H.-D., N.H. Shubin, and P.E. Olsen. 1994. A new sphenodontian (Lepidosauria: Rhynchocephalia) from the McCoy Brook Formation (Lower Jurassic) of Nova Scotia, Canada. Journal of Vertebrate Paleontology 14: 327-340.

Sulimski, A. 1975. Macrocephalosauridae and Polyglyphanodontidae (Sauria) from the Late Cretaceous of Mongolia. Palaeontologia Polonica 33: 25-102.

Sulimski, A. 1978. New data on the genus Adamisaurus Sulimski 1972 (Sauria) from the Upper Cretaceous of Mongolia. Palaeontologia Polonica 38: 43-56.

Swofford, D.L. 2001. PAUP*: Phylogenetic Analysis Using Parsimony, v. 4.0b10: Smithsonian Institution: Washington, DC.

Tchernov, E., O. Rieppel, H. Zaher, M.J. Polcyn, and L.L. Jacobs. 2000. A fossil snake with limbs. Science 287: 2010-2012.

Torres-Carvajal, O. 2003. Cranial osteology of the Andean lizard Stenocercus guentheri (Squamata: Tropiduridae) and its postembryonic development. Journal of Morphology 255: 94-113.

Townsend, T.M. 2002. Squamate molecular phylogenetics: Mitochondrial and nuclear perspectives. Ph.D. dissertation, Washington University, $282 \mathrm{pp}$.

\section{APPENDIX 1}

\section{Specimens Used for Coding Morphology}

Institutional abbreviations: AMNH, American Museum of Natural History; FMNH, Field Museum of Natural History; IGM, Institute of Geology, Mongolian Academy of Sciences, Ulaanbaatar, Mongolia; REE, Richard E. Etheridge collection; UF, Florida State Museum, University of Florida.

Anguimorpha: Carusia intermedia IGM 3/18, IGM 3/22, IGM 3/23, IGM 3/26; Xenosaurus grandis FMNH 211833; Xenosaurus platyceps UF 43396, UF 43397, UF 45590, UF 53691, UF 56122.

Gekkonomorpha: the fossil AMNH FR 21444 (see Conrad and Norell, 2006); Aeluroscalabotes felinus FMNH 188235; Coleonyx mitratus FMNH 5053; Myrmecodaptria microphagosa IGM 3/95.

Iguania and related taxa: the fossil FMNH PR 2379; Acanthosaura crucigera FMNH 222259; Acanthosaura lepidogaster FMNH 229477; Aciprion formosum AMNH FR8717; Agama agama FMNH 22189, FMNH 22190; Amphibolurus barbatus FMNH 22451, FMNH 51647, FMNH 211265; Anolis carolinensis FMNH 229898; Anolis equestris FMNH 31312; Anolis (Phenacosaurus) heterodermus AMNH
Townsend, T.M., A. Larson, E. Louis, and J.R. Macey. 2004. Molecular phylogenetics of Squamata: the position of snakes, amphisbaenians, and dibamids, and the root of the squamate tree. Systematic Biology 53: 735 757.

Uetz, P. 2006. The EMBL Reptile Database. http:// www.embl-heidelberg.de/ uetz/livingreptiles. html. European Molecular Biology Laboratory, Heidelberg. Accessed 2006.

Vidal, N., and S.B. Hedges. 2005. The phylogeny of squamate reptiles (lizards, snakes, and amphisbaenians) inferred from nine nuclear proteincoding genes. Comptes Rendus Biologies 328: 1000-1008.

Wilkinson, M., and M.J. Benton. 1996. Sphenodontid phylogeny and the problems of multiple trees. Philosophical Transactions of the Royal Society of London, Series B: Biological Sciences 351: 1-16.

Wu, X.-c. 1994. Late Triassic-Early Jurassic sphenodontians from China and the phylogeny of the Sphenodontia. In N.C. Fraser and H.-D. Sues (editors), In the shadow of the dinosaurs: early Mesozoic tetrapods, 38-69. Cambridge: Cambridge University Press.

44987; Anolis occultus AMNH 115547, AMNH 147826; Anolis sp. FMNH 98636; Anolis vermiculatus AMNH 70092, AMNH R63062; Basiliscus vittatus FMNH 98361, FMNH 98362, FMNH 98363; Callisaurus draconoides FMNH 98364, FMNH 98366; Chalarodon madagascariensis AMNH 71461; Corytophanes cristatus FMNH 22093, FMNH 206165; Crotaphytus collaris AMNH 82297, AMNH 109069, AMNH R-73715, FMNH 637, FMNH 22301, FMNH 22302; Ctenomastax parva IGM 3/ 61, IGM 3/62; Diplolaemus bibroni FMNH 7947, REE 2506; Dipsosaurus dorsalis FMNH 249785, FMNH 249786; Enyalioides palbebralis FMNH 40008; Enyalioides laticeps FMNH 31354; Gambelia sp. FMNH 211251; Gambelia wisilizenii AMNH R108315; AMNH R-141126; AMNH R-147874; Hoplocercus spinosus AMNH 89398, AMNH 90384, AMNH 90658, AMNH 93807; Iguana iguana AMNH R74631; Laemanctus longipes FMNH 213398; Leiocephalus carinatus FMNH 22754; Leiolepis belliana FMNH 229470; Leiosaurus bellii REE 2410; Microlophus a: albermarlensis AMNH R77624; Liolaemus alticolor AMNH 77610; Liolamus saxitilis AMNH R-65194; Liolaemus signifier AMNH R-90459; Liolaemus simonsii AMNH 77625; Liolaemus zapallarensis AMNH R-37733; Morunasaurus annularis AMNH R-57178; Oplurus cyclurus 
AMNH 138120; AMNH R-71462; Oplurus quadrimaculatus AMNH R-47944, AMNH R-71452; Petrosaurus thalassinus FMNH 216154; Plica plica FMNH 31355; Polychrus femoralis FMNH 81405; Polychrus guttorosus AMNH R-32675; Polychrus marmoratus AMNH R-141130; Pristidactylus achalensis REE 2487; Sauromalus ater FMNH 22248; Sauromalus sp. FMNH 31015; Sceloporus spinosus FMNH 98440; Stenocercus scapularis FMNH 40612; Stenocercus arenarius FMNH 40589; Temujinia ellisoni IGM 3/64, IGM 3/65, IGM 3/69; Tropidurus peruvianus FMNH 34191; Uromastyx aegyptius FMNH 31030; Urosaurus ornatus FMNH 98456; Uromastyx sp. AMNH R73357; Urostrophus bibroni FMNH 28863; Urostrophus vautieri REE 2507; Uta stansburiana FMNH 98463; unnamed Mongolian taxon IGM 3/858; unnamed FMNH specimen FMNH PR 2379.

Scincomorpha: Cordylus giganteus FMNH 211837, FMNH 257130, FMNH 31283; Eumeces algeriensis FMNH 229652; Eumeces copei FMNH 98509; Eumeces fasciatus FMNH 98512; Eumeces obsoletus FMNH 98516; Gerrhosaurus validus FMNH 228400, 214858; Lacerta lepida FMNH 229612, FMNH 22267; Lacerta viridis AMNH R99684, AMNH R1148; Mabuya multifasciata FMNH 120304; Podarcis taurica 213390; Scincella melanosticta FMNH 180970; Scincus scincus AMNH R2245; Sphenomorphus cyanolaemus FMNH 120244; Tiliqua scincoides FMNH 51702, FMNH 51710, FMNH 57520, FMNH 73343; Tiliqua nigrolutea AMNH R99684; Xantusia sp. FMNH 22101; Xantusia vigilis FMNH 22329

\section{APPENDIX 2}

\section{Morphological Phylogenetic Characters}

Characters Used in the Phylogenetic ANALYSIS: Following the character descriptions below, we cite the publication from which the character was taken with an abbreviation (not necessarily the original description of the character), a dash (-), and the number given the character in the cited analysis. A few characters were taken from descriptive works describing morphological features in a phylogenetic context, but not originally placed in a numbered character list. These lack the dash.

Abbreviations: AM03, Abdala and Moro, 2003; B82, Branch, 1982; BB83, BorsukBialynicka, 1983; Bell, Bell 1997; C99, Caldwell, 1999; Cir, Conrad, in press; DeBC, DeBraga and Carroll, 1993; E, Estes et al., 1988; E1964, Estes, 1964; Eagama, characters listed as possible agamid synapomorphies in Estes and Pregill, 1899, but not given an individual character number in the larger list; EB98, Evans and Barbadillo, 1998; EdQ88, Etheridge and de Queiroz, 1988; Egek, characters listed as gecko characters in Estes et al., 1988, but not given an individual character number in the larger list; Esc, characters listed as scincomorph characters in Estes et al., 1988, but not given an individual character number in the larger list; FE, Frost and Etheridge, 1989; Ga82, Gauthier, 1982; Ga88, Gauthier et al., 1988; GN00, Gao and Norell, 2000; GNC, Gao and Norell, 1998; H93, Harvey, 1993; Ke, Kearney, 2003; Kl67, Kluge, 1967; K187, Kluge, 1987; L98, Lee, 1998; LC00, Lee, 2000; M70, Meszoely, 1970; McDB, McDowell and Bogert, 1954; McG, McGuire, 1996; NG, Norell and Gao, 1997; Pr86, Pregill et al., 1986; R80, Rieppel, 1980a; R80L, Rieppel, 1980b; RZ, Rieppel and Zaher, 2000; S, Schwenk, 1988; TR, Tchernov et al., 2000.

1. Skull, percentage of total length made up by antorbital snout (DeBC-2): (0) less than 30\%; (1) greater than or equal to $30 \%$; (2) greater than $45 \%$; (3) greater than $50 \%$.

2. Skull, muzzle shape (NG-33): (0) tapering; (1) blunt and rounded.

3. Nares, posterior elongation invading contact between prefrontal and nasals or such that the posterior border of the septomaxilla are visible (E-2): (0) absent; (1) present.

4. Dermal sculpturing (E-129): (0) vermiculate sculpturing; (1) pitted; (2) bumps/hornlets.

5. Dermal sculpturing, maxilla (Cir): (0) absent; (1) present.

6. Dermal sculpturing, prefrontal (Cir): (0) absent; (1) present.

7. Dermal sculpturing, parietal/frontal (E-129): (0) absent; (1) present on frontal and parietal.

8. Premaxilla, fusion into single element (LCO01): (0) absent, paired premaxillae; (1) present.

9. Premaxilla, mediolateral breadth of nasal process (Cir): (0) absent; (1) broad, widest plane; (2) narrow, narrowest plane; (3) narrow at base, spatulate posteriorly.

10. Premaxilla, external contact with frontal (LC00-2): (0) absent, connected by nasals; (1) present; (2) contact overlain by nasals.

11. Premaxilla, incisive process (GNC-46): (0) single; (1) bipartite; (2) absent.

12. Premaxilla, contact with the nasal (FE-1): (0) premaxilla(e) overlaps the nasal(s); (1) nasal(s) overlap the premaxilla(e).

13. Nasals, internasal contact (GNC2): (0) extensive; (1) less than half their length.

14. Nasal, shape of the anterior border (Cir): (0) concave, forming the posterior border of the external naris; (1) lacking anterolateral narial process.

15. Nasofrontal suture, articulated shape in dorsal view (Cir): (0) M-shaped; (1) frontal forms an anterior wedge; (2) transverse; (3) W-shaped; 
(4) V-shaped with nasals invading frontal suture.

16. Maxilla, anteromedial process lying between vomers and premaxillae (Egek-12): (0) absent; (1) present.

17. Maxilla, strong medial processes behind the nasal process of the premaxilla (Cir): (0) absent; (1) present, separation subequal to the breadth of the nasal process of the premaxilla.

18. Maxillae, contact at midline behind nasal process of premaxilla (FE-2): (0) absent; (1) present.

19. Maxilla, nasal process inclination (Cir): (0) steeply inclined, posterior border of the naris distinct from ventral border; (1) weakly inclined, posterior border of the naris not distinct from the ventral border.

20. Maxilla, palatine flange (Cir): (0) medial flaring absent; (1) medially flared from the lateral border of the internal nares; (2) present, expanded posteromedially beyond the posterolateral process of the maxilla.

21. Maxilla, posterior extent of tooth row (E-27): (0) beyond anterior one quarter of orbit; (1) terminates at anterior border of orbit.

22. Prefrontal, dorsolateral tuberosity (Cir): (0) absent; (1) present.

23. Prefrontal, blocks contact between maxilla and nasal (GNC-10): (0) absent; (1) present, extends anteriorly to the naris; (2) present, makes contact with the premaxilla.

24. Prefrontal, makes contact with jugal (R80-24): (0) absent; (1) present.

25. Lacrimal (Egek-28): (0) present, large, and extending for more than half the distance to the external naris; (1) present, discrete, and limited to orbital margin; (2) present on orbital margin, but fused to the prefrontal; (3) absent; (4) present, but reduced, not making contact with the prefrontal.

26. Lacrimal foramen, size (FE-6): (0) small, similar in size to palatine foramen; (1) large, approximately two times the smallest diameter of the palatine foramen or more.

27. Jugal, shape (GNC-13): (0) angulated; (1) little angulation, curved.

28. Jugal, postorbital branch (McDB): (0) without anterior or posterior flanges; (1) dilated.

29. Jugal, postorbital process rugosities (GNC17): (0) absent; (1) present.

30. Jugal, posteroventral process (GNC-14): (0) present, well defined; (1) absent.

31. Jugal, relationship to maxilla (Cir): (0) mostly medially; (1) mostly dorsally.

32. Jugal-squamosal contact (E-18): (0) absent; (1) present.

33. Frontals (E-6): (0) separate in adults; (1) fused in adults.
34. Frontals, shape as a unit (Cir): (0) anterior and posterior borders subequal in width; (1) trapezoid; (2) concave lateral margins, minimum width less than three fifths posterior border width; (3) tapering posteriorly.

35. Frontals, constriction between orbits (E-7): (0) absent, interorbital margin linear; (1) present, anterior portion of the frontal is hourglassshaped.

36. Frontal, dorsoventral inflation (Cir): (0) absent; (1) present.

37. Frontals, subolfactory processes (Pr86): (0) ventral downgrowths; (1) partly surrounding the olfactory bulbs anteriorly; (2) partly surrounding the olfactory bulbs posteriorly; (3) make contact with the parabasisphenoid (RZ-54).

38. Frontals, subolfactory processes make contact at midline (E-10): (0) absent; (1) present.

39. Frontals, make contact with the maxilla anteriorly (Esc-4): (0) absent; (1) present.

40. Frontals, participation in the orbitonasal foramen (C99-7): (0) absent, prefrontals with large contributions; (1) present, prefrontals blocked from the orbitonasal fenestra.

41. Frontals, parietal tabs (C99-9): (0) absent; (1) present; (2) present, elaborated into dorsomedial extensions on top of the parietals.

42. Frontoparietal suture, dorsal view (EB98131): (0) U-shaped, anteriorly arched; (1) transverse; (2) W-shaped; (3) U-shaped, posteriorly arched.

43. Frontoparietal fontanelle (GN00): (0) absent; (1) present.

44. Parietal, lateral flange at the frontoparietal suture (Cir): (0) gently curved, laterally tapering; (1) with broad, squared, lateral tabs so that the postfrontal margin of the frontal is parallel with the postfrontal margin of the parietal.

45. Parietal fusion (E-21): (0) parietals paired; (1) parietals fused.

46. Parietal, frontal tabs (C99-17): (0) absent; (1) present within the contact or dorsally; (2) present on the ventral surface.

47. Parietal, median adductor crest expressed as a keel (FE-10): (0) absent, flat parietal table extends to the posterior margin; (1) present.

48. Parietal, decensus parietalis (E-23): (0) weakly developed/absent; (1) present as anteroposteriorly elongate crest; (2) present, anteroposteriorly narrow ventral projection.

49. Parietal, pineal foramen (E-26): (0) within parietal; (1) within frontal; (2) at frontoparietal suture; (3) absent.

50. Parietal fossa, posterior margin (Cir): (0) open, crests extend posterolaterally; (1) closed, crests meet at midline; (2) absent. 
51. Parietal, posterior flange (not associated with a sagittal, jaw adductor, crest) (Cir): (0) absent; (1) present.

52. Parietal, transverse posterior margin between the supratemporal processes (Cir): (0) present, space between supratemporal processes greater than the width of the supratemporal process base; (1) absent, no transverse posterior margin between the supratemporal processes.

53. Parietal, nuchal fossa (GN00): (0) absent; (1) present; (2) present and extending substantially onto the skull table.

54. Parietal, supratemporal processes length from the level of the parietal notch compared to the parietal anterior to that point (Ga82-30): (0) greater than half; (1) less than half; (2) absent.

55. Parietal, contact with supratemporal arch (C99-15): (0) only at the anterior and posterior extremes; (1) increased contact anteriorly and posteriorly.

56. Parietal, attachment of jaw adductor musculature (E-54): (0) dorsally; (1) ventrally; (2) reduced, appear to attach only laterally.

57. Supratemporal (Egek-10): (0) present; (1) absent.

58. Supratemporal, length relative to depth (Cir): (0) less than 2.5 times as long as deep; (1) more than three times as long as deep.

59. Postfrontal/postorbital contact with the frontal/parietal, forking of medial surface (RZ-25): (0) absent; (1) present.

60. Postorbital/postfrontal, tubercle (McG-7): (0) absent; (1) present.

61. Postfrontal (Cir): (0) present; (1) absent.

62. Postfrontal, shape (Cir): (0) anteroposteriorly elongate, not a strong lateral bar; (1) irregular or round and reduced in size; (2) mediolaterally developed bar bordering the supratemporal fenestra and orbit.

63. Postorbitofrontal, fusion (E-14): (0) absent; (1) present.

64. Postfrontal, contact with the parietal (E-15): (0) absent; (1) present; (2) present, for more than half the parietal length.

65. Postorbital (posterior ramus of postorbitofrontal) (E-16): (0) present; (1) absent.

66. Postorbital, contribution to the postorbital bar (E-17): (0) 1/2 or more; (1) less than half.

67. Postorbital, posterior extent (E-83) : (0) less than half the length of the supratemporal fenestra; (1) more than half the length of the supratemporal fenestra; (2) more than three quarters the length of the supratemporal fenestra; (3) contacts the supratemporal.

68. Squamosal, contact with postorbitofrontal (RZ-38): (0) present; (1) absent.

69. Squamosal, dorsal process (C99-25): (0) present; (1) absent.
70. Palpebral ossification(s) (E-36): (0) absent; (1) present, a single ossification articulating with or located near the prefrontal; (2) present, multiple ossifications running down the lateral surface of the prefrontal and frontal.

71. Septomaxilla, contact with the osseous nasal cavity roof (FE-54): (0) absent; (1) present.

72. Vomers, fusion (E-38): (0) absent; (1) present.

73. Vomer, contact with the palatine (Cir): (0) subequal in breadth to the contact with the maxilla; (1) about $1 / 2$ the breadth of the contact with the maxilla; movable; (2) absent (TR-47).

74. Palatines, medial expansion anteriorly (Ga8884): (0) absent; (1) present.

75. Palatine, length (GNC-51): (0) longer than wide; (1) subequal in length and width.

76. Palatines, choanal groove (RZ-101): (0) very short/absent; (1) distinct, elongate.

77. Palatine, secondary palate formed around choanal groove (E-43): (0) absent; (1) present, ventromedial fold partly hide the choanal groove; (2) present, ventromedial processes hide most or all of the dorsomedial processes; (3) contact at midline.

78. Palatine, teeth (E-82): (0) present, patches; (1) absent; (2) present, single line.

79. Pterygoid, ventromedial process (GNC-32): (0) absent; (1) present.

80. Pterygoid, teeth (E-83): (0) arranged in multiple rows or patches; (1) in a single line; (2) absent.

81. Pterygoid, contact with vomer (Ga88-26): (0) present; (1) absent.

82. Interpterygoid vacuity, midline contact of vomers (Cir): (0) present, invaded by interpterygoid vacuity; (1) present, contact for their length; (2) present, contact anteriorly and posteriorly; (3) absent.

83. Interpterygoid vacuity, midline contact of palatines (Cir): (0) absent; (1) present; (2) vomer-pterygoid contact present.

84. Interpterygoid vacuity, midline contact of pterygoids (Cir): (0) absent; (1) present.

85. Interpterygoid vacuity, broadest point versus distance from basicranial joint to quadrate (Cir): (0) two fifths or more; (1) one third or less.

86. Palate, orientation of the ectopterygoid and the pterygoid transverse process (Cir): (0) mostly oriented mediolaterally; (1) oriented at $>30$ degree angle from the perpendicular to the sagittal.

87. Ectopterygoid, makes contact with palatine anterior to the suborbital fenestra (E-45): (0) absent; (1) present; (2) present, contact broader than suborbital fenestra; (3) present, closes suborbital fenestra (Ke-99). 
88. Ectopterygoid, lateral exposure behind maxilla (McDB): (0) absent; (1) present.

89. Braincase, unfused epiphyses on the sphenooccipital tubercle present on the ventral surface (NG-27): (0) absent; (1) present.

90. Braincase, occipital condyle (Egek-9): (0) single unit made of basioccipital and exoccipitals, ovoid or subovoid; (1) bipartate, constructed of exoccipitals; (2) single unit made of basioccipital and exoccipitals, U-shaped; (3) formed only by the basioccipital.

91. Braincase, anterior extension of crista prootica (Egek-52): (0) terminates at inferior process; (1) extends onto the basipterygoid process; (2) crista prootica absent.

92. Epipterygoid (E-47): (0) present; (1) absent.

93. Prootic, supratrigeminal process $(\mathrm{E}-50)$ : $(0)$ absent or faint ridge; (1) distinct, anterior process visible in lateral view.

94. Prootic, crista alaris (Ke-79): (0) absent; (1) present, short, and not extending farther anteriorly than the inferior process of the prootic; (2) present, elongate, and overhanging the inferior process of the prootic.

95. Prootic, crista prootica (RZ-66): (0) well developed, lateral and ventral aspects; (1) reduced, extending mostly laterally.

96. Prootic, entocarotid fossa (GNC-30): (0) present as distinct fossa within the recessus vena jugularis; (1) reduced/absent.

97. Basisphenoid, posterolateral flanges laterally overlying basioccipital (BB83): (0) absent; (1) present; (2) fusion of basioccipital to the basisphenoid.

98. Basisphenoid, relationship with the posterior opening of the Vidian canal (E-53): (0) houses it; (1) shares it with the prootic; (2) within prootic; (3) shared with parietal.

99. Basioccipital, spheno-occipital tubercle (NG23): (0) short and ventrally directed; (1) elongate and posterolaterally directed.

100. Basioccipital, location of the spheno-occipital tubercle (RZ-76): (0) posteriorly, crista tuberalis nearly vertical; (1) anteriorly, crista tuberalis posterodorsally inclined.

101. Otooccipital, hypoglossal foramen (RZ-69): (0) separated from vagus foramen; (1) internally subdivided or confluent.

102. Otooccipital, foramen rotundum (Cir): (0) hidden by spheno-occipital tubercle in ventral view; (1) visible in ventral view.

103. Stapes, internal (quadrate) process lost (E141): (0) present; (1) absent.

104. Quadrate, suspension (RZ-49): (0) monimostylic; (1) streptostylic; (2) suspended mainly from supratemporal; (3) suspended mainly from opisthotic; (4) suspended mainly from squamosal.
105. Quadrate, pterygoid lappet (E-37): (0) present; (1) absent.

106. Quadrate, tympanic crest (RZ-51): (0) longerthan or equal toposterior crest; (1) shorter than posterior crest; (2) absent.

107. Mandible; fusion of articular, prearticular, and surangular (RZ-129): (0) absent; (1) articular-prearticular, surangular.

108. Mandible, intramandibular septum (RZ-116): (0) terminates more than two tooth widths posterior to the last tooth position; (1) terminates at, or nearly at, the posteriormost tooth position.

109. Mandible, external border of the anterior surangular foramen (Cir): (0) formed only by the surangular; (1) margin with coronoid contribution; (2) margin with dentary contribution; (3) margin with coronoid and dentary contribution; (4) anterior surangular foramen absent.

110. Mandible, groove associated with anterior surangular foramen (Cir): (0) absent; (1) present.

111. Mandible, posterior mylohyoid foramen (Cir): (0) present; (1) absent.

112. Mandible, position of posterior mylohyoid foramen (FE-24): (0) anterior to the coronoid apex; (1) posterior to the coronoid apex.

113. Dentary, shape of long axis (DeBC-67): (0) ventrally convex; (1) straight.

114. Dentary, posterior extent (EB98-213): (0) to the level of the posterior margin of the coronoid process (eminence); (1) extends to the midpoint of mandible between the coronoid eminence and the articular condyle.

115. Dentary, Meckel's canal (E-55): (0) open; (1) partly closed; (2) closed and fused.

116. Dentary, subdental shelf (E-58-59): (0) present; (1) absent; (2) present, enlarged (E-58).

117. Dentary, anterior inferior alveolar foramen (E1964): (0) does not contribute; (1) contributes to dorsal border; (2) forms anterior and dorsal border; (3) foramen indistinct.

118. Dentary, posterodorsal coronoid process(es) (RZ-113): (0) large; (1) small; (2) absent.

119. Dentary, coronoid, and surangular processes (E-63): (0) absent; (1) present; (2) intramandibular hinge.

120. Dentary, angular process compared with surangular process (Ga88-41): (0) terminate at about the same posterior level; (1) terminates anteriorly; (2) extends posteriorly.

121. Splenial (Ke-125): (0) present; (1) absent; (2) present, fused to the postdentary bones.

122. Splenial, extent of anteromedial walling of Meckel's canal (E-67): (0) extends for more than two thirds of the dentary; (1) extends for less than half of the dentary. 
123. Splenial, posterior extent (E-66): (0) extends posterior to the apex of the coronoid; (1) terminates at, or anterior to, the coronoid apex.

124. Coronoid, height of coronoid at process relative to the length of the mandible (Cir): (0) short, broad; (1) tall, narrow.

125. Coronoid, posterior extent of the labial flange (Cir): (0) absent; (1) extends mostly labially, does not overlap the posterior margin of the coronoid process in lateral view; (2) extends beyond the posterior margin of the coronoid process in lateral view.

126. Coronoid, posterior overlap by surangular (E71): (0) absent; (1) present.

127. Coronoid, ventral margin (RZ-128): (0) flat or concave; (1) convex.

128. Coronoid, contact with the anterior inferior alveolar foramen (Cir): (0) absent; (1) present.

129. Angular (RZ-132): (0) present; (1) absent.

130. Prearticular, crest (E-73): (0) absent; (1) present.

131. Articular, retroarticular process (E-75): (0) posteriorly directed; (1) medially deflected.

132. Articular, retroarticular process with posterior broadening (E-78): (0) absent; (1) present.

133. Articular, pit on the retroarticular process (E74): (0) present; (1) absent.

134. Articular, tubercle on the medial margin of retroarticular process (E-76; GN00): (0) absent; (1) present as a tubercle; (2) present, elaborated into a finger-like process.

135. Articular, torsion of retroarticular process (GNC-70): (0) absent; (1) present; (2) present and strongly twisted.

136. Dentition, spacing (Cir): (0) closely spaced; (1) widely separated; spaces between tooth bases greater than half the width of a tooth shaft; (2) tightly packed with tooth shafts making contact for most of their height, ctenodont.

137. Dentition, form of teeth (Ga82-34) : (0) straight, pointed; (1) triangular; (2) trenchant, curved; (3) incipient cusps on posterior teeth; (4) teeth with multiple crowns; (5) globidont; (6) squared dorsal margin; (7) mediolaterally expanded with transverse cutting edges.

138. Dentition, marginal tooth implantation (RZ146): (0) labially pleurodont; (1) acrodont; (2) modified pleurodont; (3) enclosed by expanded interdental ridge; (4) subacrodont.

139. Dentition, caniniform teeth (Eagama-1): (0) absent; (1) present.

140. Dentition, replacement (E-85): (0) develop lingually, large resorption pit; (1) posterolingually, resorption pit; (2) posterolingually, no resorption pit.

141. Dentition, premaxillary teeth compared to maxillary teeth (RZ-156): (0) similar; (1) markedly smaller; (2) absent.
142. Hyoid, second ceratobranchial (E-91): (0) present; (1) absent.

143. Hyoid, second epibranchials (E-90): (0) present; (1) absent.

144. Notochord, in adults (K187-2): (0) persistent; (1) obliterated.

145. Vertebrae, centrum morphology (K187-1): (0) amphiplatyan; (1) amphicoelous; (2) procoelous.

146. Vertebrae, neural spines (GNC-78/Ke-135): (0) short and broad; (1) tall and narrow; (2) absent.

147. Vertebrae, obliqueness of condyles (E-92): (0) absent/weak, posterior apex of condyle visible; (1) moderate, articulating condylar surface slightly visible in ventral view; (2) strong, articulating surface not visible in ventral view.

148. Vertebrae, zygosphene-zygantra (RZ-169): (0) absent; (1) present, zygosphene articular surface faces dorsolaterally; (2) present, zygosphene articular surfaces face ventrolaterally.

149. Vertebrae, presacral number (E-105-106): (0) 25 or fewer; (1) 26; (2) 27 or more.

150. Presacral vertebrae, lumbar rib fusion: (0) full; (1) suture visible.

151. Atlas, dorsal margin (Cir): (0) horizontal; (1) posteroventrally inclined.

152. Atlas, lateral process (Cir): (0) well defined with some posterior overlap of the axis; (1) small, a 'hill-like' projection; (2) absent.

153. Cervical vertebrae (E-107-108): The character states in this character are somewhat subjective, but follow usage by various previous authors. They are formulated so that they apparently reflect observable sets of variation. (0) eight; (1) seven or fewer; (2) nine; (3) 10 or more.

154. Cervical, intercentra (E-97): (0) intervertebral; (1) sutured to the posterior part of the preceding centrum; (2) fused to posterior part of preceding centrum; (3) fused to the succeeding centrum (Cir); (4) absent.

155. Cervicals, hypapohyseal keel (EB98-149): (0) absent; (1) present.

156. Dorsal vertebrae, intercentra (EB98-86): (0) present; (1) absent.

157. Caudal vertebrae, dorsoventral height (including the neural spines and chevrons; Bell-9): (0) less than three times length of centrum; (1) greater than three times length of centrum.

158. Caudal vertebrae, transverse processes (E-100102): (0) single; (1) double, diverging; (2) double converging; (3) absent.

159. Caudal vertebrae, autotomy planes (E-103): (0) present on transverse process(es); (1) present posterior to the transverse process(es); (2) absent; (3) present anterior to transverse processes. 
160. Ribs, anterior presacral ribs, shape (Cir): (0) without flattening near midshaft; (1) with flattening near midshaft.

161. Ribs, postxiphisternal inscriptional ribs (FE40): (0) making contact with the dorsal ribs, not making contact at midline; (1) making contact at the dorsal ribs, one or more pairs confluent at midline; (2) free dorsally, confluent ventrally.

162. Clavicles, shape (RZ-196): (0) rodlike; (1) expanded proximally with notch or fenestra; (2) absent.

163. Clavicle, shape (E-116): (0) straight, without "elbow'; (1) strongly curved/angled.

164. Coracoid, anterior (primary) coracoid emargination (E-112): (0) absent; (1) present.

165. Coracoid, posterior emargination (E-113): (0) absent; (1) present.

166. Epicoracoid cartilage, contact with mesoscapula (E-114): (0) present; (1) absent.

167. Scapula, secondary scapular fenestra formed by a scapular epicoracoid bar (E-111): (0) absent; (1) present.

168. Sternum, rib attachments (E-109): (0) five; (1) four; (2) three; (3) two or fewer.

169. Interclavicle (E-118): (0) present; (1) absent.

170. Interclavicle, anterior process (E-120): (0) absent; (1) present, single; (2) present, double.

171. Sternum, proximity to the lateral arms of the interclavicle (FE-33): (0) separated by more than one third the posterior process of the interclavicle; (1) separated by one third or less the length of the posterior process.

172. Sternum, fontanelle (E-121): (0) absent; (1) present.

173. Xiphisternum, branching (Cir): (0) more than one branching; (1) one branching; (2) unbranched.

174. Ectepicondylar foramen (EB98-103): (0) foramen; (1) groove; (2) absent altogether.

175. Carpus, intermedium (Egek-24): (0) present; (1) absent.

176. Pelvis (RZ-207): (0) fused into a single ossification; (1) strongly sutured; (2) nonsutural contacts.

177. Pubis, relative length of the symphysial portion compared to the tubercular portion (E-124): (0) shorter than; (1) subequal to, slightly longer than; (2) more than half again as long.

178. Ilium, anterior process (RZ-208): (0) present; (1) absent.

179. Pes, medial, and lateral plantar tubercles on metatarsal V (R80L): (0) even with one another or overlapping levels; (1) lateral tubercle distally placed; (2) lateral tubercle distally placed, approaching condyle; (3) greatly shortened metatarsal $\mathrm{V}$ precludes identification.
180. Astragalus and calcaneum, fusion (L98-215): (0) separate; (1) fused; (2) calcaneum unknown.

181. Femoral/precloacal pores (E-144): (0) absent; (1) present.

182. Integument, scale organ ornamentation (FE52/H93): (0) absent; (1) spinules; (2) spikes.

183. Squamation, cephalic scales (E-147/M70): (0) absent; (1) small and irregularly shaped; (2) enlarged plates.

184. Squamation, mid-dorsal scale row (E-146): (0) differing from surrounding scales, elongate with apices; (1) similar to surrounding scales.

185. Squamation, gular fold with distinctive midventral squamation (FE-47): (0) absent; (1) present.

186. Squamation, cycloid scales (E-148): (0) absent; (1) present.

187. Squamation, imbrication (M70): (0) absent; (1) present.

188. Osteoderms, dorsal surface of the body (E127): (0) absent; (1) present.

189. Osteoderms, ventral surface of the body (E126): (0) absent; (1) present.

190. Squamation, osteodermal thickening (Cir): (0) absent, osteoderms thin plates or non-calcified; (1) present, irregularly shaped; (2) present, polygonal mounds.

191. Glossus, filamentous tongue papillae (S-6-9): (0) absent; (1) peg-like; (2) asymmetrical, forming points.

192. Glossus, division of foretongue (E-137): (0) absent; (1) notched more than $10 \%$ of length; (2) notched more than $20 \%$; (3) notched more than $40 \%$; (4) notched more than $50 \%$; (5) notched more than $50 \%$ of length.

193. Glossus, cross-section of tongue (E-138): (0) rounded and glandular; (1) flattened foretongue; (2) keratinized and mushroom-shaped foretongue in cross-section.

194. Ear, external opening (Ke-13): (0) present; (1) absent.

195. Inner ear, ciliary restraint for hair cells (E140): (0) tectorial, lacking sallet systems; (1) tectorial and sallet; (2) more than half of hair cells inertial.

196. Endolymphatic sacs, extension into the nuchal musculature (K167-C/EdQ88-35): (0) absent; (1) present, exit through supraoccipital and parietal; (2) present, exit epiotic foramen; (3) present, exit through vagus foramen.

197. Hemipenis, sulcus (B82): (0) simple; (1) divided.

198. Neurology, ulnar nerve position (E-142): (0) 'lacertid'-style; (1) 'varanid'-style.

199. Neurology, dorsal leg muscles (E-143): (0) peroneal nerve present; (1) peroneal nerve absent, interosseus innervation. 
200. M. pseudotemporalis profundus, anterior head (E-133): (0) absent; (1) present, not expanded; (2) present, expanded.

201. M. rectus abdominis lateralis (E-134): (0) absent; (1) present.

202. M. retractor pterygoidei (AM03-53): (0) present; (1) absent.

203. Biogeography: (0) global; (1) Madagascar; (2) South America; (3) North America/Central America; (4) Europe/Western Asia; (5) SubSaharan Africa; (6) North Africa/Arabia; (7) India; (8) East Asia; (9) Australia.

\section{APPENDIX 3}

\section{Character Matrix}

Character-state matrix used in this analysis in PAUP* (Swofford, 2001)-ready format. Note that suprageneric taxa appear in CAPITAL LETTERS. OplurusQa refers to Oplurus quadrimaculatus AMNH R-47944, and OplurusQb refers to $O$. quadrimaculatus AMNH R-71452. FMNHiguana refers to a new iguanian under description by Conrad et al. (in press). Four species of Anolis and three species of polychrus were included in the analysis. PolychrusMARM, PolychrusFEM, and PolychrusGUTT refer to Polychrus marmoratus, $P$. femoralis, and $P$. guttorosus, respectively. AnolisHETERO, AnolisOCC, and AnolisVERM refer to Anolis (Phenacosaurus) heterodermus, A. occultus, and $A$. vermiculatus respectively. Character 203 (biogeography) was not included in our tree search, but it is included for possible biogeographical use.

\#NEXus

BEGIN DATA ;

DIMENSIONS NTAX $=50 \mathrm{~N}_{\text {CHAR }}=203$;

FORMATMISSING=? GAP $=-$ SYMBOLS $=$ " 012345 $6789^{\prime \prime}$;

OPTIONS MSTAXA=POLYMORPH ;

\section{MATRIX}

RHYNCHOCEPHALIA 100-000010 $2001\{12\} 000\{01\} 00000\{12\} 00\{01\} 00$ 0110000-00 100-11000- 0?00000?00 $0 ? 01002000 \quad 0000000000 \quad 01-10 ? 0000$ $0000000000 \quad 0000011-00$ 1-010\{01\} 3 00- 1--00-0?00 000000\{01\}\{01\}00 $0000100\{01\} 01 \quad 02\{01\} 0010001000$ 0000?00 00-0010001 001000000?00000-000004

Ardeosaurus 10000?10?0 ?0003?0000 000?3?1000 00000?0-10 11001?-?0? ??00110110 0?01001011 ?????????
????01???? ????0????? ?? ? 12 ? 0 ? 01

?? ?? ? 0? ? ?? 4

????????? ?????????? ???? 1?0?? ??2?????? 0

??? 1?0???? 00?00? 00 ? ?0?1????? ?? ???????

Bavarisaurus 100-000010 ?00?3????0 100???100100\{01\}01?0-00 020?0?-00? ???001010? 0001001011 ??????10?? ?????????? ??10?0?21? ???10???0? 1??01?0?01 0?1000000?

?0?2????? 1 ???????00?? 4

?????????

???1??0???

01??11200?

?00?????00

?????????

Eichstaettisaurus

110-000010

?00???000? 000?301001 0?\{01\}?1?100? 010000-20? 0?01010010 ?0?????1?2 ????010??? ???100???? ????0????? 0???000000 0???100021 ?111001?00 ???0??0??? ????????? ??4

Myrmecodaptria

???0??100? 010?301001

?1?01?-20? 0101110010

????1?0102 1???1110?0

???1100?00 ??010?12000?001000? ??????????

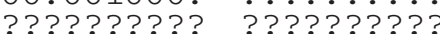
???????? ??8

Scandensia ??0?001010 ?0????0100 ??100?10?1 ???? 1??? ?????????? ????????? ?????????? ??10?2??10 0???????00 00001000?1 ??0001000? ???0010??0 ?????????? ?? 4

AMNHgekkonomorph ????3????0 0001301001 000-00-00- 1?0001??10 ?010010102 1000010001 ?0????0-11 00100202111101200 ? ???????? ???????? ?????????? ???????? ??8

$000101001 ?$ ?0??????? ???1????0? ??1??1?00? ???????00-

01010?001? 01101?11?? $00001-01 ?$ ???2????0? 0011?10?? 1 ?????????? ??2????1?1

?0??????1? ??????-0?? ?????????? ??????0??? 00??001??? ?11100??01 ??????????

??0-000??? 0002101011 $00010110 ? ?$ 1001001001 00?1101?00 ?????????? ?????????

EUBLEPHARINAE

$100-0\{01\} 0110$ $000031000100003010-1 \quad 0010101111$ $010011-03-0 ?\{02\} 0-1\{01\}-10000$ $11--110 \quad 0\{01\} 10010102 \quad 1100011001$ $1002100001 \quad 0113100-\{01\} 0 \quad 011022$ 320- 00011010\{01\}0 1110120000 $000\{01\} 2010\{12\} 10210100011011$ $10011011\{01\} 10111131$ ??1101000$111000 ? 000$ 0?0

Palaeoxantusia

?????10?1 100010011?

?10-0?0?3? 1?02110000

???00?0102 110001010?

?0001111??

$000210101 ?$ $0-1201201 ?$ $00 ? ? 002 ? 00$ 
01?1??1??? 0000004000 ?????????? ?????????

$011122010-$ ?????????? ?????????? ?? 3

\section{Xantusia}

$10001111\{12\} 0$ $000\{01\}\{23\} 0000\{01\} 1000201\{01\}\{0$ $1\} 100\{01\} 2\{01\} 010\{01\} 11100\{01\} 2-$ $20\{01\} \quad\{01\} ? ? 1110100$ 0?1200-010 $01100101021110\{01\} ?\{02\} 10010010$ 00000 00?1101-01 011122110- 0111 111?110000004000 00012010?1 1101 1?0?0? 011100?100 ???0002101 10210 00000112020 ???? ?? 3

\section{LACERTIDAE}

1000000110 $00001\{01\}\{01\} 000000 ?\{13\} 00000\{0$ $1\} 0\{01\} 2100-11$ 110012-1\{03\}? 0?? 1 $1100100 ?\{01\} ? 01 ? 011000001110\{12\}$ $1000\{01\} ? 000000021021000001001-$ 00 000002020-000100100100000030 $00\{01\} 0012011\{02\} 1$ ?? $0\{01\} 1\{01\} 0$ 10? $0111010\{01\} 00 \quad\{01\}\{01\}\{12\} 00$ $12001\{01\} ? 2100\{01\} 000 \quad 0320101$ $\{01\} 0110-$

\section{SCINCIDAESS}

$1000101\{01\} 10$

$\{02\} 0013010010001200\{01\}\{01\} 00\{0$ 1\} $12101011110-12-20\{01\} 102011001$ $00002\{01\} 10011011101\{12\} 102111$ $0\{01\} 10000000200110\{01\} 001110100$ 011112010- 0000010000 1111100001 $0 ? 11201021 \quad 11011100010111001101$ $10021\{01\} 21\{02\} 1 \quad 0 ? 21011110 \quad 0120$ 20??0? ?1-

CORDYLOIDEA 10001111100001301001 $000 ?\{12\} 000\{01\} 0 \quad\{01\} 0\{01\} 2100-$ $\{01\} 1\{01\} 1001\{02\}-2\{03\}$ ? 1 ? 01110 $010000101201\{01\} \quad 001101110\{12\}$ $11000100000002001\{01\} 00 \quad 00011$ $000\{01\} 10100\{01\} 23\{01\} 0-0001011$ $0001\{01\} 111\{02\} 00000 ? 012011\{02\} 1$ ?? $\{01\} 0110\{12\} 0 ? 0\{01\} 11000\{01\} 00$ $0010002\{01\}\{02\} 1 \quad 10210\{01\} 1110$ $01\{12\} 020 ? 0\{01\} 11$ ? $\{15\}$

\begin{abstract}
Carusia 1000111010 100130?001 0001200010 0112100-11 01001?-20? $0100010110 \quad 0-11010001$ ? 001100101 $1110010000000200110010 ? 1101130$ $001000011000012 ? 10000010120001$ 0??12????? ???0?????? ?????????1 ????????? ??1????? 1 ????????? ??8
\end{abstract}

Xenosaurus 10001111101011300001 0001100110 0112100-01 010010-101 $0 ? 11010010 \quad 0-110100010010010112$ $1100010100 \quad 0002011\{01\} 001001101$ $\begin{array}{lllll}130 & 0110001110 & 0001201000 & 101010\end{array}$ $30010111201121\{01\} 002110020001$ $1000100\{01\} 0100021\{01\} 10011000$ $10022100 ? ? 0011$ ? 3
Uromastyx

$001----12\{01\}$

$20\{01\} 0311101 \quad 01\{01\} 130\{01\} 101 \quad 01$ 12100-00 01101000220000010000 1--$0021000\{01\} 00000102021100001200$ 10001010 00? $1100 ? 000010013210$ 1-$110000000\{01\}\{02\} 02111-0001201001$ $\begin{array}{lll}1010110021 & 0001100001 & 1120111011\end{array}$ ????0???? ?????00??? ??6

Zapsosaurus 10?0010??? 01??1?1001 1?121????? 0?200001?0 ?1??0?10?? 11000?0?00 0???01?000 001010?110 011110??00 ???12????? ????1??01? ???????? ????????? ?? 8

Anchaurosaurus

?0003?1?1? 010?101001 011010002? 00200001?0 ????????12 ????00?000 00?1100?00 ??1011021? 0002004000 0??12?00?1 ???00?0??? ?????0?0?? ???????? ??8

Ctenomastax 1000001110 010?101001 11121?0-00 00100001100201011010 1???0?0000 ??????0000 ??001?02?? 00110?1?00 0????????? ?????????? ????????? ???????0??? 8

Temujinia 0100101001 0020000010 1100000?00 ?? 10100210 ??? ?? ?? ? ?? ?? ?? ?? ?? 8

1000001110 11121 ????? 020101101 ? $00 ? 0011000$ 011110??00 ?????????? ??????????

?????????? ?1101?002? ?000000112 00?1100?00 00020040?0 ????????? ??????????

100-000110 $1 ? 12100-00$ ?????????? ?0??0???00 0111101000 ?????1000? ???????00-

?0013?1111 ?1001?002? ?0?000?112 00?1100?00 0002020010 ?????????? ?????????

?0??3? 1111 01001?002? ??00000112 00?1?00?10 00?2004000 ?????????? ??????????

Rhampholeon 2011301101 110010003 ? $-100000101$ ?0-4101-20 $001200410-$ 12-00103110010??11?

Brookesia 0110310010 0001000000 1110100000 0011013212 011121 ??00 -0-110013? ?? 1

$000201111\{01\}$ $01103100100010000-00$ $0-02010000$ 1---001000 1110100000 2100100-00 ??1101320- 1--1100-00 011121??00 0010111020 -0-110013? ??201?000?? 5

01020111-0 0010000-00 $1---001000$ 2100100-00 $1--1200-00$ 0010111020 ??201?000-

2000301101 100-10023? $-100000101$ ? $0-4101-20$ $001200410-$ 12-001031100101?11?

Physignathus 000-0001100010301100 0100111100 0112000-00 0101100021 
0010000000 1110000000 $000101-211$ 0?? 12????? ????????? ?? 9

$1---002000$ 0000000000 $1--1201000$ ?????????? ?? $1000000-$

Isodontosaurus

00003?1?0? 010?101001 011010002? 0010001-00 ????0??102 ???0???0?0 ???1?11?20 00100010?? 00?2005000 0????????? ???????? ? ????????? ???????? ??

Saichangurvel

?0003?111? 0100101001 ?1101?002? 0010000110 ?0???????? 1??0010??? ???1?00??? ????????? 000200400? 0??1200001 ?0111?0?0? ???0101010 ????????? ??8

CROTAPHYTIDAE

$\{01\} 010011110$

0000301\{01\}01 0101100010 1112100-00 $01\{01\} 012002000100001010-0-001000$ $1000000\{12\} 1111000100000000010000$ $0001100-100\{01\} 1020321\{01\} 0011101$ $000 \quad 0002004010 \quad 10012000010001110$ $0\{12\} 0 \quad 001110\{01\} 100 \quad 0110101001$ \{01\}01100000-0100?0001? ??3

IGUANIDAE

$1\{01\} 0001\{01\} 110$ $0000301001 \quad 010\{01\} 101001 \quad 1\{01\} 1\{0$ $1\} 100-0001001000\{12\} 0$ 0??0000001 $010 ? 00 ? 000100000011\{12\} 11100 ? 0\{0$ $1\} 00001010\{01\} 1000001100-00001$ $0203\{01\} 10 \quad 01011$ ? $1100 \quad 0002004000$ $00012001011000110000\{01\} 001101100$ 0100101001 00100?000- 0100?0000? ??-

\begin{tabular}{|c|c|c|}
\hline FMNHiguana & 100???? 110 & 00?03????? \\
\hline 0????? $101 ?$ & ?? $12110-? ?$ & $010 ? 10 ? 02$ \\
\hline ????00??0? & 0?0?0??0?? & ??000??? 1 \\
\hline 1????????? & ?????????? & ?????00?? \\
\hline ?1??? 2?? & ???1????0? & \\
\hline & ?????1? & 0?? \\
\hline & $0-$ & \\
\hline
\end{tabular}

ANISOLEPINAE 10001111100010300001 $01001000\{01\} 0 \quad 00121\{01\} 0-00 \quad 0100$ 120020 0??000000? 0?00001000 010 $000011111101 ? 0000 \quad 00101 ? 0000 \quad 000$ $110\{01\}-\{01\}\{01\} \quad 0111200210 \quad 0111$ $101 ? 00 \quad 00020040000001200001 \quad 10001$ $103001111100\{12\} 001000101000 \quad 011$ $0000\{01\} 00$ ???0?11?1? ??

LEIOSAURINAE 10001111100010300001 $010\{01\} 100000 \quad 0\{01\} 12100-00 \quad 0100$ 120020 0??000010? 0?11001000 0\{0
1\}00000111 11101?0000 0010\{01\}1\{ $02\} 000$ 0001100-11 \{01\}01120\{01\}210 0111101 ? $00000200\{34\} 0000001200001$ $1000110\{03\} 31 \quad 1111\{01\} 00100 \quad 0000$ \{01\}01001 0\{01\}1000000- ???0?11?1? ??3

PHRYNOSOMATIDAE

$1\{01\} 0\{02\} 00\{01\} 120 \quad 0010300001 \quad 01$ $00\{13\} 0\{01\} 001 \quad 1112100-00 \quad 0100$ $1000220000000100 \quad 0 ? 1 ? 001000000$ $00001121\{01\}\{01\} 00100000000010000$ $0001100-\{02\} 0 \quad 01100012100101\{01\}$ $01 ? 00 \quad 000200\{04\} 000 \quad 1001200101$ $10011100110\{01\} 01001200111110\{1$ 2\}001 0011\{01\}0000-0100?000\{01\}? ?? 3

PolychrusMARM $\quad 100\{02\} 011111$ 0010??0-01 0101100111 0012110-?0 ?1001?0030 0000000111 1---00100? ?000000211 $1110110000 \quad 0010112-00$ 0001100?00 ??1120-212 0101101000 10120040000001200011 10001100?0 10111002001000101101 ????1????? ????????? ??

PolychrusFEM $100\{02\} 01111 ?$ 00?0?00-01 0101100010 0112110-10 $0100100020 \quad 0010000111 \quad 1--001000$ ? $00001021\{12\}$

$00100110000001101-00$ $0101101 ? 000002004000$ 100?110?31 1?11000200 1010100100 0100?11?1?

1110110000 0110200210 0001200001 ?000100001 ?? $\{23\}$

PolychrusGUTT 0010300-10 01001 ? 0020 ?000000211 0001100 ? 01 1002004000 ??? ?? ?? ? ?????????
0100100001 0010000011 0110000000 011020?200????????? ?????????? ?? 2
$100\{02\} 001011$ 0012110-00 1---00100? 00?01?1000 0111101000 ?????????? ??? 1??? ?

AnolisHETER ?00\{01\}111110 0010300$1101001101101112110-000100100020$ 0001010001010100100 ?

1111?0??10 0010100000 1-11203212 1--1?01?00 0??????? ????????? ?????????? ?????????? ???

Anolisocc 110-000130 0100100000 0112110-00 0001000001020100100 ? 11100000000000010010 1-1120120- 0111101100 00012000001000110030 0000100001 ????????? ?? 3

AnolisVERM $1100111130 \quad 0000301011$

0100100110 0112110-10 010010100?
$0000300-11$ 0100100020 ? 010000111 $0001100-31$ 0002004000 1011000100 ???????? 
0001000101 0111000000 0111203210 0001200000 0000101001 ??3
$010100100 ?$ $00 ? 0110000$ 0101101110 10?01100?1 ??????????
$? 010000111$ 0001100-01 0102004000 ? 011100100 ?????????

Leiocephalus 00000111101100300001 $0100101001 \quad 0112100-00 \quad 0100100020$ 0 ??000010? 0?01001000 110000011 \{12\} 11100?01000000111000 0001101$30011120020-0101001 ? 000002004000$ $00012000 ? ?$ ???????1? ?????????? ????????? 0???10???? ?????00?0? ??3

Stenocercus $000001111\{01\}$ $00\{01\} 01010010\{01\} 01101001 \quad 1112$ 100-00 0100100020 0010000100 01 $00001000 \quad 0000000111 \quad 1110100010$ 0000011100 0001100-01 011120020$0101101000 \quad 0002004000 \quad 0001200001$ 0001110011 $011 ? 101000$ ??2

$\{01\} 0111 ? 0100$

??1110?00- ?????01?0?

TROPIDURIDAE $\quad\{01\} 0000\{01\}\{01\} 110$ $00\{01\} 0\{13\} 010\{01\} 1 \quad 010010\{01\}\{0$ 1\}01 1112100-00 0100100022 002 $00001\{01\} 0 \quad 010\{01\} 001000100000$ $011111100100\{01\} 00000011\{01\} 00$ $0\{01\} 01100-\{23\} 1011\{01\} 20\{01\} 20-$ $0101001000000200\{24\} 000 \quad\{01\} 00$ $1200001 \quad 100111001$ ? $0\{01\} 11\{01\}$ ?1100 \{01\}110?0100? 1\{01\}11\{01\}0 ?00- ?????0100? ? $1\{23\}$

$\begin{array}{lll}\text { LIOLAEMINAE } & 0000011110 & 0110100-01 \\ 0100101011 & 1112100-00 & 0100100022 \\ 0010001-10 & 0101001000 & 1100000111 \\ 1110110000 & 0000010 ? 00 & 0001101-01 \\ 1-11100210 & 0101101000 & 0002004000 \\ 0001200000 & 11 ? 0110011 & ? 001100100 \\ 011 ? 102000 & 0 ? ? ? 1 ? ? ? ? & \text { ????00?1? } \\ \text { ??2 } & & \end{array}$

Hoplocercus 00020011100010111000 $01004110010112110-00 \quad 0100100020$ 0010000101010100100 ? 0000010111 $100011000000101110010101000-20$ $011000\{01\} 20-\quad 0001101000 \quad 001200$ $\begin{array}{llll}4000 & 0001200001 & 11 ? 0110010 & 1011\end{array}$ $000\{01\} 00 \quad 0110112000$ ??1??????? ?????????? ??2

Morunasaurus 00020011100000310-00 0100111001 00121?0-10 010010002? 01000001010101010000 ?000010111 1000110000 00?0111?00 0001101-20 001000021101011010000002004000 0???????? ????????? ????????? ????????? ????????? ????????? ??2
Enyalioides

0002011110

$0010\{01\} 0000101004110010112110$ $\begin{array}{llll}0 & 0100100020 & 0000000101 & 0101\end{array}$ $001000 \quad 0000000111 \quad 1100110000 \quad 00$ 10111000 0001100-00 00100002001011010000002004000 0??1200001 $1000110011 \quad 101100\{01\} 100 \quad 01201$ $12001001000000-0100 ? 0001 ?$ ??2

Oplurusoh 0100111110 0100101001 1012110-00 0000000100 ????0?1000 11100100100010001000 $011120000-$ $0001200 ? ? 1$ 0????????? ?? 1

OplurusCYC 0100100011 0110000100 1110110110 $011100020-$ 0 ?? 12000? 1 0 ????????? ?? 1

OplurusQ1 0110100001 000000??00 1110010100 $011120120-$ 0????????? 0 ?? ?? ?? ? ?? 1

Chalarodon 01?0100001 $001000 ? ? ? ?$ ?????????? $011020120-$ ????????? 0?? ?????? ?? 1

Polrussia 11??1?10?1 ?? 100?000? ??00000000 ??102??20?????????? ????????? ?? 8

0100111111

Igua 01?-000??? ????????? ??1?1????? 0??0?0???? ?????????? ?????????? ?????????? ?????????? ?????????? ?????????? ?????????? ????????? ????????? ?? 8

Priscagama 0100100110
0101101000 00?01??? 1? 01?100????

0100111110 1?12110-00 1---001??? 0010001000 0111101000 00?01???1? 01?100???? 00120?0-00 0101001000 00?00? 1000 0101101000 ????????1? 01?100????

???0?11??? ?112110-?? ?????????? ???0?????0 0101101000 1???????1? 01?000????

00?-0001?? 1112100-? 0 1?0-0?000? ????????00 0101101?00 ?????????? ??????????

0000301101 0101100020 1000010211 01?1100?01 0002004000 ????0??10? ??????0?1?

0010301101 0101100020 1000010211 0002004010 ????0??10? ?????00?1?

0010301101 01001?0010 ?000010211 $00 ? 1100 ? 30$ 0002004000 ????0??10? ??????0?1?

? 0??????? 0110100020 ?0??????? 0?????0?01 ?????040?0 ????0??20? ?????00? 1?

??????001? ?1101?00?? ???0??0101 ?1????0?01 ???2?000?? ?????????? ?????????

????????? ?1101?0020 ?000000??? ????????? ????????? ?????????? ?????????

1002111111 ?011311111 11121?0-00 ??001?-02? 0101100? 30 


\begin{tabular}{|c|c|c|}
\hline $\begin{array}{l}0100010110 \\
1010100000 \\
00 ? ? 00020- \\
0 ? ? ? ? ? ? ? ? ? \\
0 ? ? ? ? ? ? ? ? ? \\
\text { ??8 }\end{array}$ & $\begin{array}{l}1 ?--011000 \\
\text { ????0?0?00 } \\
00110 ? 1 \text { ? } 00 \\
\text { ?????????? } \\
\text { ??1??????? }\end{array}$ & $\begin{array}{l}\text { ?00000? } 111 \\
\text { ?? ? } 1 \text { ? } 00 ? 00 \\
0 ? ? ? 0011 \text { ? } \\
\text { ????????? } \\
\text { ?????? ??? }\end{array}$ \\
\hline $\begin{array}{l}\text { Mimeosaurus } \\
0100101110 \\
\text { ?00001??00 } \\
0 ?-? 1000 ? ? \\
001 ? 001 ? ? ? \\
0 ? ? 12 ? 0 ? ? ? \\
\text { ?????????? } \\
\text { ??8 }\end{array}$ & $\begin{array}{l}0002111110 \\
01121 ? ? ? 0 ? \\
1 ?--01100 ? \\
\text { ???0?? } 1 ? 00 \\
00110 ? 1 ? 00 \\
\text { ?????1???? } \\
\text { ??1??????? }\end{array}$ & $\begin{array}{l}\text { ?000311111 } \\
\text { ? } 1001 ?-02 ? \\
\text { ?00000? } 112 \\
\text { ?0? } 1 ? ? 0 ? 00 \\
\text { ???20011? } \\
\text { ?????????? } \\
\text { ?????????? }\end{array}$ \\
\hline $\begin{array}{l}\text { Phrynosomim } \\
00103 ? 1101 \\
\text { ?1001?-02? } \\
\text { ?000000102 } \\
\text { ??????0?00 } \\
00 ? 20011 \text { ? } \\
\text { ?01?????00 } \\
\text { ?????????? }\end{array}$ & $\begin{array}{l}\text { us } \\
0100101110 \\
0000010 ? ? 0 \\
1100100 ? 0 ? \\
\text { ?? 1?00??0- } \\
\text { ?????????? } \\
\text { ?????????? } \\
\text { ??8 }\end{array}$ & $\begin{array}{l}0102111110 \\
1112100-00 \\
1 ?--01000 ? \\
\text { ???? } 1 ? ? 200 \\
00 ? 10 ? 1 ? 00 \\
\text { ?????????? } \\
\text { ?????????? }\end{array}$ \\
\hline $\begin{array}{l}\text { CORYTOPHANII } \\
001030100\{0 \\
0112100-00 \\
---00001\{01 \\
0000000211 \\
0000001100 \\
11101 ? 00 \\
1000110\{03\} \\
00101\{01\}\{0 \\
0001 ? ? ?\{23\}\end{array}$ & $\begin{array}{l}\text { DAE } \\
1\} \quad 01\{01\} 010 \\
\text { y } 010\{01\} 1 \\
0 \quad 0 ? \\
1110100000 \\
-0100102032 \\
002004000 \\
\{12\}\{01\} \\
1\} 00010100 ?\end{array}$ & $\begin{array}{l}001\{01\} 110 \\
01\{01\}\{01\} \\
02\} 10\{02\} 0 \\
01\} 1001000 \\
0010\{01\} 10 \\
1\{01\} 0\{01\} \\
0001200101 \\
0100000100 \\
000-0100 ?\end{array}$ \\
\hline
\end{tabular}

;

ENDBLOCK ;

\section{APPENDIX 4}

\section{Anatomical Abbreviations}

$\begin{array}{ll}\text { api } & \text { anterior iliac process } \\ \text { ar } & \text { articular } \\ \text { asca } & \text { astragalocalcaneum } \\ \text { at } & \text { atlas } \\ \text { atu } & \text { anterior tubercle } \\ \text { aup } & \text { autotomy plane } \\ \text { ax } & \text { axis } \\ \text { bc } & \text { braincase } \\ \text { bpt } & \text { basipterygoid process } \\ \text { c } & \text { coronoid } \\ \text { cl } & \text { clavicle } \\ \text { co } & \text { coracoid } \\ \text { d } & \text { dentary } \\ \text { dpc } & \text { deltopectoral crest } \\ \text { dt } & \text { distal tarsal } \\ \text { e } & \text { epipterygoid } \\ \text { ec } & \text { ectopterygoid }\end{array}$

\begin{tabular}{|c|c|}
\hline $\begin{array}{l}\text { ecf } \\
\text { ect }\end{array}$ & $\begin{array}{l}\text { ectepicoracoid foramen } \\
\text { ectepicondyle }\end{array}$ \\
\hline$f$ & frontal \\
\hline fe & femur \\
\hline fi & fibula \\
\hline fop & pineal foramen \\
\hline $\mathrm{pf}$ & frontoparietal fontanelle \\
\hline & glenoid \\
\hline & humerus \\
\hline hd & humeral head \\
\hline $\mathrm{O}$ & muscle scar for M. ilio-costalis \\
\hline il & ilium \\
\hline & ischium \\
\hline & internal trochanter \\
\hline & jugal \\
\hline $\mathrm{L}$ & left \\
\hline 1 & lacrimal \\
\hline $\operatorname{lp}$ & lateral plantar tubercle \\
\hline mld & insertion of the M. longissimus dorsi \\
\hline in & mandible \\
\hline mtu & median tubercle of the humerus \\
\hline $\mathrm{mx}$ & maxilla \\
\hline $\mathrm{n}$ & nasal \\
\hline ns & neural spine \\
\hline nu & nuchal fossa \\
\hline of & obturator foramen \\
\hline p & parietal \\
\hline pa & palatine \\
\hline pas & palmar sesamoid \\
\hline $\mathrm{pf}$ & postfrontal \\
\hline pis & pisiform \\
\hline plf & palatine foramen \\
\hline $\mathrm{pm}$ & premaxilla \\
\hline po & postorbital \\
\hline poc & paroccipital process of the otooccipital \\
\hline poz & postzygapophysis \\
\hline pr & prootic \\
\hline prf & prefrontal \\
\hline prz & prezygapophysis \\
\hline ps & presacral vertrebra(e) \\
\hline psc & $\begin{array}{l}\text { housing (bulla) for the posterior semi- } \\
\text { circular canal }\end{array}$ \\
\hline pss & pseudospine \\
\hline $\mathrm{pt}$ & pterygoid \\
\hline $\mathrm{pu}$ & pubis \\
\hline $\mathrm{q}$ & quadrate \\
\hline $\mathrm{R}$ & right \\
\hline $\mathrm{r}$ & radius \\
\hline rap & retroarticular process \\
\hline $\mathrm{sa}$ & surangular \\
\hline $\mathrm{sc}$ & scapula \\
\hline so & supraoccipital \\
\hline $\mathrm{sp}$ & splenial \\
\hline $\mathrm{sq}$ & squamosal \\
\hline $\mathrm{sr}$ & sacral rib \\
\hline $\mathrm{ssc}$ & suprascapula \\
\hline st & supratemporal \\
\hline & tooth (teeth) \\
\hline
\end{tabular}


ti tibia

tp transverse process

ul ulna

up ulnar patella 1cf primary coracoid emargination

2cf secondary coracoid emargination

I-V digit identities

V-2 second phalanx of digit V 
Complete lists of all issues of the Novitates and the Bulletin are available at World Wide Web site http://library.amnh.org/pubs. Inquire about ordering printed copies via e-mail from scipubs@amnh.org or via standard mail from: American Museum of Natural History, Library-Scientific Publications, Central Park West at 79th St., New York, NY 10024. TEL: (212) 769-5545. FAX: (212) 769-5009.

(2) This paper meets the requirements of ANSI/NISO Z39.48-1992 (Permanence of Paper). 